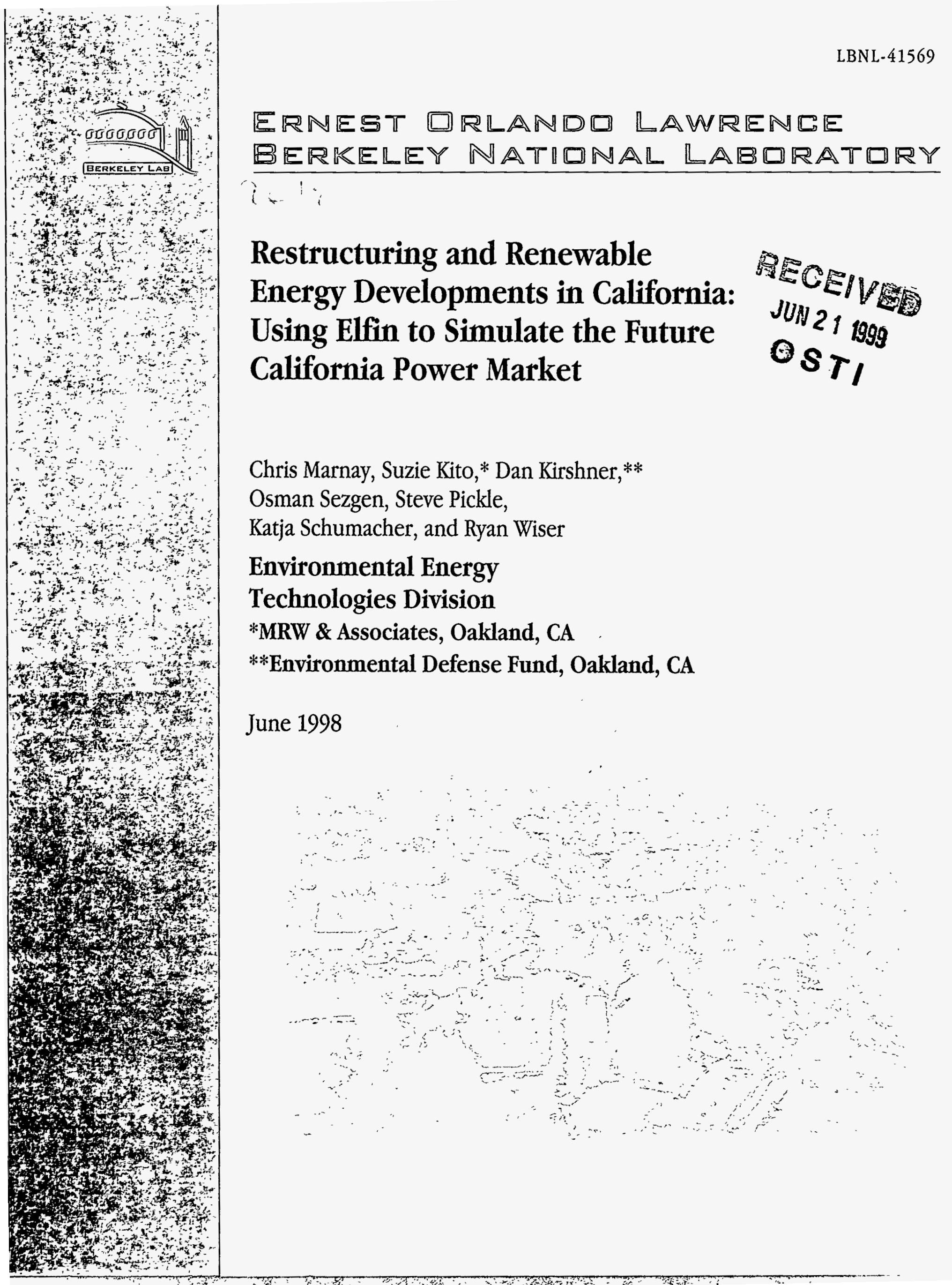




\section{DISCLAIMER}

This document was prepared as an account of work sponsored by the United States Government. While this document is believed to contain correct information, neither the United States Government nor any agency thereof, nor The Regents of the University of California, nor any of their employees, makes any warranty, express or implied, or assumes any legal responsibility for the accuracy, completeness, or usefulness of any information, apparatus, product, or process disclosed, or represents that its use would not infringe privately owned rights. Reference herein to any specific commercial product, process, or service by its trade name, trademark, manufacturer, or otherwise, does not necessarily constitute or imply its endorsement, recommendation, or favoring by the United States Government or any agency thereof, or The Regents of the University of California. The views and opinions of authors expressed herein do not necessarily state or reflect those of the United States Government or any agency thereof, or The Regents of the University of California.

This report has been reproduced directly from the best available copy.

Available to DOE and DOE Contractors

from the Office of Scientific and Technical Information

P.O. Box 62, Oak Ridge, TN 3783 !

Prices available from (615) $576-8401$

Available to the public from the

National Technical Information Service

U.S. Department of Commerce

5285 Port Royal Road, Springfield, VA 22161

Ernest Orlando Lawrence Berkeley National Laboratory is an equal opportunity employer. 


\section{DISCLAIMER}

Portions of this document may be illegible in electronic image products. Images are produced from the best available original document. 


\title{
Restructuring and Renewable Energy Developments in California: Using Elfin to Simulate the Future California Power Market
}

\author{
Chris Marnay, Suzie Kito, ${ }^{\dagger}$ Dan Kirshner, ${ }^{*}$ \\ Osman Sezgen, Steve Pickle, Katja Schumacher, and Ryan Wiser \\ Environmental Energy Technologies Division \\ Ernest Orlando Lawrence Berkeley National Laboratory \\ University of California \\ Berkeley, California 94720 \\ ${ }^{\dagger}$ currently with MRW \& Associates \\ Oakland, California \\ *Environmental Defense Fund \\ Oakland, California
}

June 1998

The work described in this study was funded by the Assistant Secretary of Energy Efficiency and Renewable Energy, Office of Utility Technologies of the U.S. Department of Energy under Contract No. DE-AC03-76SF00098. 


\section{Contents}

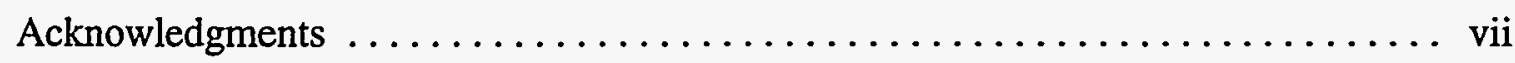

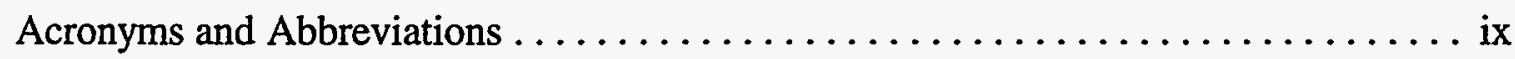

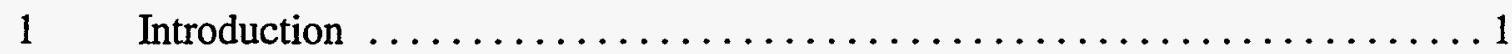

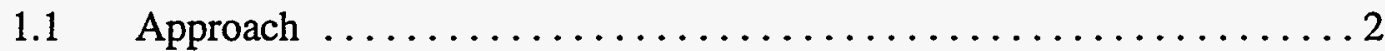

1.2 Organization of the Report $\ldots \ldots \ldots \ldots \ldots \ldots \ldots \ldots \ldots \ldots \ldots$

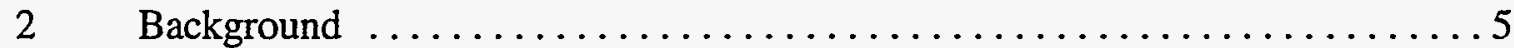

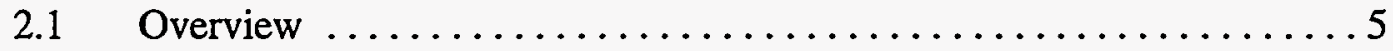

2.2 PURPA and Qualifying Facilities in California ..............

2.3 The California Restructuring Decision $\ldots \ldots \ldots \ldots \ldots \ldots \ldots \ldots$

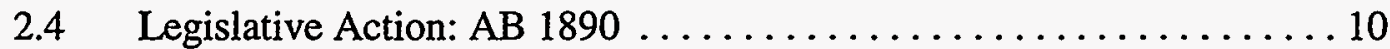

2.5 Alternative Policies for Fostering Renewables $\ldots \ldots \ldots \ldots \ldots \ldots 10$

2.6 The Policy Question .............................. 11

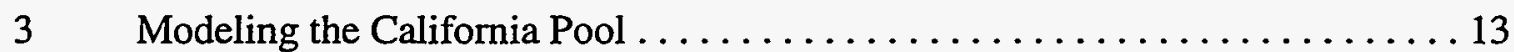

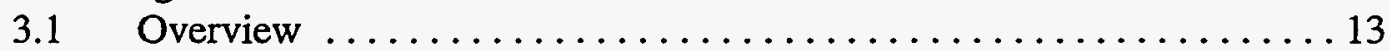

3.2 Elfin's Pool Price Payments and ITRE Logic $\ldots \ldots \ldots \ldots \ldots \ldots \ldots$

3.3 Key Assumptions in the California Pool . . . . . . . . . . . . . 17

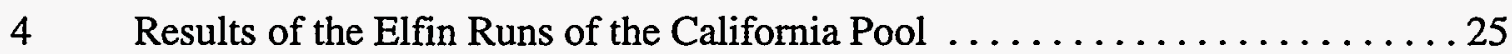

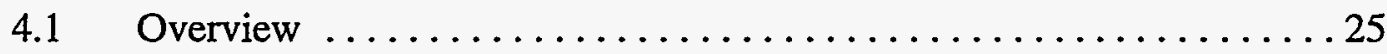

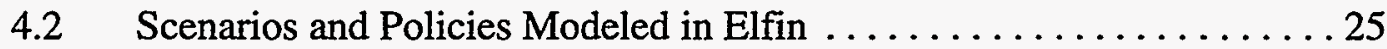

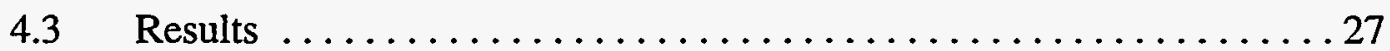

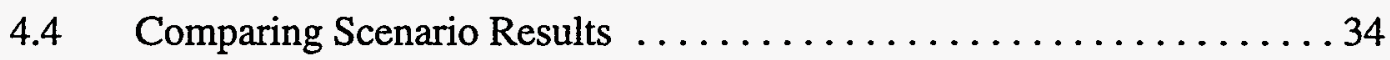

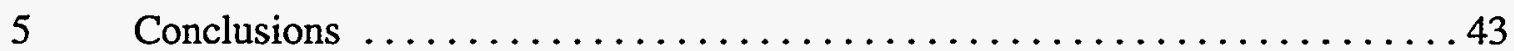

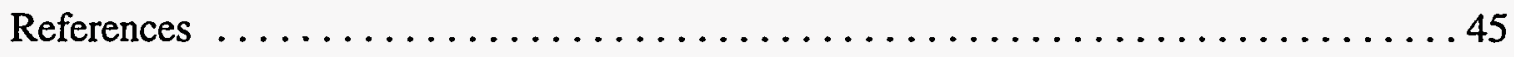

Appendix A: Detailed Results $\ldots \ldots \ldots \ldots \ldots \ldots \ldots \ldots \ldots \ldots \ldots \ldots . \ldots 47$

Appendix B: The Expansion Planning Logic of Elfin $\ldots \ldots \ldots \ldots \ldots \ldots \ldots$.

B.1 Traditional Cost-Minimizing Capacity Expansion Planning . . . . . . 89

B.2 The MC-ITRE Algorithm . ...................... 90

B.3 Towards a Competitive Expansion Logic $\ldots \ldots \ldots \ldots \ldots \ldots \ldots 90$

B.4 Market Dispatch Logic ........................... 91

B.5 How Much Entry Will Occur . . . . . . . . . . . . . . . . 92

B.6 Finding the Best Plan ........................... 95 
B.7 Revised Algorithm . . . . . . . . . . . . . . . . . . . 95

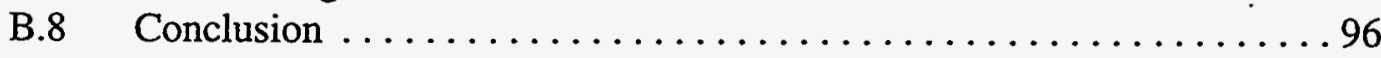

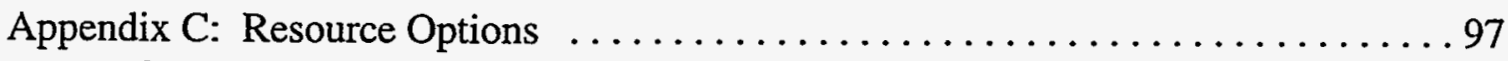

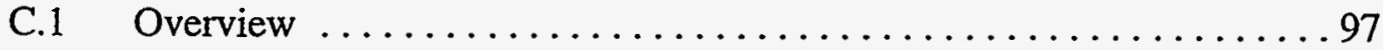

C.2 Ranges of Costs and Other Operational Parameters . . . . . . . . . 97

C.3 Summary of Parameters Used in this Analysis . . . . . . . . . . 108

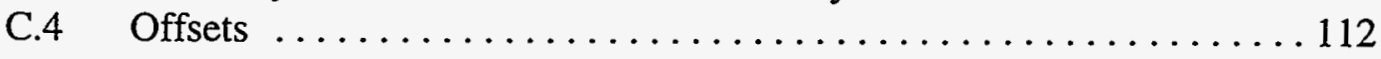

Appendix D: Extreme Search Test for Market Equilibrium Plans . . . . . . . . 113

D.1 Procedure ................................ 113

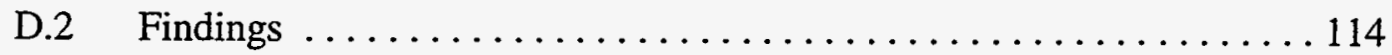

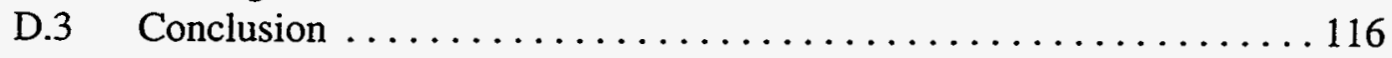

Appendix E: Simulation Difficulties in the B Policy Simulation $\ldots \ldots \ldots \ldots \ldots 117$

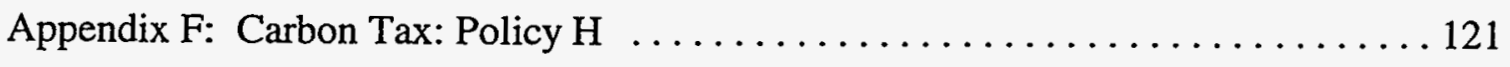

Appendix G: Cost Duration Curves for the California Pool ............. 123 


\section{Tables}

Table 2-1.

Dependable Capacity for California Utilities. . . . . . . . . . 6

Table 2-2.

Table 3-1.

Table 3-2.

Dependable Capacity for California Utilities' Non-Utility Generators 7

Peak Week Capacity Included in California Data Set for 1995 . . . . 18

Capacity, Sales, Imports, and Exports for LADWP, SMUD,

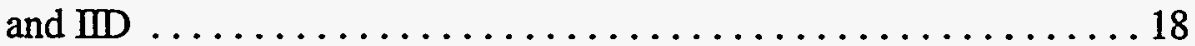

Table 4-1.

Table 4-2.

Assumptions for Neutral, Good, and Bad Renewable Environments 26

Table 4-3.

Summary of Elfin Pool Results with No Renewables Policies . . . . 28

Summary of Elfin Pool Results with a Straight Purchase

Requirements and a Neutral Environment ............ 30

Table 4-4. Summary of Elfin Pool Results with a Banded Purchase

Requirement and a Neutral Environment ............. 31

Table 4-5. Summary of Elfin Pool Results with Surcharge Policy with a

Neutral Environment ......................... 33

Table 4-6. Total Generation $(\mathrm{GWh})$ for $\mathrm{N}$ Cases $\ldots \ldots \ldots \ldots \ldots \ldots \ldots$

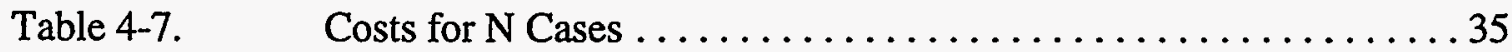

Table 4-8. Benefits for $\mathrm{N}$ Cases in Terms of Reductions of Emissions and

Thermal Dependency ......................... 37

Table A-1. $\quad$ Resource Mix Under Scenario ON (GWh/a) . . . . . . . . . 48

Tables A-2-6. Key Indicators for Scenario ON . . . . . . . . . . . . . . . . 49

Table A-7. $\quad$ Resource Mix Under Scenario OG (GWh) $\ldots \ldots \ldots \ldots \ldots \ldots \ldots$

Tables A-8-12. Key Indicators for Scenario OG .................. 51

Table A-13. Resource Mix Under Scenario OB (GWh) $\ldots \ldots \ldots \ldots \ldots \ldots . \ldots 54$

Table A-14-18. Key Indicators for Scenario OB . . . . . . . . . . . . . . . . 54

Table A-19. Resource Mix Under Scenario AN (GWh) . . . . . . . . . . 57

Tables A-20-24. Key Indicators for Scenario AN . . . . . . . . . . . . . 57

Table A-25. Resource Mix Under Scenario AG (GWh) . . . . . . . . . 60

Tables A-26-30. Key Indicators for Scenario AG . . . . . . . . . . . . . 60

Table A-31. Resource Mix Under Scenario $A B \ldots \ldots \ldots \ldots \ldots \ldots \ldots \ldots$

Tables A-32-36. Key Indicators for Scenario AB . . . . . . . . . . . . . 63

Table A-37. Resource Mix Under Scenario BN (GWh) $\ldots \ldots \ldots \ldots \ldots \ldots 6$

Tables A-38-42. Key Indicators for Scenario BN . . . . . . . . . . . . . 66

Table A-43. Resource Mix Under Scenario BG (GWh) . . . . . . . . . . 69

Tables A-44-48. Key Indicators for Scenario BG . . . . . . . . . . . . . . 69

Table A-49. Resource Mix Under Scenario DN (GWh) . . . . . . . . . . 72

Tables A-50-54. Key Indicators for Scenario DN . . . . . . . . . . . . . 72

Table A-55. Resource Mix Under Scenario DG (GWh) $\ldots \ldots \ldots \ldots \ldots \ldots$

Tables A-56-60. Key Indicators for Scenario DG . . . . . . . . . . . . . 75

Table A-61. Resource Mix Under Scenario DB (GWh) . . . . . . . . . . 78

Tables A-62-66. Key Indicators for Scenario $\mathrm{DB} \ldots \ldots \ldots \ldots \ldots \ldots \ldots \ldots$ 
Table A-67. Resource Mix Under Scenario HN (GWh) $\ldots \ldots \ldots \ldots \ldots \ldots$

Tables A-68-72. Key Indicators for Scenario $\mathrm{FIN} \ldots \ldots \ldots \ldots \ldots \ldots \ldots \ldots \ldots$

Table A-73. Resource Mix Under Scenario HG (GWh) ... . . . . . . . 84

Tables A-74-78. Key Indicators for Scenario F[G . . . . . . . . . . . . . . . 84

Table A-79. Resource Mix Under Scenario HB (GWh) ... . . . . . . . 87

Tables A-80-84. Key Indicators for Scenario $\mathrm{FB} \ldots \ldots \ldots \ldots \ldots \ldots \ldots \ldots \ldots$

Table C-1. Gas Combined Cycle Costs and Other Parameters . . . . . . . . . 98

Table C-2. Gas Combustion Turbine Costs and Other Parameters . . . . . . . .99

Table C-3. Wind Plant Costs and Other Parameters . . . . . . . . . . . 100

Table C-4. Geothermal Costs and Other Parameters . . . . . . . . . . . . . 101

Table C-5. Solar Thermal Costs and Other Parameters . . . . . . . . . . . . 103

Table C-6. DOE Solar Thermal Plant Costs $\ldots \ldots \ldots \ldots \ldots \ldots \ldots \ldots$

Table C-7. Plant Costs and Other Parameters . . . . . . . . . . . . . . 104

Table C-8. Nuclear Plant Costs and Other Parameters . . . . . . . . . . . 105

Table C-9. Coal Gasification Combined Cycle Plant Costs and Other

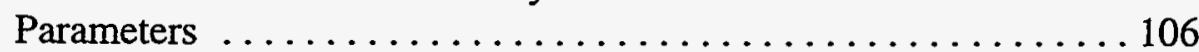

Table C-10. Advanced Coal Plant Costs and Other Parameters . . . . . . . . 107

Table C-11. Biomass Plant Costs and Other Parameters . . . . . . . . . . . . . 108

Table C-12. Summary of Capital Costs Assumptions . . . . . . . . . . . . . 109

Table C-13. Other Characteristics of Generic Technologies . . . . . . . . . . 110

Table C-14. Emissions Characteristics of Generic Technologies . . . . . . . 111

Table D-1. Start Plans for the MEP Search Test . . . . . . . . . . . . . 114

Table D-2. $\quad$ MEPs Found by Each Search . . . . . . . . . . . . . . 115

Table F-1. Summary of Elfin Pool Results with a Low Carbon Tax and a

Neutral Environment . . . . . . . . . . . . . . . . 121 


\section{Figures}

Figure 2-1. Overall Resource Mix for California Power Generation $1994 \ldots \ldots \ldots 11$

Figure 3.1. Gas and Oil Plant Commission Dates $\ldots \ldots \ldots \ldots \ldots \ldots \ldots \ldots$

Figure 4-1. Cumulative New Capacity Under Scenario ON . . . . . . . . . . . . . 27

Figure 4-2. Cumulative New Capacity Under Scenario OG . . . . . . . . . . . 29

Figure 4-3. Cumulative New Capacity Under Scenario AN . . . . . . . . . . . 32

Figure 4-4. Cumulative New Capacity Under Scenario DN . . . . . . . . . . . . 31

Figure 4-5. Cumulative New Capacity Under Scenario BN . . . . . . . . . . . 34

Figure 4-6. Total Social Cost of Generation in Comparison to ON Case ...... 36

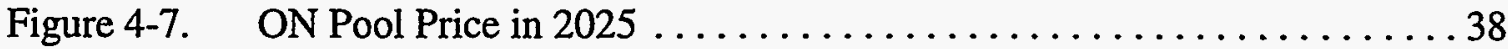

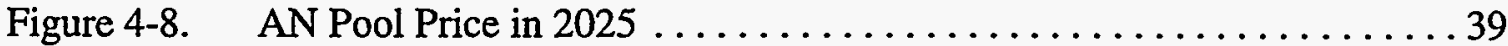

Figure 4-9. Percentage Deviation in Costs and Benefits from ON Case in $2025 \ldots 41$

Figure A-1. Resource Mix Under Scenario ON $\ldots \ldots \ldots \ldots \ldots \ldots \ldots \ldots \ldots$

Figure A-2. Resource Mix Under Scenario OG $\ldots \ldots \ldots \ldots \ldots \ldots \ldots \ldots \ldots \ldots$

Figure A-3. Resource Mix Under Scenario OB .................... 53

Figure A-4. Resource Mix Under Scenario AN $\ldots \ldots \ldots \ldots \ldots \ldots \ldots \ldots \ldots$

Figure A-5. Resource Mix Under Scenario AG $\ldots \ldots \ldots \ldots \ldots \ldots \ldots \ldots \ldots \ldots$

Figure A-6. Resource Mix Under Scenario AB ....................62

Figure A-7. Resource Mix Under Scenario BN . . . . . . . . . . . . . . . 65

Figure A-8. Resource Mix Under Scenario BG . . . . . . . . . . . . . . 68

Figure A-9. Resource Mix Under Scenario DN $\ldots \ldots \ldots \ldots \ldots \ldots \ldots \ldots \ldots$

Figure A-10. Resource Mix Under Scenario DG ..................... . 74

Figure A-11. Resource Mix Under Scenario DB . . . . . . . . . . . . . . . . . 77

Figure A-12. Resource Mix Under Scenario HN $\ldots \ldots \ldots \ldots \ldots \ldots \ldots \ldots \ldots$

Figure A-13. Resource Mix Under Scenario HG $\ldots \ldots \ldots \ldots \ldots \ldots \ldots \ldots \ldots$

Figure A-14. Resource Mix Under Scenario HB .................... 86

Figure B-1. Technology Profit Function $\ldots \ldots \ldots \ldots \ldots \ldots \ldots \ldots \ldots \ldots \ldots \ldots \ldots \ldots \ldots$

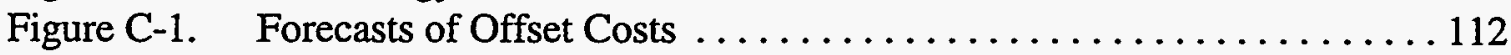

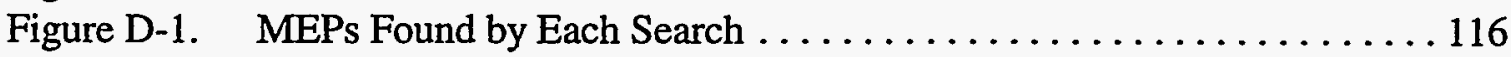

Figure E-1. Per-kWH Subsidy to Wind $-\mathrm{BN} \ldots \ldots \ldots \ldots \ldots \ldots \ldots \ldots \ldots \ldots$

Figure E-2. Net Total Subsidy to Wind $-\mathrm{BN} \ldots \ldots \ldots \ldots \ldots \ldots \ldots \ldots \ldots \ldots$

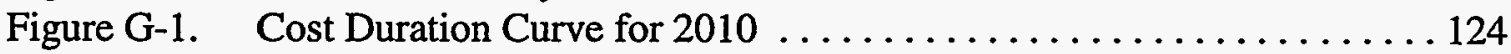

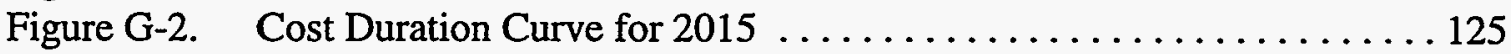

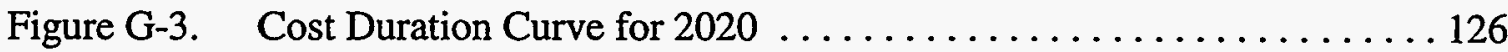

Figure G-4. Cost Duration Curve for $2025 \ldots \ldots \ldots \ldots \ldots \ldots \ldots \ldots \ldots \ldots \ldots$

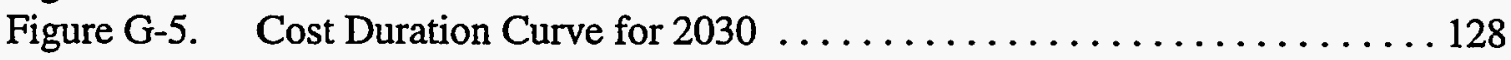




\section{Acknowledgments}

The work described in this study was funded by the Assistant Secretary of Energy Efficiency and Renewable Energy, Office of Utility Technologies of the U.S. Department of Energy under Contract No. DE-AC03-76SF00098. The authors would also like to thank Joseph Eto of the Berkeley Lab; Diane Pirkey, Jack Cadogan, and Joe Galdo at the U.S. DOE; Pat MacAuliffe, Angela Tanghetti, and Joel Klein at the CEC; and Francis Chapman at EDF for their invaluable assistance with this work. 


\section{Acronyms and Abbreviations}

$\begin{array}{ll}\text { AB 1890 } & \text { California State Assembly Bill } 1890 \\ \text { ANPC } & \text { Adjusted Net Present Cost } \\ \text { BRPU } & \text { Biennial Resource Planning Update } \\ \text { CEC } & \text { California Energy Commission } \\ \text { CPUC } & \text { California Public Utilities Commission } \\ \text { CTC } & \text { Competition Transition Charge } \\ \text { DISCO } & \text { Distribution Company } \\ \text { DOE } & \text { United States Department of Energy } \\ \text { DSM } & \text { Demand Side Management } \\ \text { EDF } & \text { Environmental Defense Fund } \\ \text { EIfin } & \text { Electric Utility Financial \& Production Cost Model } \\ \text { EPRI } & \text { Electric Power Research Institute } \\ \text { ER94 } & \text { 1994 Electricity Report of the California Energy Commission } \\ \text { FERC } & \text { Federal Energy Regulatory Commission } \\ \text { ICEM } & \text { Iterative Cost-Effectiveness Method } \\ \text { ID } & \text { Imperial Irrigation District } \\ \text { IOU } & \text { Investor Owned Utility } \\ \text { ISO } & \text { Independent System Operator } \\ \text { ITRE } & \text { Iterative Test for Resource Evaluation } \\ \text { LADWP } & \text { Los Angeles Department of Water and Power } \\ \text { MEP } & \text { Market Equilibrium Plan } \\ \text { NPC } & \text { Net Present Cost } \\ \text { O\&M } & \text { Operation and Maintenance } \\ \text { PG\&E } & \text { Pacific Gas and Electric } \\ \text { PURPA } & \text { Public Utilities Regulatory Policy Act } \\ \text { PX } & \text { Power Exchange } \\ \text { QF } & \text { Qualifying Facility under the terms of PURPA } \\ \text { RFP } & \text { Request for Proposal } \\ \text { RPS } & \text { Renewable Portfolio Standard } \\ \text { RWG } & \text { Renewables Working Group } \\ \text { SCE } & \text { Southern California Edison } \\ \text { SDG\&E } & \text { San Diego Gas and Electric } \\ \text { SMUD } & \text { Sacramento Municipal Utility District } \\ \text { SO4 } & \text { Standard Offer \#4 QF Contract } \\ \text { TSC } & \text { Total Social Cost } \\ \text { WEPEX } & \text { Western Power Exchange } \\ & \end{array}$




\section{Introduction}

The California Public Utilities Commission's (CPUC) historic decision of December 20, 1995 signaled the beginning of a new era for the state's electric utility industry. Prompted by some of the highest electricity rates in the nation, the Commission's decision started the phase out of the regulated world of protected utility customer bases and guaranteed returns on investment and replaced it with plans for a competitive environment in which electricity generators will market their product to intermediaries as well as directly to end-use customers. With some modification, the CPUC's vision for a competitive power market was adopted and endorsed by the California State Legislature with the passage of Assembly Bill 1890 (AB 1890), a bipartisan electric industry restructuring bill signed into law by Governor Wilson on September 23, 1996. The new, restructured market for electric power will likely be cutthroat, price-driven, and commodity-oriented; however, the sustainability and environmental impact of generation technologies will be important to some customers, and green marketing strategies are emerging. Nonetheless, restructuring appears to pose significant problems for renewable energy generators, who stand to lose the existing support mechanisms that have helped make their relatively higher-cost resources financially viable. To the extent that $A B 1890$ offers support to the renewables industry, it is temporary in nature and must be renewed by future legislatures. Should renewable power cease to be viable under restructuring, California would lose the sustainability, environmental, and fuel supply diversity benefits that renewable energy offers.

In this study, we attempt to model the California power sector in the next century in order to assess the potential impact of restructuring on renewably generated electricity. Specifically, we use the Elfin production costing and capacity expansion planning model to address three broad research questions: (1) Are new renewable resources likely to be viable in California's competitive electric industry of the next century? (2) What policies could foster the growth of renewable resources? And (3), what are the costs and benefits associated with these policies? These questions are important not just in California, but across the country and internationally as many other states, regions, and countries have begun to restructure their electricity industry.

In assessing the impact of restructuring on renewables, we focus on several new policies designed to support renewables in a market environment. While competition may favor renewable resources that produce during peak periods (e.g., solar), competitive power markets are likely to be detrimental to renewable resources in as much as the benefits associated with renewables (fewer emissions, resource diversity, reduced fuel price risk exposure) will no longer be considered in a regulated resource planning system. With restructuring, existing renewables support mechanisms -including regulatory proceedings and a variety of state and federal policies-will be modified and in some cases eliminated. New policies already under consideration to support renewables include: minimum 
renewables purchase requirements (MRPR), also called renewable portfolio standards (RPS), and surcharge-funded renewables programs. Carbon tax policies, if enacted, would also have a major impact on the viability of renewable generation. We attempted to model variants of all three of these policy options in this work. Provisions to support green marketing have also been debated and facilitated, but are not modeled or assumed in this study.

\subsection{Approach}

Although our general approach is applicable to other jurisdictions considering restructuring, our focus in this report is on the effects of restructuring on renewables in California. California is among the states furthest along in restructuring, and a large share of national renewable generation is in the state. Data sets with detailed operational parameters for generation resources are publicly available, although are rapidly becoming outdated. And, the Elfin model has been specifically adapted for California's regulatory process and has been updated to reflect changing market conditions.

In keeping with our goal to look beyond the uncertainties associated with California's fouryear transition period to full competition, we focus on the quarter century after 2005. By looking beyond the transition period, we are able to put aside some complex problems and uncertainties associated with the transition, notably the recovery of stranded assets through the competitive transition charge (CTC) and the renewal of subsidies. Under AB 1890, utilities must retire their traditional ratebase, and the traditional arrangement under which a plant is constructed by utility investors with cost recovery in rates guaranteed for prudent investments disappears. The net outstanding ratebase is to be collected during the transition through the CTC. We assume that this process, along with utility divestiture, will be completed on schedule and that at the beginning of our forecast period, 2006, all generators can be treated as independent competitors. Even though generation companies will likely hold multiple stations and local monopoly power may exist, we assume that each generator bids at its marginal cost and accepts the market share that such bidding provides. Moreover, that transmission constraints may create local market power is overlooked in this work because the computational demands and the limitations of our model argue against consideration of this issue; further, the importance and persistence of transmission constraints well into the next century is hard to gauge.

To determine the effects of restructuring on renewable energy resources, we use Elfin, an expansion planning and production cost model developed by the Environmental Defense Fund (EDF 1997). Elfin was developed in the context of California regulatory proceedings, but EDF has since modified the model to reflect expected market conditions. Traditional production cost models have simulated operations solely on the basis of minimizing cost. Elfin now estimates prevailing pool prices, including an energy payment to generators, and iteratively estimated payments to committed generators with pool prices below their bid prices, and to generators dispatched out of order for purposes of maintaining target spinning 
reserve levels. The current model version builds only resources that will be profitable over the lifetime of the project; that is, the net present value of the revenue stream exceeds the net present value of all costs for the project lifetime. More detailed information regarding Elfin algorithms is found in Appendix B.

Building a data set for the future California pool was the major task undertaken during this project. The pool is assumed to consist of the electricity demand and generation resources of the current three major California investor-owned utilities (IOU), Pacific Gas and Electric (PG\&E), Southern California Edison (SCE), and San Diego Gas and Electric (SDG\&E). The source of the data for these three companies is the ER94 filings by the companies with the California Energy Commission (CEC). The new data set is built on the assumption that the demand forecast by the three current vertically integrated IOUs can be simply summed to represent the future pool demand, and that all of the assets reported by these companies represent the full complement of generating assets currently available to meet this load. Implicit in this assumption is the belief that bilateral contracting will behave in the same way as the pool, overall. That is, the fact that a large segment of demand will be met through bilateral agreements and that the prices for these sales need not directly reflect pool prices and payments can be overlooked, at least initially, because, overall, these transactions will reflect pool prices. Therefore, treating the whole pool as a single competitive market represents a reasonable first approximation of ultimate conditions. Imports to the state are treated as large generators that are also available to meet this demand. Imports from the Southwest are treated as a large coal generator, and imports from the Northwest are treated as a partial hydro and partial coal station.

The outcome of an Elfin run is a profit-maximizing market equilibrium plan (MEP) that details when and how many units of possible generic generating technologies will be constructed. An MEP is a construction program for all available generating technologies that guarantees all entrants are profitable but that no additional generator can be built profitably. That is, no additional economic entry is possible and the industry remains in a sustainable equilibrium. Further, of the market equilibrium plans found by Elfin's search algorithm, the one under which entrants make the most overall profit is deemed the best overall plan. In other words, investors in technologies cannot make more total profit with any other combination of new construction. Of course, like any economic concept of equilibrium, this approach represents an idealized outcome, but one that we believe approximates the likely real-world result.

Having established a base plan, we run several scenarios with different combinations of assumptions and renewable energy support policies. For example, we vary the growth rate of gas prices as this will significantly affect the types of resources that Elfin finds profitable. That is, with high gas prices, fewer combustion turbines and combined-cycle plants will make money in the new market environment and this would favor wind, biomass, and other technologies. We also vary capital costs of renewable and gas-fired technologies and assess the costs and benefits of renewable policy options, including carbon taxes, renewable 
purchase requirements, and renewable subsidies. Costs are defined as the costs of renewable resources in excess of the less expensive resources that Elfin would have chosen. The benefits are measured in terms of reduced emissions, fuel diversity, and energy independence. We quantify these benefits to the extent possible.

\subsection{Organization of the Report}

The rest of this report proceeds as follows:

- In Chapter 2, we provide some basic background information on support for renewables in California, on the expected operation of the power pool and bilateral markets, and on the three key policy types modeled here.

- In Chapter 3, we discuss the Elfin production cost and expansion planning model as well as key assumptions that we made to model the future California pool.

- In Chapter 4, we present results from the successful Elfin models runs.

- In Chapter 5 we discuss the implications of the study, as well as key areas for future research.

- Additional information on results, Elfin's expansion planning logic, and resource options can be found in the appendices. 


\section{Background}

\subsection{Overview}

This chapter provides background information on the development of renewables in California, on the CPUC's restructuring decision, and on key provisions of California's restructuring legislation, $A B$ 1890. We discuss the development of the renewables industry to highlight California's historic commitment to the development and growth of the renewables industry and to illustrate the importance of government policies in fostering this growth. We consider three types of policies: renewable purchase requirements, surchargefunding subsidies, and carbon taxes. We pay particular attention to the role of the independent system operator (ISO), the power exchange, and the utilities in the restructured environment, and we discuss how market participants will be paid for energy and other ancillary services they provide.

\subsection{Public Utilities Regulatory Policy Act and Qualifying Facilities in California}

In response to the oil crisis of 1973 and in recognition of the United States' dependence on fossil fuels, Congress enacted the Public Utilities Regulatory Policy Act of 1978 (PURPA). The purpose of PURPA was to open the market to non-traditional electricity supply options in an effort to:

- $\quad$ increase the supply of electricity, leading to lower rates over time;

- $\quad$ reduce reliance on oil and gas, with their high price volatility; and

- $\quad$ increase system reliability by the presence of a large number of smaller facilities, since the probability that a number of facilities will fail at the same time is much smaller than the probability that one large facility will fail.

In response to the passage of PURPA and the adoption of Federal Energy Regulatory Commission (FERC) regulations in 1978, the CPUC established standards for the purchase of power from qualifying independent power facilities (QF). On January 21, 1982, the Commission issued Decision 82-01-103, which developed "standard offer" contracts describing the terms and conditions associated with utilities' obligations to purchase power from a $\mathrm{QF}$ at avoided cost. The standard offers represents a complete transaction, with prices, interconnection requirements, and other relevant terms. These offers were to be available to all QFs without exception or conditions.

The commission developed four standard offers-three short-run standard offers based on shortage and running costs of existing utility resources, and a long-run offer based on the 
costs of a new utility resource that could be avoided by purchasing power from QFs. Because the short-run offers did not appear to provide the desired stimulus to the growth of the QF industry, the CPUC developed an interim long-run offer to be used while it developed the final long-run offer. The interim long-run standard offer contracts guarantee fixed-priced payments over long time periods (up to 10 years) to provide QFs with some certainty in the return on their investments.

Primarily as a result of the fixed-price contracts, the QF industry has grown from a handful of projects to a mature industry representing well over $10,000 \mathrm{MW}$ of installed capacity, although less than this amount in terms of dependable capacity (Kito 1992). Table 2-1 shows the dependable capacity of Pacific Gas \& Electric (PG\&E), Southern California Edison (SCE), San Diego Gas \& Electric (SDG\&E), and the total for California in 1994. The nonutility category can be further broken down and it shows QF capacity as well as some self generation (see Table 2-2).

Table 2-1. Dependable Capacity for California Utilities

\begin{tabular}{|c|c|c|c|c|c|c|c|c|}
\hline$\because$ & $\begin{array}{l}\text { PGE } \\
\text { (MW) }\end{array}$ & (\%) & $\begin{array}{r}\mathbf{s} \\
(\mathbf{M W})\end{array}$ & $(\%)$ & $\begin{array}{r}\text { SDD } \\
\text { (MW) }\end{array}$ & $\begin{array}{l}E \\
\text { (\%) }\end{array}$ & $\begin{array}{l}\text { State } \\
\text { (MW) }\end{array}$ & $\begin{array}{l}\text { tal } \\
\text { (\%) }\end{array}$ \\
\hline Oil \& Gas & 7,080 & $35 \%$ & 8,746 & $43 \%$ & 1,951 & $63 \%$ & 22,579 & $40 \%$ \\
\hline Coal & 0 & $0 \%$ & 1,938 & $10 \%$ & 0 & $0 \%$ & 4,239 & $7 \%$ \\
\hline Geothermal & 756 & $4 \%$ & 0 & $0 \%$ & 0 & $0 \%$ & 1,036 & $2 \%$ \\
\hline Nuclear & 2,160 & $11 \%$ & 2,327 & $12 \%$ & 430 & $14 \%$ & 5,326 & $9 \%$ \\
\hline Hydro & 4,540 & $22 \%$ & 785 & $4 \%$ & 0 & $0 \%$ & 6,830 & $12 \%$ \\
\hline $\begin{array}{l}\text { Pumped } \\
\text { Storage }\end{array}$ & 1,188 & $6 \%$ & 217 & $1 \%$ & 0 & $0 \%$ & 3,222 & $6 \%$ \\
\hline Non-Utility & 3,648 & $18 \%$ & 4,177 & $21 \%$ & 236 & $8 \%$ & 8,297 & $15 \%$ \\
\hline Imports & 852 & $4 \%$ & 1,913 & $9 \%$ & 486 & $15 \%$ & 5,136 & $9 \%$ \\
\hline Total & 20,224 & $11 \%$ & 20,103 & $100 \%$ & 3,103 & $100 \%$ & 56,665 & $100 \%$ \\
\hline
\end{tabular}

Source: "Electricity Report," California Energy Commission, November 1995, Table 7-1. 
Table 2-2. Dependable Capacity for California Utilities' Non-Utility Generation

\begin{tabular}{|c|c|c|c|c|c|c|c|c|}
\hline 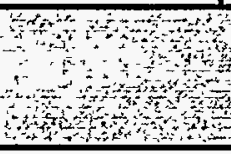 & (MW) & 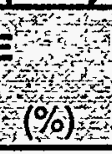 & 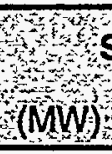 & $\begin{array}{l}\% \\
(\%) \\
(\%)\end{array}$ & MW: & $(\%)$ & stat & $\begin{array}{l}\text { tal } \\
(\%) \\
(\%)\end{array}$ \\
\hline $\begin{array}{l}\text { Fossil } \\
\text { Cogeneration }\end{array}$ & 1862 & $51 \%$ & 2,090 & $50 \%$ & 162 & $69 \%$ & 4,114 & $50 \%$ \\
\hline Biomass & 627 & $17 \%$ & 302 & $7 \%$ & 7 & $3 \%$ & 936 & $11 \%$ \\
\hline Geothermal & 154 & $4 \%$ & 701 & $17 \%$ & 0 & $0 \%$ & 855 & $10 \%$ \\
\hline Hydro & 36 & $1 \%$ & 13 & $0 \%$ & 3 & $1 \%$ & 73 & $1 \%$ \\
\hline Wind & 167 & $5 \%$ & 165 & $4 \%$ & 0 & $0 \%$ & 333 & $4 \%$ \\
\hline Solar & 1 & $0 \%$ & 364 & $9 \%$ & 0 & $0 \%$ & 365 & $4 \%$ \\
\hline $\begin{array}{l}\text { Self- } \\
\text { Generation }\end{array}$ & 801 & $22 \%$ & 542 & $13 \%$ & 64 & $27 \%$ & 1621 & $20 \%$ \\
\hline Total & 3648 & $100 \%$ & 4,177 & $100 \%$ & 236 & $100 \%$ & 8,297 & $100 \%$ \\
\hline
\end{tabular}

Source: California Energy Commission 1995. "Electricity Report." November. Table 7-1.

Note: Dependable capacity for wind and hydroelectric is usually reduced by $80 \%$ to reflect the "firm" or "effective" capacity. This occurs because wind and hydroelectric power projects generally have low capacity factors compared to other resources.

Because the ten-year fixed-price portion of the final long-term Standard Offer \#4 (SO4) contracts was based on predictions of high future fossil fuel prices, the terms of the contract were very lucrative for $\mathrm{QF}$ projects. At its peak, the net statewide subsidy to renewable QFs under SO4 contracts probably exceeded a billion dollars annually. Once QFs reach the end of the ten-year, fixed-price portion of the SO4 disappears, however, the contract payment becomes variable and is based on the pool price plus an approximately $2.5 \phi / \mathrm{kWh}$ capacity payment. Given that the earlier predictions of high fossil fuel prices were incorrect, and that the market price for electric power is now quite low, QFs with SO4 contracts face a significant revenue drop as they move from the fixed to the variable-price portions of their contracts. In general, revenues to renewable QFs are halved in this shift, and the sudden drop in revenues to renewable QFs is referred to as the "cliff." By the end of the restructuring transition period, the beginning of our forecast period, virtually all renewable QFs holding SO4 contracts will have exhausted the long-run fixed-price portion of their contracts, and will have fallen off the "cliff." In the base case of this study, we assume that renewables compete entirely without any subsidy; that is, all resources are left to compete on economics alone. 


\subsection{The California Restructuring Decision}

\subsubsection{Reorganization of the Industry}

\section{Independent System Operator}

In its December 1995 decision, the CPUC indicated that it intended to establish an independent system operator (ISO) to operate the utilities' transmission systems. Previously, the investor-owned utilities (i.e., PG\&E, SCE, and SDG\&E) owned and operated their transmission systems. The primary reason for transferring control from the utilities to an ISO is that the utilities could use the transmission system strategically to their benefit and to the detriment of other market participants. The Commission, in its decision, enumerated four immediate and lasting advantages of an ISO:

1. The state will achieve a permanent and functional resolutions of transmission access disputes between the transmission-owning utilities and those dependent upon access to the system.

2. There will be a lasting efficiency gain resulting in cost savings due to combining the now distinct control function of many entities under the auspices of a statewide independent system operator.

3. There will be an operational efficiency inherent in a transmission network which has no economic interest other than fostering open access and the facilitation of supply from generators irrespective of their ownership.

4. There will be a consistent pricing system for the use of the common network facilities that prevents cost shifting and supports the competitive market. (CPUC 1995, p. 30).

\section{Power Exchange}

As outlined by the CPUC, the Power Exchange (PX) will be separate from the ISO and will "function as a clearinghouse by providing a transparent market for generation with hourly or half-hourly price signals evident to users and long-term investors" and thus "provide critical information vital to informed market decisions by generators, wholesale buyers, and end users." (CPUC 1995, p.47). The PX will be open to all generators, including municipalities and out-of-state generators, and will work by accepting supply and demand bids and through this process determine time-differentiated market-clearing prices. The utilities are required to bid their generating capacity into the PX and to buy electricity from the PX to serve their customers. 


\section{Utilities}

Utilities will continue operate their generation and distribution facilities and will be responsible for procuring energy for their full-service customers.

\section{Timetable}

The California ISO and the PX became operational in April 1998.

\section{WEPEX and Payment Provisions}

The CPUC left many implementation issues unresolved. In particular, the CPUC ordered the investor-owned utilities to submit proposals to the Federal Energy Regulatory Commission (FERC) for the design and operation of the ISO and the PX. The investor-owned utilities formed a working group, WEPEX, and submitted their initial proposal on April 29, 1996 to FERC. On November 29, 1996 FERC approved key parts of the WEPEX filing, conditionally authorizing the establishment of the ISO and PX, subject to a "Phase II" filing of March 31, 1997. For the purposes of this analysis, the WEPEX filings were used to delineate the responsibilities of the ISO and the PX and how bids would be submitted and market clearing prices for energy and ancillary services would be established.

The PX will accept both supply and demand bids. The supply bids will include three parts: the energy bid, the no-load bid, and the start-up bid. The PX will determine the market clearing price, develop a preferred schedule, and submit this schedule to the ISO. The ISO will recommend changes to reduce transmission congestion and, based on this information, the PX will resubmit its schedule. After the final schedule is chosen by the ISO, the PX will provide the supply, demand, and price schedules to the buyers and sellers. This final price schedule is considered a financial commitment. Any unexpected changes in demand will be met with supply from the shorter-term hour-ahead market, at the prices of the hour-ahead market.

\subsubsection{Proposed Minimum Renewable Purchase Requirement}

In its December 1995 decision, the CPUC indicated its support for a minimum renewable purchase requirement (MRPR). The MRPR would require that a certain percentage of a state's annual electric use (or capacity) come from renewable energy. To implement the policy, a renewables purchase requirement (as a percent of energy or capacity sales) would be applied and enforced upon retail electric suppliers in the state. Individual obligations would be tradeable through a system of renewable energy credits (RECs), which is designed to add flexibility in meeting the MRPR. In advocating such a policy, the Commission left 
many issues unresolved: what is the appropriate level for such a MRPR, should requirements be equally applicable to all distribution companies (DISCO), what type of noncompliance penalty should be established, should the MRPR be established on a MW or MWh basis, is a transition strategy necessary, are floors for certain technologies appropriate, etc.? A Renewables Working Group (RWG) was authorized by the Commission to assess and provide recommendations on many of these issues. The RWG Report was submitted to the CPUC on August 23, 1996 (Renewables Working Group 1995).

\subsection{Legislative Action: AB 1890}

Although the CPUC initiated the process of electric power industry restructuring, it was the State Legislature's passage of $A B 1890$ which will actually bring about restructuring in California because changes beyond the jurisdiction of the CPUC are required. In contrast to the CPUC's MRPR approach, AB 1890 established a surcharge-funded program to partially support existing, new, and emerging renewables in the state between January 1998 and December 2001. The policy will sunset on December 31,2001, and no additional longterm renewables policy is proposed. Total renewables funding over this four-year period will apparently equal $\$ 540$ million. These funds are to be collected by the three largest investorowned utilities (IOUs) through distribution surcharges. The California Energy Commission is to administer the distribution of these funds, with the provision that not less than 40 percent of the monies collected by the IOUs go either to existing or new and emerging renewable projects. $\mathrm{AB} 1890$ directed the $\mathrm{CEC}$ to issue a report to the legislature outlining its recommendations on fund distribution. Finalized in late March, 1997, the CEC report calls for a variety of different approaches including: technology-specific production incentives for existing technologies, competitively auctioned production incentives for new technologies, multiple requests for proposals (RFP) using different mechanisms for emerging technologies, customer incentives and customer education (CEC 1998).

\subsection{Alternative Policies for Fostering Renewables}

In addition to an MRPR and surcharge-based renewables support mechanisms, there are numerous other alternative policies to foster the development of renewable resources. These policies include: imposing criteria pollutant and/or carbon externality taxes on traditional generation sources (e.g., oil, natural gas, coal) and fostering the development of voluntary green markets. Here we examine only three policy types: an MRPR, a surcharge-based production credit, and a carbon-oriented externality tax. 
Figure 2-1. Overall Resource Mix for California Power Generation 1994

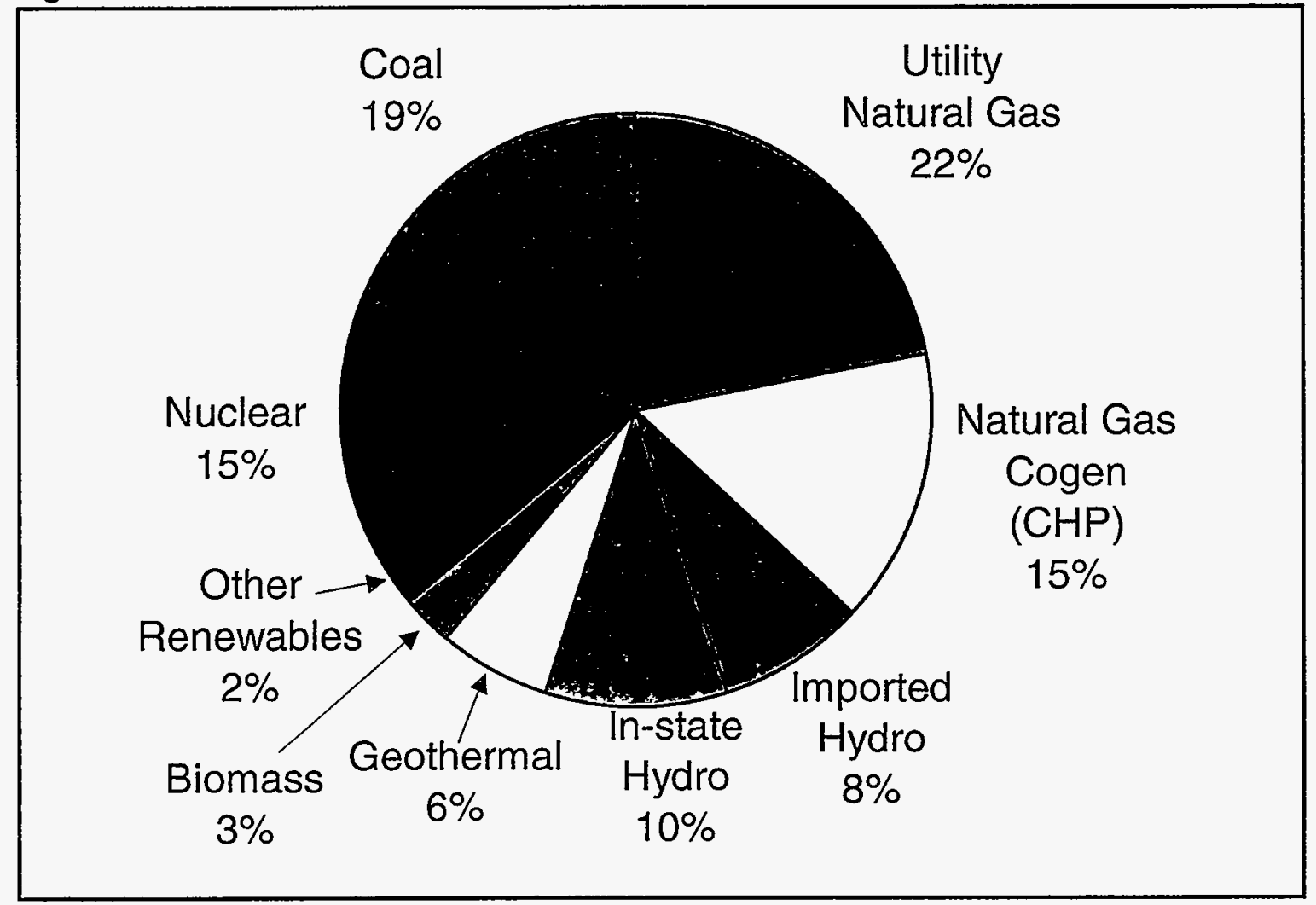

\subsection{The Policy Question}

The overall fuel mix of power generated for use in California is shown in Figure 2-1. The state's approximately $250 \mathrm{TWh}$ of electricity consumption is derived from a surprisingly diverse fuel mix. This is partially fortuitous, since there is considerable hydro in the state and nearby, because the state's nuclear stations have operated successfully, and because there is a considerable geothermal resource. There are no coal stations in California, but coal is a factor both because some of the imported electricity is generated from coal and because California utilities own coal-generating capacity out-of-state. California has also actively sought diversity through its policies to foster renewable generation and cogeneration. In fact, California has more than 90 percent of the total U.S. generation of each of geothermal, wind, and solar, and about 15 percent of biomass.

Looking into the next century, however, most of the nuclear capacity was commissioned in the 1980 s and so will be nearing retirement by the 2000 teens, the hydro resource is fully developed and output is unlikely to increase significantly, and, most importantly, the pie is growing significantly. Population growth in the state is expected to be around 1.5 percent per year for some time, raising electricity demand. The net effect of these processes will be an inevitable increase in the thermal share in generation, making the state more dependent on imported fuel and less likely to meet Kyoto greenhouse gas emission reduction goals. The 
challenge is, in the face of falling nuclear and hydro shares in generation, to ensure that the share of the other carbon-free generation does not decline, and, preferably, increases.

The key policy question under consideration in this study then is how can the tools we have available to simulate the future California market be used to evaluate the effectiveness of alternative policy instruments to enhance the renewable share of generation, and how can these simulation tools be improved? 


\section{Modeling the California Pool}

\subsection{Overview}

In this chapter, we briefly discuss Elfin's logic for calculating pool prices, including energy, commitment, and spin payments, and discuss key assumptions that were used to create the California pool data set. For the pool data set, we relied primarily on the Elfin data sets that were created for the 1994 Electricity Report (CEC 1995), with some modifications. The expansion planning options were developed using a variety of sources, including the Elfin data sets, EPRI (1993), and DOE (1994).

\subsection{Elfin's Pool Price Payments and Iterative Test for Resource Evaluation (ITRE) Logic}

\subsubsection{Elfin's Pool Price Payments}

\section{Energy Payments}

The energy payment concept in Elfin works on the assumption that the bid price of the most expensive unit operating in a particular time period (e.g., hourly) sets the pool price for all operators. Elfin does not currently calculate hour-by-hour marginal energy payments, but does calculate (a) the average marginal energy payment over as many as 99 subperiods from a typical week from up to 13 seasons, and (b) the payments that each resource block will receive during each time period. Because the computational requirements of calculating so many subperiods during the search for an MEP are prohibitive, only three subperiods and four seasons were used during the search, although, once the MEP has been found, subsequent estimations of pool prices were made using more subperiods and seasons. The average marginal energy payments in each subperiod are calculated by multiplying the marginal energy costs by the time marginal and summing these blocks. For example, if during the peak period one unit was marginal for 75 percent of the time at a cost of $3 \phi / \mathrm{kWh}$ and one unit was marginal for 25 percent of the time at a cost of $5 \phi / \mathrm{kWh}$, the average marginal cost during the peak period would be $3.5 \phi / \mathrm{kWh}[(0.75 \times 3.0)+(0.25 \times 5.0)]$. This final amount would be reported in the Elfin results. Elfin also disaggregates these results by resource block - essentially providing the amount of time each resource block would be operating during each subperiod and the average payment this unit would receive for the time that it runs. While nothing in the algorithm requires it, in this work we assume that all generators bid their marginal cost. This is equivalent to assuming that no market power exists and no generator can gain by strategic bidding. 
Because generators are not perfectly reliable and there is always a positive probability that load cannot be met, the social cost of outage is properly included as an ultimate high cost supply resource. Therefore, in some instances, the energy payment will be greater than the cost of running existing units. This occurs when the system is expected to be unable to meet load because of unexpected outages, for example. In these instances, we have specified the value of energy not served as $\$ 1.00 / \mathrm{kWh}$ and this drives up the pool price considerably during peak periods. Another way to think of this is that as the pool develops, some customers may submit demand-side bids, indicating that they will curtail their energy at a price of say, of $\$ 1.00 / \mathrm{kWh}$. If the ISO has no other options, they would curtail this load and the $\$ 1.00 / \mathrm{kWh}$ would be on the margin for a short period of time. While this assumption has a powerful effect on the peak pool price and, therefore, seems to be of great significance and worthy of a sensitivity analysis, in practice prices are so peaky that the overall effect on the year-round pool price is not great.

\section{Commitment Payments}

If power systems operated smoothly with generators started, stopped, and dispatched instantaneously, then the energy payment alone would ensure generators covered their fuel costs. However, operations in practice are complex and many other services than simple energy inflow must be provided by generators. Commit and spin payments reflect rewards for two such services.

Because plants cannot be started and stopped instantaneously, generators are forced to run at times when the pool price is below their marginal operating costs. Elfin estimates a commit payment that ensures that during any subperiod, the last generator committed during the subperiod is made whole for its full operating costs. This commit payment is distributed to all generators.

This approach has proven to be a poor representation of actual practice as it is emerging in California, in which generators self-commit, numerous generators are kept running to meet reliability requirements under private ISO must-run contracts, and the ISO purchases four ancillary services in open markets (Klein 1997). Simulating this system is not feasible for long-range planning, so we accept commitment and spin payments as a reasonable proxy.

\section{Spin Payments}

At times of high load it becomes more difficult for systems to maintain their spinning reserve requirement, which is a small margin of generating capacity kept fully functional and ready to replace any failing generator. When combustion turbines are started, thermal generators are backed down to provide the spinning requirement. As such, these generators are not 
creating as much revenue as they potentially could. Elfin makes these generators financially whole by providing them with a spin payment equivalent to their sacrificed revenues.

\subsubsection{Elfin's ITRE Logic}

For the purpose of this work, the expansion planning logic of Elfin has been considerably restructured. All expansion planning has solves two problems, an upper one in which new capacity is chosen, and a lower one in which existing plant is operated and the pool prices calculated. For the lower problem, Elfin uses a load duration curve model to dispatch resources. Elfin first creates a load duration curve for each specified subperiod and then dispatches the least expensive resources, subject to user-specified constraints (e.g., a unit must operate throughout the week if its committed to meet load any time during the week). For the upper problem, Elfin uses the Iterative Cost Effectiveness Method and the Iterative Test of Resource Effectiveness (ICEM-ITRE).

ICEM tests the cost effectiveness of resources in each year of the optimization. ICEM will calculate the cost effectiveness of all resource options and build the most cost effective, as long as it is cost effective in its first year. ICEM continues to build the most cost-effective resources until no further resources are cost effective and then moves on to the next year. With ICEM, once a resource is built, it cannot be taken out of the resource mix.

ITRE tests the cost effectiveness of resources in each year that resources are eligible for inclusion, and adds the resources in years in which the benefits are greatest. Net benefits might be greater in later years because technology costs could have decreased. ITRE's advantage over ICEM is that ITRE might wait for a few years to build a new technology in order to capture larger benefits, whereas ICEM might build in the early years and thereby foreclose more cost-effective opportunities in the future. Also, ITRE can eliminate chosen resources and can find better solutions as a result.

During this project, EDF has modified Elfin's ITRE logic considerably in order to reflect new market conditions. Under old ITRE logic, Elfin added new plants to the resource mix if they reduced the total net present value of costs of running the entire system during the time period under consideration. In the pool, actual system operations are assumed to be identical to current approaches. That is, the ISO runs the system through time no differently than an existing IOU. What is quite different in the pool is the decision-making process for capacity expansion. Under the new ITRE logic, Elfin only adds new plants if they are able to cover their fixed and variable costs (i.e., if they break even). The most profitable projects are built first and ultimately all projects that break even, or better, are built. An example illustrating how the old and new logic could result in different resource plans is helpful. Imagine an instance where building a new combined-cycle unit would displace an inefficient unit and that these "production" benefits were more than offset by the annualized capital and operation and maintenance (O\&M) costs of the new plant. In this case, overall costs are 
reduced and Elfin builds the new plant. However, imagine now that this new plant does indeed reduce production costs, but the revenues this plant receives are not sufficient to cover its annualized capital expenditures. Thus, under the new logic, even though this plant reduces overall system costs during the time period under consideration, the plant is not profitable and, therefore, will not be built.

The paradigm adopted in the new ITRE logic is that of an investment community which invests in the most profitable resources first. This community will continue to invest until no more profitable opportunities exist. Unfortunately, unlike the simple cost-minimization algorithm of the previous ITRE, the search for plans in which no more profitable entry is possible is unstable and time consuming, and no unique solution exists. All MEPs must be found and the best chosen from among them. All MEPs represent sustainable market equilibria in which all entrants earn positive net present profits on constructed units, but no additional unlimited-entry generation units can be profitably built. Since all existing capacity will, in general, become less profitable as more capacity enters, its profitability cannot be considered in choosing the best MEP. Therefore, the choice of best MEP must be based on the profitability of unlimited-entry generation only. The paradigm, therefore, is one where investors in the unlimited-entry technologies (e.g., gas combined cycle) will find the MEP which maximizes their profits.

As explained above, we adjusted Elfin's iterative test for resource evaluation (ITRE) logic to select the most profitable resource options to be built, rather than those that minimize overall net present cost of a centrally planned utility. In practice, the search for a combination of new capacity construction is completed in two steps. In the first step, the traditional minimum-cost solution is found. This is the expansion plan that Elfin would select if it were run for the previous centrally planned, cost minimizing, regime. We start the search for a market-driven construction plan from this point because we know that in a perfect world, the cost-minimizing and profit-maximizing plans should be the same, or, at least very similar. In the second step, with this given starting plan, Elfin switches to its market simulation mode and calculates projected pool prices, including energy, commitment, and spin payments. Given these projected payments, Elfin evaluates resources based upon their profitability and builds the most profitable resource in its most profitable year. In this search, Elfin is restricted to adding one resource at a time. Elfin then recalculates projected pool prices, and again evaluates potential resource additions. If a previously added resource becomes unprofitable at any time during the search, it is deleted from the expansion plan. Elfin continues this iterative process until no additional resources can be profitably added to the system, and yet all the resources that are in the plan can be profitably built. Unfortunately, there may be several plans that meet this criteria, although, in practice, they tend to be similar plans. To select among these "market equilibrium plans" (MEPs), Elfin selects the one that is most profitable to the new entrants as the "best" plan. 


\subsubsection{Limitations of Elfin}

There are several limitations associated with using Elfin to model the California pool. The computational demands of searching for MEPs is daunting, often taking days of computer time. A tradeoff of accuracy and computer time is inevitable. One of the major sacrifices was the need to run Elfin with only four seasons and three subperiods, meaning the year is represented by 12 load duration curves. While we ran the expansion plan with fewer time periods in order to use the program more efficiently, we then often, in separate production cost runs, developed expected pool prices using a greater number of time periods.

Another limitation associated with Elfin is that the model does not take into consideration transmission constraints. In the near term, these constraints are important. Limits on transmission lines will prevent complete trading between areas and thus the system as whole will not be operated as efficiently as it could in the absence of these constraints and pool prices will differ across the state. While these constraints are important in the near term, we assume that these constraints will be largely eliminated by the year 2005 .

A third limitation of the Elfin model is that it does not simulate strategic bidding. For example, we expect that hydro resource owners will strategically bid into the pool in order to maximize revenues. This problem arises because Elfin bases its logic on actual costs, whereas the pool will operate based upon bids submitted by resource owners, who will likely bid strategically. If an external source of strategic bids were available, they could simply replace the cost data in Elfin and all could proceed as before. Unfortunately, there is no easy solution and thus we assume for the purposes of this project that no strategic bidding occurs. Bushnell and Borenstein (1996) look at market power and strategic bidding in the California pool using a Cournot mode and find that the California utilities may be able to exert considerable market power in the pool.

\subsection{Key Assumptions in the California Pool}

\subsubsection{Resources Included in Data Set}

We include generating resources from the ER-94 data sets of Southern California Edison (SCE), Pacific Gas \& Electric (PG\&E), and San Diego Gas \& Electric (SDG\&E) in the data set (see Table 3-1). The CEC will not release the ER-96 data sets into the public domain. We do not include resources from Los Angeles Department of Water \& Power (LADWP), Sacramento Municipal Utilities District (SMUD), or Imperial Irrigation District (IID) (see Table 3-2). The rationale for the exclusion of the municipalities and irrigation districts is that it would be difficult to determine the current and future amounts that they might bid and/or buy from the pool and that these amounts are likely to be relatively small compared to the size of the entire pool. While LADWP was expected to import roughly 19 percent of its energy for 1995, this energy is primarily from the Northwest and Southwest and not from 
other California utilities. In addition, LADWP is expected to export only a small amount of energy (approximately $2 \%$ ). SMUD, by contrast, is expected to import nearly 75 percent of its energy, with $2,978 \mathrm{GWh}$ to come from SCE and PG\&E. While this represents a large amount of SMUD's power (31\%), this is only a small fraction of expected pool sales.

Table 3-1. Peak Week Capacity Included in California Data Set for 1995 (MW)

\begin{tabular}{|c|c|c|c|c|}
\hline & PG\&E & SCE & SDGEE & TOTAL \\
\hline \multicolumn{5}{|l|}{ Utility-Owned } \\
\hline Nuclear & 2,160 & 2,324 & 430 & 4,914 \\
\hline Oil \& Gas & 6,740 & 9,856 & 1,879 & 19,607 \\
\hline Oil \& Gas ${ }^{\ddagger}$ & 874 (347 in) & $517\left(225,{ }^{\dagger}\right.$ in $)$ & & \\
\hline Coal & 0 & 1,943 & 0 & 1,943 \\
\hline Geothermal & 677 & 0 & 0 & 677 \\
\hline Hydroelectric & 5,015 & 1,580 & 0 & 6,595 \\
\hline Pumped Storage & 1,158 & 217 & 0 & 1,375 \\
\hline Subtotal & & & 2,309 & \\
\hline QFs/Self Generation* & 4,054 & 4,159 & 315 & 8,528 \\
\hline Imports & & & & 6,600 \\
\hline
\end{tabular}

Table 3-2. Capacity, Sales, Imports, and Exports for LADWP, SMUD, and IID

\begin{tabular}{|lrrr|}
\hline & LADWP & SMUD & IID \\
\hline 1995 Annual Peak (MW) & 5,692 & 2,362 & 624 \\
1995 Sales (GWh) & 27,911 & 9,430 & 2,654 \\
Imports (GWh) & 5,223 & $\sim 6,983$ & na \\
Exports (GWh) & 626 & 0 & na \\
\hline
\end{tabular}

Source: ER 1994 files.

In addition, we have represented all of the electricity inflows as generic imports from the Southwest and Northwest. These imports behave as monolithic units. The Southwest is entirely coal, while the Northwest has a hydro lower block and a coal upper block. A more complete analysis would estimate out-of-state resources and associated loads and allow utilities and other private power producers to bid in only excess energy into the California pool. 
In terms of actual resources, we included all existing utility assets, including nuclear, coal oil/gas, geothermal, hydroelectric, and pumped and battery storage units, although we did make some modifications. Notably, we took out all penalty factors to ensure that plants were dispatched economically. ${ }^{1}$ We included only nuclear, wind, and solar PV units as must runs, and, finally, we did not implement local reliability constraints. We have also included the qualifying facilities found in the three utilities' data sets. We assume that the marginal costs for all of these units is zero or, in other words, that all energy that the QFs produce will be accepted into the pool. This assumption is least plausible for cogeneration units because these units will incur variable costs when they operate. However, in the absence of detailed information on the steam load of each generator, a zero marginal cost assumption is reasonable.

There are, however, some resources that were in the utilities ER94 data sets that we excluded for this analysis. In particular, we exclude the biennial resource planning update (BRPU) resources because the majority of these contracts will not be implemented, DSM resources because the savings estimates are potentially uncertain, and utility-specific contracts because we chose to model these as blocks of energy being imported from the Northwest and Southwest.

\subsubsection{Load Forecast and the Annual Load Profile}

We combine the load forecasts that were found in the ER94 data set for the planning areas of SCE, PG\&E, and SDG\&E, taking into consideration that the utilities had different peak days. The combined load for 1995 was approximately $38 \mathrm{GW}$, growing annually at a rate ranging from 1.3 to 2.2 percent. To simplify, we use a base case of 1.5 percent load growth and specify the high and the low load growth rates at three and zero percent, respectively.

\subsubsection{Retirements}

Because the ER94 data sets only extend through 2013 and provide little information on expected retirements, and because we expect substantial numbers of retirements within the time frame of this study, we chose to set retirement dates for the nuclear facilities and oil and gas plants. For other types of plants (e.g., hydroelectric, coal, and QFs), we assume no retirement within the time frame of this study on the theory that this capacity will likely be replaced in kind upon retirement.

These penalty factors are usually added to account for aspects of operations not represented in the model. 
Figure 3-1. Gas and Oil Plant Commission Dates

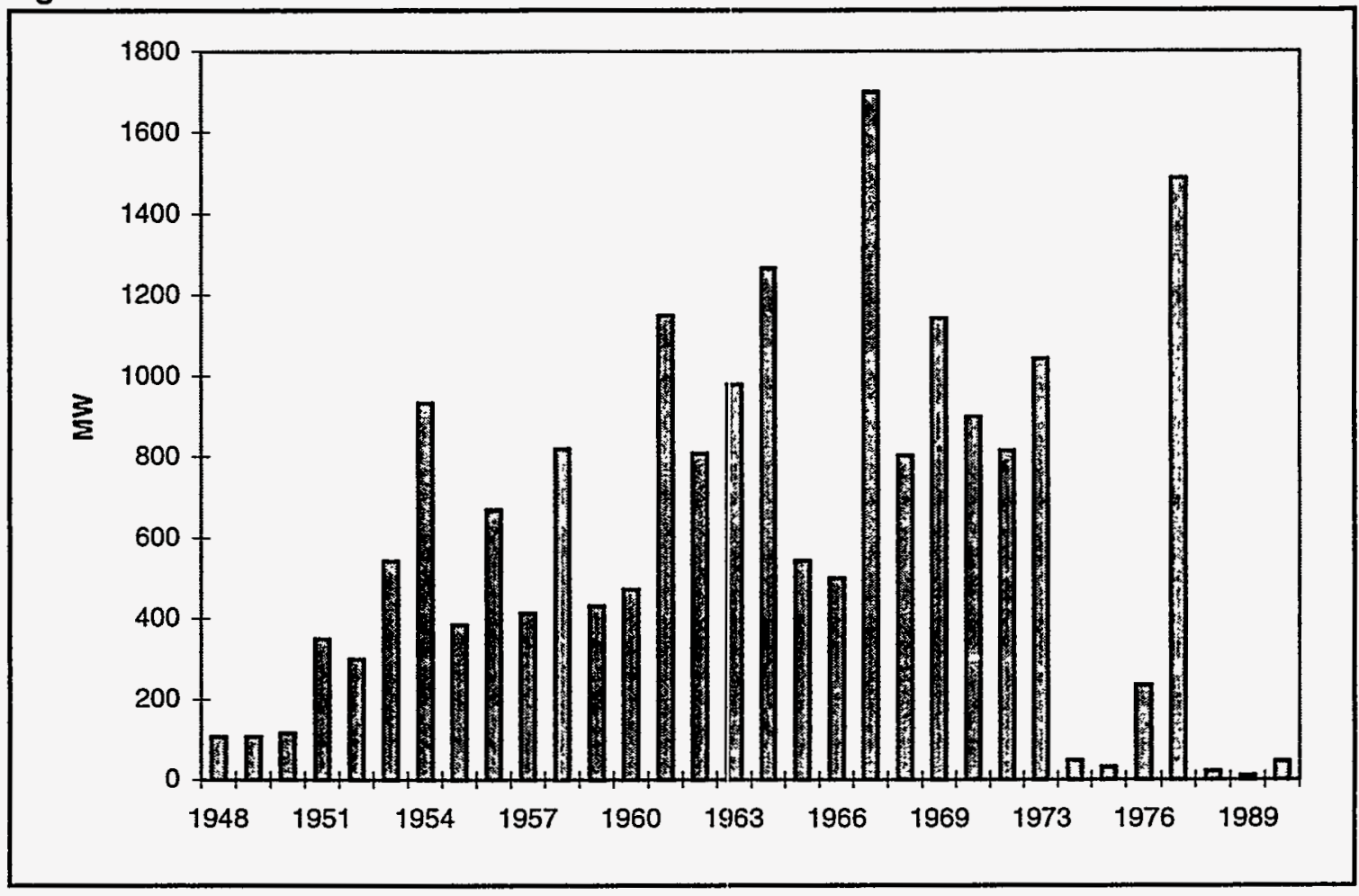

For the nuclear units, we assume that they will be retired after 30 years of operation. This means that the nuclear plants that supply California will retire between 2013 and 2018. We also assume a fairly ambitious retirement schedule for the oil and gas plants in the next century, in large part because many of these plants were built in the 1950s and 1960s (see Figure 3-1) and, therefore, will be quite old in 2010 and beyond. Assuming that these plants have engineering lives of 40 to 50 years, many of these plants will retire between 2000 and 2020. Exactly when these units retire will have important implications for the pace of new construction of generation in California.

We considered a number of scenarios for retirements, including (1) imposing retirement at the end of the engineering life of the plants (2) using the utilities' retirement scenarios through 2013 and imposing mandatory retirements at the end of the engineering lives for the remaining plants, (3) imposing no retirements, but tying repower to retirements and allowing Elfin to retire units economically, and (4) retiring units economically. Ultimately, we selected option 2. The ER94 data sets for PG\&E and SDG\&E provided data on retirements and plants put on short-term reserve, which we interpreted as early retirement. The ER94 data set for SCE did not provide retirement dates, but retirement dates for some of the plants were obtained from Elfin runs for the ER94 report. For the remaining plants, we implemented the following retirement scheme: 
$100 \mathrm{MW}$ or less:

101 to $300 \mathrm{MW}$ :

$301 \mathrm{MW}$ or greater: retired in 2014 if greater than 40 years old retired in 40th year for remaining plants retired in 2014 if greater than 45 years old retired in 45th year for remaining plants retired in 2014 if greater than 50 years old retired in 50th year for remaining plants

Combustion Turbines: $\quad$ retired in 2014 or in 30th year, whichever is earlier

No retirement dates were specified for hydroelectric units, coal plants, or QFs. We assume that no hydroelectric plants retire during the time frame of this study. The ER94 data set does not provide retirement dates for SCE's nearly 2,000 MW of coal capacity, roughly three quarters of which came on line between 1969 and 1971. In addition, SCE added 50 MW in $1979,320 \mathrm{MW}$ in 1986 , and $50 \mathrm{MW}$ in 1993. We assume that this capacity does not retire because it will be profitable and would be replaced when it is retired. We use the utilities' estimates of QF retirement through 2013, after which we assume no units retire. We assume that cogeneration plants are tied to an industrial facility and would be replaced upon retirement.

We treat geothermal capacity slightly differently. ER94 indicates that geothermal capacity degrades over time, and we assume that this degradation continues, with the steam reserves depleted by 2026.

\subsubsection{Cost of Existing Resources}

We obtained much of the cost information for existing resources from the ER94 data sets, although we greatly simplified the fuel costs and developed fixed O\&M costs for oil and gas plants. The variable O\&M costs for existing plants varied considerably across plants and utilities. SCE used $\$ 0.00098 / \mathrm{kWh}$ for its oil and gas plants; SDG\&E used $\$ 0.00014 / \mathrm{kWh}$; and $P G \& E$ used values varying from $\$ 0.000004 / \mathrm{kWh}$ to $\$ 0.005 / \mathrm{kWh}$. PG\&E also specified variable costs for its geothermal units of about $\$ 0.001 / \mathrm{kWh}$ and for its coal plants, varying from $\$ 0.0014 / \mathrm{kWh}$ to $\$ 0.0041 / \mathrm{kWh}$.

The utilities generally used different gas price forecasts. We simplified all of the fuel costs and used base case, high, and low cost scenarios in our analysis. For natural gas, we assume that the price in 1995 varies from the summertime low of $\$ 1.78$ to $\$ 2.25 / \mathrm{GJ}$ in December with real growth rates of zero, 1.5 , and three percent. ${ }^{2}$ For SCE's existing coal units, we simplified the utility's estimates of future coal prices, which ranged from $\$ 1.01$ to $\$ 1.73 /$ GJ 
with real growth rates ranging from zero to 1.7 percent. We assume that the coal fuel costs represent contract prices and will not change during our study period. For new coal units, we assume that the coal price is $\$ 1.42 / \mathrm{GJ}$ in 1995 and escalates at 1.5 percent. In addition, the Northwest and Southwest imports are also tied to this generic coal price. For geothermal, we assume that geothermal operators pay for the steam at a rate of about $\$ 0.60 / \mathrm{GJ}$, with real growth rates of zero, 1.5, and three percent. For nuclear plants, we assume fuel costs of approximately $\$ 0.005 / \mathrm{kWh}$ with a real growth rate of zero percent. Finally, we assume distillate fuel costs $\$ 4.58 / \mathrm{GJ}$ with real growth of 1.3 percent, and no fuel costs for cogeneration facilities, that is, cogenerators bid a zero price into the pool.

Fixed O\&M for existing plants was not contained in the ER94 data sets. We assume that existing oil and gas plants (excluding combustion turbines) have fixed O\&M costs of $\$ 50 / \mathrm{kW}$, which is roughly double that of new plants. We recognize that the fixed O\&M costs will be variable and higher for progressively older plants, but did not want to add this additional level of complexity to our analysis. Note that the fixed O\&M costs do not affect the pool price, only the retirement decision. In addition, we did not include fixed O\&M data for any other existing plants other than the oil and gas plants.

\subsubsection{Resource Options}

Some of most important assumptions in any capacity expansion exercise are the specifications of generic resource options. Computational constraints require that the number of options be small, while the desire to represent the true range of technical choices available argues strongly for a large number of options. The ITRE method used by Elfin is, fortunately, much less limiting in this regard than dynamic programming based methods, which quickly reach the limits of computational feasibility when numerous options are considered. For this analysis, we included the following 12 potential resource options:

\footnotetext{
- $\quad$ NG combined cycle

- NG combined cycle repower

- $\quad$ NG combustion turbine

- advanced coal

- coal gasification

- biomass

- geothermal

- solar thermal

- solar photovoltaic

- wind farm

- wind with combustion turbine

- nuclear
} 
For each option, we specify low, medium, and high capital costs and a variety of operational parameters (e.g., variable and fixed O\&M, heat rates, etc.). Appendix C provides a more complete description of the current cost ranges for these various technologies and explains how we chose the capital cost ranges for the technologies examined in this report. This appendix also presents emissions and offset values that are used.

In later work, simulations containing many more options have been conducted, notably ones in which the wind resource has been represented by 36 specific sites, rather than generically (Sezgen, Marnay, and Bretz 1998). 


\section{Results of the Elfin Runs of the California Pool}

\subsection{Overview}

In this chapter we present key results of our Elfin runs of the California market. A more expansive set of tables and figures detailing the results of each scenario modeled is presented in Appendix A. In the next section, we discuss the assumptions used for the policies modeled. These policies include imposing a minimum renewable purchase requirement, imposing carbon emission taxes, and providing subsidies to encourage the development of the renewable technology that appears closest to economic viability, namely wind. In the following section, we present the results of these runs. We report results for the construction of new renewable capacity. We also attempt to compare the benefits and social costs of renewables by reporting the emissions resulting from the various scenarios, thermal dependence, and natural gas usage, and the overall net present cost of running the system through the forecast period. We begin by presenting results of runs in which no policy is assumed and the effects of our three renewables environments, "neutral," "good," and "bad," can be plainly seen. Each of our policy cases is modeled under each of these three environments, but here we focus on the results of a "no policy" case under each environment and on other policies modeled in only the "neutral" environment. Results of policies modeled in the "good" and "bad" environments are shown in Appendix A, and serve primarily as sensitivity results for equivalent runs conducted under neutral environment assumptions. In the subsequent section, we present more comparative details of the simulations.

\subsection{Scenarios and Policies Modeled in Elfin}

Our approach is to conduct full Elfin ITRE runs for a limited set of policy cases under each of three economic environments. The three different future environments are:

1. conventional wisdom or best guess, called "neutral."

2. favorable to renewable technologies (i.e., high gas prices, etc.), called "good"

3. unfavorable to renewables (i.e., low gas prices, etc.), called "bad"

Growth in electricity demand in all three environments is assumed to be 1.5 percent per year. Table 4-1 specifies other aspects of these three economic climates. The actual dollar values of "high," "low," and "base" costs can be found in Table C-12 of Appendix C. In the good environment, coal and nuclear additions are not allowed in order to represent a future in which these resources are excluded on environmental or political grounds. 
Table 4-1. Assumptions for Neutral, Good, and Bad Renewables Environments

\begin{tabular}{|lccc|}
\hline & Neutral (N) & Good (G) & Bad (B) \\
\hline Renewable Capital Costs & Base & Low & High \\
Gas-Fired Capital Costs & Base & Base & Low \\
Nuclear \& Coal Included & Yes & No & Yes \\
Gas Price Growth (\% per year) & 1.5 & 3.0 & 0.0 \\
\hline
\end{tabular}

Under each of the renewable environments, we modeled a number of policy cases in which efforts to promote the development of renewable technologies are estimated. We report here on the base case plus four example policy cases, as follows:

- Policy 0: no policy (i.e., no new or existing policies present)

- Policy A: non-hydro renewable purchase requirement (15\% generation)

- Policy B: $\quad$ surcharge policy $(\$ 620 \mathrm{M} /$ year to lowest cost renewable)

- Policy D: 15 percent MRPR with technology bands (set at current market shares)

Note that our focus is on the quarter century beginning in 2005. As noted above, we assume no special preferences designed to benefit renewables are in place, other than the policies explicitly being modeled.

The three environments and five policy types combine for a total of 15 scenarios, although we were not able to simulate all cases satisfactorily, as is explained below. Using the adjusted Elfin logic described in Appendix B, we attempted and completed full Elfin runs for most of these cases. Not all of these scenarios are within the bounds of credibility, however. A wide range of improbable cases has been attempted due to our desire to (a) demonstrate the viability and potential pitfalls of our approach, and (b) identify some of the limiting or boundary cases. All cases are named with two-character names, for example, AN implies policy A, the purchase requirement is implemented in the $(\mathrm{N})$ eutral renewables environment.

In this chapter, results are reported for all three Policy 0 scenarios, and for the $\mathrm{AN}, \mathrm{BN}$, and DN scenarios. Simulating Policy B created some special simulation problems that are described in Appendix E. Policy $\mathrm{H}$ was particularly troublesome and has been relegated to Appendix F. However, summary results are presented for all the $\mathrm{N}$ scenarios. 


\subsection{Results}

\subsubsection{Policy 0: No Policy}

In our Policy 0 cases, renewable generation competes head-to-head with all other technology options. In this first set of runs, we sought to determine whether unsubsidized renewable generation would be viable in the California market under our best estimate of current costs and trends, and given other circumstances that are both favorable and unfavorable to renewables as represented in the good and bad environments. Results for the final forecast year, 2030, are summarized in Table 4-2, and cumulative new capacity construction is shown in Figure 4-1. Despite large new total capacity additions of approximately $40 \mathrm{GW}$, no renewable capacity is added. In fact, all new capacity is of just three types, repowers of existing units, new combined cycles (CC), and new combustion turbines (CT). This result reflects conventional wisdom that only new gas-fired capacity can compete in the future California market, absent subsidies, taxes, or significant increases in the gas price. The steady increase in thermal dependency results in a steady increase of carbon emissions. Per $\mathrm{kWh}$ carbon emissions rise from $113 \mathrm{~g}$ in 2010 to 126 in 2030 and because of increasing generation, total carbon emissions are 50 percent higher. Here then is the heart of the California dilemma. Absent policy intervention, while in many ways clean compared to electricity generation elsewhere, the power sector will become increasingly thermal dependent and increasingly undesirable from a greenhouse gas perspective.

Figure 4-1. Cumulative New Capacity Under Scenario ON

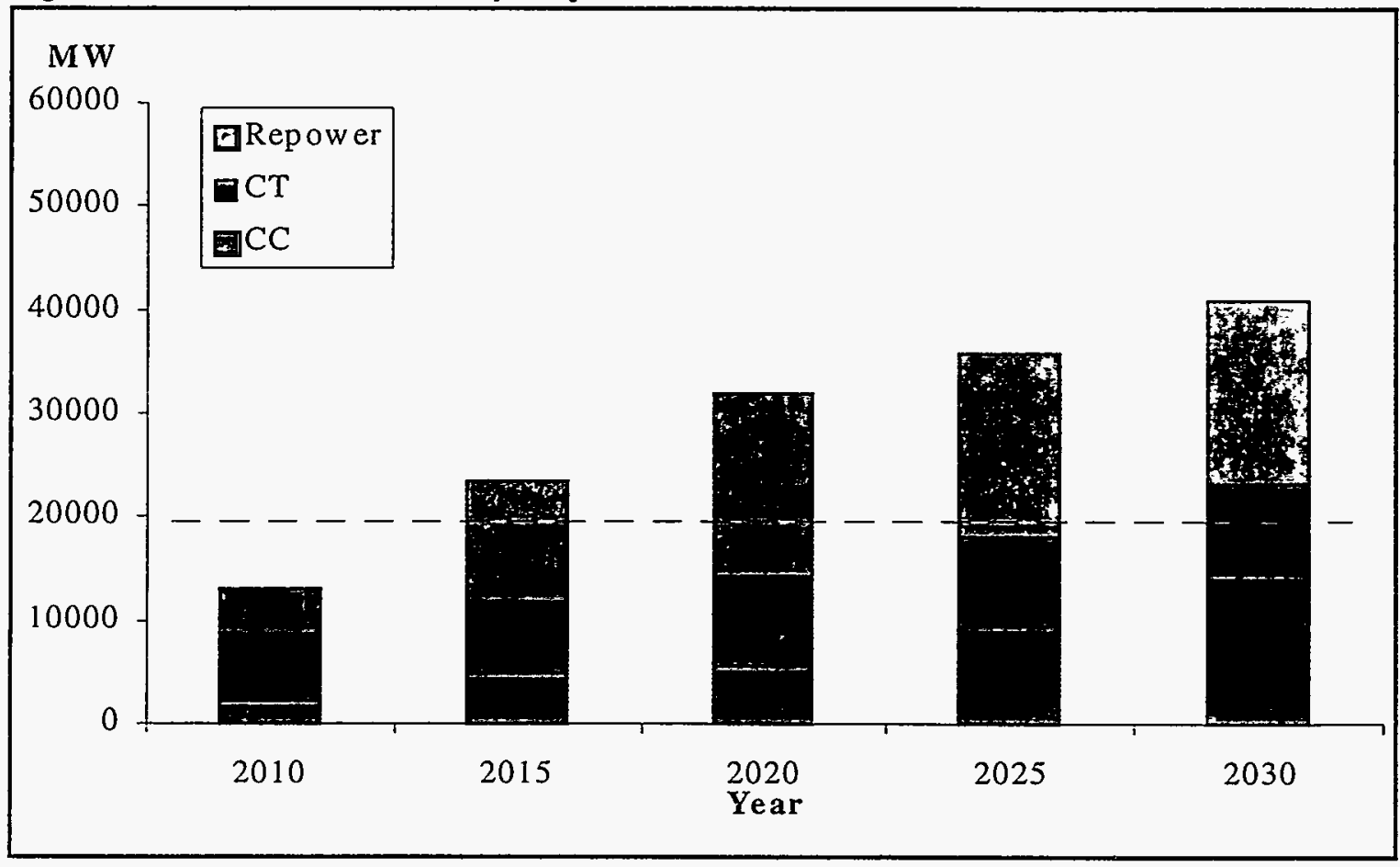


Table 4-2. Summary of Elfin Pool Results with No Renewables Policies

\begin{tabular}{|lccc|}
\hline & Neutral (ON) & Good (OG) & Bad (OB) \\
\hline $\begin{array}{l}2030 \text { Cumulative New } \\
\text { Renewable (GW) }\end{array}$ & 0 & 85 & 0 \\
2030 NOx Emissions (kt) & 224 & $188(84 \%)$ & $152(68 \%)$ \\
2030 Carbon Emissions (Mt) & 40 & $21(53 \%)$ & $37(94 \%)$ \\
$2030 \%$ Thermal & $81 \%$ & $36 \%$ & $81 \%$ \\
2030 Gas Consumption (EJ) & 1.6 & $0.5(32 \%)$ & $2.0(125 \%)$ \\
NPV System Costs (10 $\$$ ) & 132 & $153(116 \%)$ & $102(78 \%)$ \\
\hline
\end{tabular}

Table 4-2 indicates that renewable technologies would be built in California only under the favorable circumstances of the good environment (i.e., high gas prices and low renewable costs), but in this environment, a remarkable $85 \mathrm{GW}$ of wind capacity is chosen, as can be seen in Figure 4-2. Because of the low capacity factor of wind generation, more capacity of this technology than thermal generation must be built to meet energy requirements. Wind generation is first built in 2016 , by which time wind capital costs have fallen to $\$ 792 / \mathrm{kW}$. Furthermore, wind is the only renewable technology adopted, a result that derives directly from the fact that no artificial limits are imposed on the availability of wind generation at the assumed cost. ${ }^{4}$

In terms of NOx emissions, the good environment results in a 16 percent reduction from the neutral case, while the bad environment produces a 32 percent reduction. The bad environment results in greater NOx emissions reductions because low gas price growth (i.e., $0 \%$ ) leads to greater gas generation displacing coal which has significantly higher NOx emissions per $\mathrm{kWh}$ generated. In contrast, the good environment results in a 47 percent reduction in carbon emissions, whereas the bad environment delivers only a six percent reduction, surprisingly little benefit compared to the reduction in NOx emissions. The good environment's sharp drop in carbon emissions is due to the increase in wind generation.

In the neutral and the bad environments, California remains dependent upon gas and other thermal technologies, such as coal, while the good case shows a marked reduction in thermal dependence and gas consumption. In both the neutral and bad environments, 81 percent of

Note that in Elfin, technical change is represented by predetermined declines in costs and/or improvements in operating characteristics. There is no internal logic that relates costs and performance of technologies to indicators of technical experience, such as installed capacity.

In new work (Sezgen, Marnay, and Bretz 1998), the availability of new wind generation to the California pool relative to its cost is being studied to better understand constraints on the supply of wind. Of course, other constraints exist on the construction of generic resources, which should also be studied. 
Figure 4-2. Cumulative New Capacity Under Scenario OG

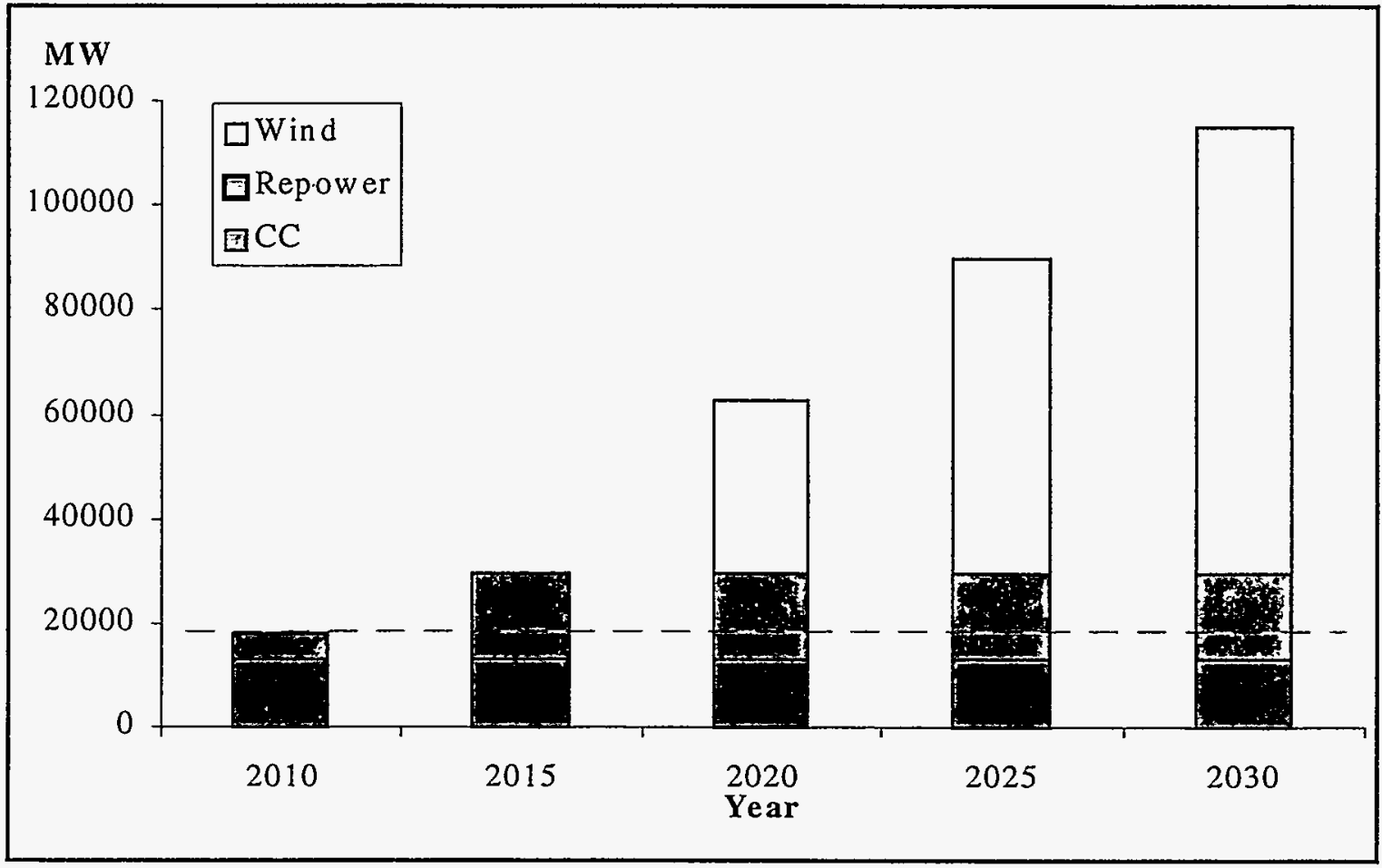

the electricity generated comes from thermal technologies, while in the good case, only 36 percent of the energy comes from thermal technologies. Gas consumption in 2030 rises well above today's level of about $0.43 \mathrm{EJ}$ in all three environments. It reaches $1.6 \mathrm{EJ}$ in the neutral case, climbs to nearly $2.0 \mathrm{EJ}$ in the bad case, and to $0.5 \mathrm{EJ}$ in the good case.

System costs are driven mostly by gas price growth. The bad environment has lower costs because we assume a gas price growth of zero percent for this scenario, whereas we assume 1.5 percent gas price growth in the neutral case. The good environment has higher costs because we assume gas price growth of three percent, and this assumption leads to the construction of a technology with higher capital costs, namely wind.

The 0 , or no policy case under the neutral environment $(0 \mathrm{~N})$ serves as our base case for subsequent policy comparisons. The good and bad environments serve primarily to demonstrate that the model responds to test stimuli and shows how results might vary under diverse economic conditions. As with all simulations run, detailed results can be found in Appendix A. 
4.3.2 Policies A and D: Purchase Requirements With and Without Technology Bands

In policy case $\mathrm{A}$, we modeled a minimum renewable purchase requirement. Under this policy, we assume that 15 percent of energy must come from the cheapest non-hydroelectric renewable technology-wind. This compares with a current non-hydro renewables California energy share of about 11 percent (Renewables Working Group 1996). In general, existing renewable energy projects are assumed to persist into the indefinite future because we were unable to determine whether these technologies would fold for economic reasons or because they had reached the end of their engineering lives. The one exception is geothermal capacity owned by PG\&E, which gradually degrades over time, and for which data were available in the PG\&E data set. As a result of these assumptions, existing renewables meet a slowly declining percentage of the 15 percent purchase requirement, and new wind generation, clearly the least expensive technology under our assumptions, meets the remaining portion of the requirement.

In Policy D, we modify the MRPR by adding purchase requirements for specific renewable technologies. These technology bands are designed to ensure purchases of less competitive and more expensive renewable technologies, such as biomass and PV. We set the technology bands in Policy D at levels consistent with current market share.

The results of these runs are summarized in Tables 4-3 and 4-4, and cumulative capacity construction is shown in Figures 4-3 and 4-4.

Table 4-3. Summary of Elfin Pool Results with a Straight Purchase Requirement and a Neutral Environment

\begin{tabular}{|lcc|}
\hline & No Policy (ON) & $\begin{array}{c}\text { 15\% Purchase Requirement } \\
\text { Without Technology Bands (AN) }\end{array}$ \\
\hline Cumulative New Renewable (GW) & 0 & 17 \\
2030 NOx Emissions (kt) & 224 & $224(100 \%)$ \\
2030 Carbon Emissions (Mt) & 40 & $36(91 \%)$ \\
$2030 \%$ Thermal & $81 \%$ & $71 \%$ \\
2030 Gas Consumption (EJ) & 1.6 & $1.3(84 \%)$ \\
NPV System Costs $\left(10^{9} \$\right)$ & 132 & $135(103 \%)$ \\
\hline
\end{tabular}


Table 4-4. Summary of Elfin Pool Results with a Banded Purchase Requirement and a Neutral Environment

\begin{tabular}{|lcc|}
\hline & No Policy (ON) & $\begin{array}{c}\text { 15\% Purchase Requirement } \\
\text { with Technology Bands (DN) }\end{array}$ \\
\hline $\begin{array}{l}\text { Cumulative New Renewable } \\
\text { (GW) }\end{array}$ & 0 & 7 \\
2030 NOx Emissions (kt) & 224 & $224(100 \%)$ \\
2030 Carbon Emissions (Mt) & 40 & $37(93 \%)$ \\
$2030 \%$ Thermal & $81 \%$ & $73 \%$ \\
2030 Gas Consumption (EJ) & 1.6 & $1.3(86 \%)$ \\
NPV System Costs (10 $\$$ ) & 132 & $148(112 \%)$ \\
\hline
\end{tabular}

Figure 4-3. Cumulative New Capacity Under Scenario AN

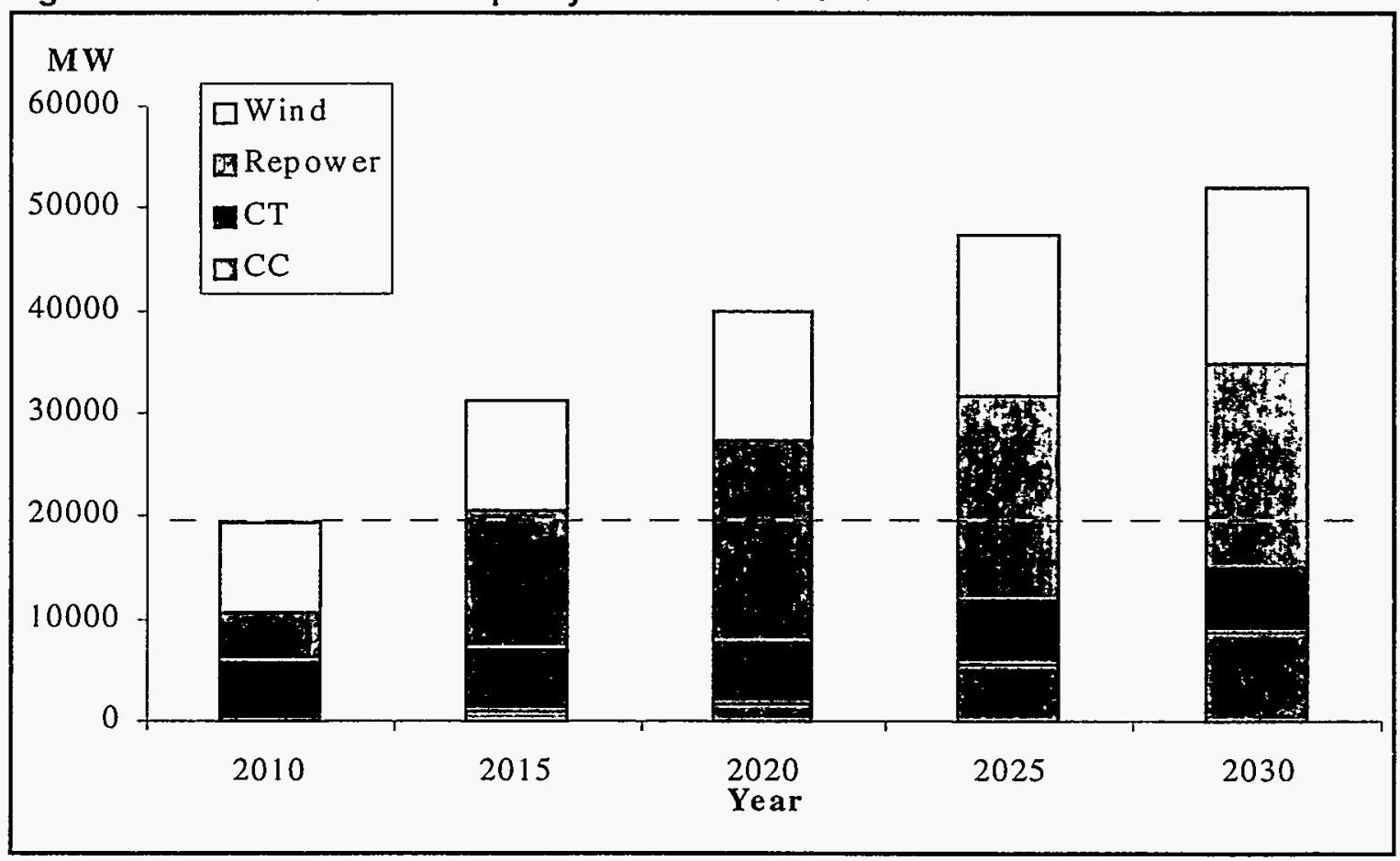

In both runs, NOx emissions are unchanged. This is a disappointing result and one not easily explained. One would certainly expect the fall in thermal generation to result in measurable NOx emissions reductions, but this is not the case. It could be that the generation being displaced is from clean new plants, and, at the same time, generation is shifting among generators in such a way that emissions from existing resources are increasing. This could also happen if the share of generation is shifting from air basins with more stringent regulations towards ones with less stringent regulations. However, this is a puzzle that cannot be resolved here. In future work, a more careful accounting should be made of the 
Figure 4-4. Cumulative New Capacity Under Sicenario DN

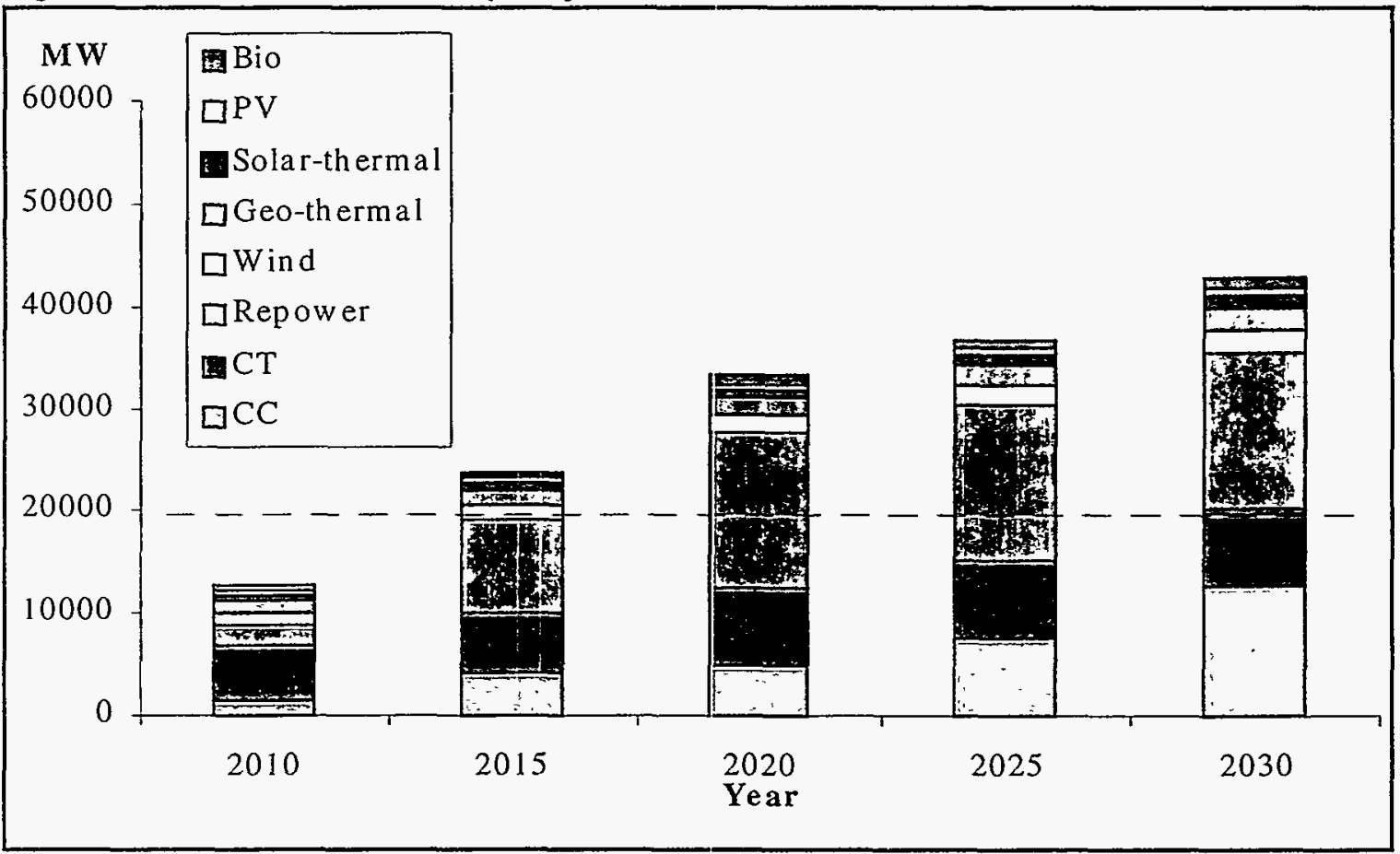

origin and shift in NOx emissions between these scenarios. In contrast, there is a slight drop in carbon emissions. Both policies result in reduced thermal dependence and gas consumption. However, Policy A does appear to result in more new renewable construction and lower carbon emissions, thermal dependence, and gas consumption than Policy D. This is not surprising given that the "bandless," least-cost MRPR approach of Policy A results in greater renewable energy generation. Policy A produces $33 \mathrm{TWh}$ of new renewable electricity in 2030, all wind, whereas Policy B produces 28 TWh because of the higher overall cost of the mixed renewable generation compared to wind. In other words, while both policies result in higher renewable generation, Policy $\mathrm{A}$ is more effective than $\mathrm{D}$ from the point of view of pure renewable development because gas competes more effectively against the mix of technologies required by Policy D than against wind only in Policy $\mathrm{A}$.

While both policies are more costly than the base case, the purchase requirement with technology bands is decidedly more expensive than the straight purchase requirement. Again, this is not surprising given that one of the goals of Policy D is continued purchases from more expensive renewable technologies. However, in both of these cases, sustained orderly development of renewable technology is assured, and this should be recognized as a benefit because this will avoid a "boom and bust" cycle. 


\subsubsection{Policy B: Surcharge Policy}

In Policy $\mathrm{B}, \mathrm{a} \$ 620$ million per year surcharge-based policy was simulated. While there are many ways to distribute surcharge monies collected to fund renewables programs (Wiser and Pickle 1997), we assume that monies are simply distributed to the least-cost renewable developers via an auction mechanism. It should be noted that the level of surcharge collection in this policy is quite large compared to many current surcharge policies and proposals. In California, for example, a total of $\$ 540$ million is to be collected for renewables over a period of four years. Again, however, our goal here is to merely assess the viability of our approach and test some limiting cases. We did not actually choose the value of $\$ 620$ million per year, as will be clear from the discussion below. However, we did seek to simulate an overall subsidy level in this general range because conventional wisdom during California's MRPR debate was that the cost of a 15 percent MRPR could well be in this range. We therefore hoped to produce a case that would be roughly comparable to our MRPR simulations. Obviously, both A and B cases are somewhat extreme as we were seeking to exercise the model and identify boundaries We hope to assess smaller surcharge levels in future work.

Our results are shown in Table 4-5 and Figure 4-5.

Table 4-5. Summary of Elfin Pool Results with Surcharge Policy and a Neutral Environment

\begin{tabular}{|lcc|}
\hline & Neutral (ON) & \$620M\$/a Surcharge (BN) \\
\hline 2030 Cumulative New Renewable (GW) & 0 & 29 \\
2030 NOx Emissions $(k t)$ & 224 & $224(100 \%)$ \\
2030 Carbon Emissions (Mt) & 40 & $34(85 \%)$ \\
$2030 \%$ Thermal & $81 \%$ & $64 \%$ \\
2030 Gas Consumption (EJ) & 1.6 & $1.1(73 \%)$ \\
NPV System Costs $\left.\left(10^{9} \$\right)\right)$ & 132 & $132(100 \%)$ \\
\hline
\end{tabular}

Compared with the base, or neutral, case, a $\$ 620 \mathrm{M}$ per year surcharge policy results in 29 GW of new renewable construction, 15 percent lower carbon emissions, thermal dependence of 64 percent and 27 percent less gas consumption. As in previous policy scenarios, however, there is no change in NOx emissions. 
Figure 4-5. Cumulative Capacity Construction Under Scenario BN

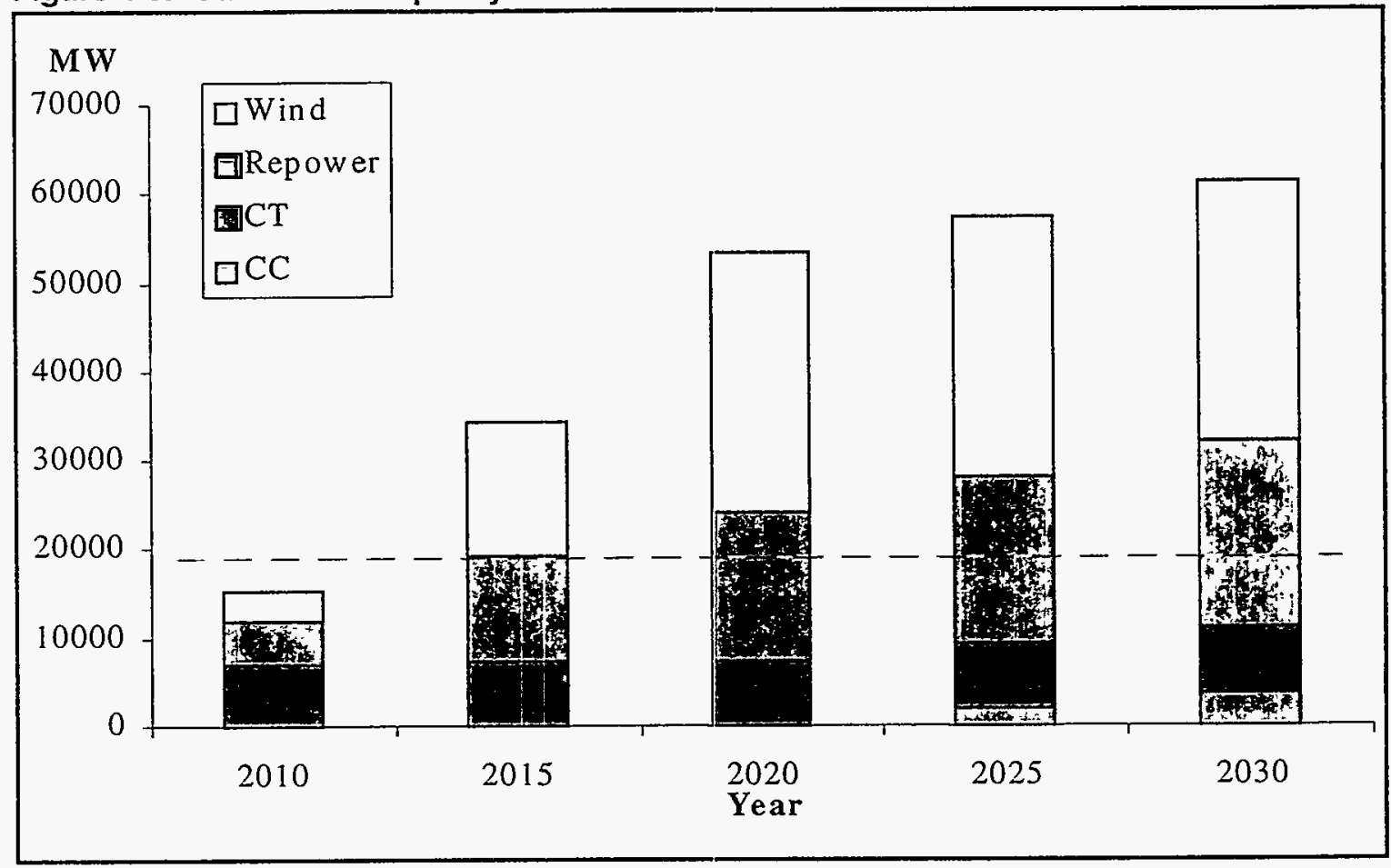

\subsection{Comparing Scenario Results}

In this section, the results of all policy cases are compared directly. Table 4-6 reports the total generation for each case in each of five benchmark years. Elfin does not have hard generation or capacity constraints. That is, the level of construction of new capacity and the overall output are chosen economically, in this case, such that the returns to investors in new capacity is maximized. No unprofitable investments are made. Dispatch is organized on traditional cost-minimizing principles and failing to serve load under the assumed cost structure, notably the cost of unserved energy itself, is a less costly dispatch outcome, then it is chosen. In other words, adequate capacity to meet reserve requirements is not necessarily built, and load is not necessarily met. In comparing results, therefore, an important first question to consider is how much demand went unserved.

The one notable result in Table 4-6 is that generation is lower in all years for the HN carbon tax case that is fully reported in Appendix. F. This result emerges because costs are significantly higher in the HN case, and, therefore, unserved energy appears as a more attractive option to Elfin. 
CHAPTER 4

Table 4-6. Total Generation (GWh) for N Cases

\begin{tabular}{|rrrrrr|}
\hline & $\mathbf{2 0 1 0}$ & $\mathbf{2 0 1 5}$ & $\mathbf{2 0 2 0}$ & $\mathbf{2 0 2 5}$ & $\mathbf{2 0 3 0}$ \\
\hline ON & 255,921 & 276,039 & 298,532 & 321,070 & 346,167 \\
AN & 255,921 & 276,037 & 298,532 & 321,069 & 346,153 \\
BN & 255,920 & 276,034 & 298,524 & 321,047 & 346,183 \\
DN & 255,921 & 276,038 & 298,532 & 321,070 & 346,170 \\
HN & 255,911 & 276,016 & 297,986 & 320,012 & 343,450 \\
\hline
\end{tabular}

Table 4-7 shows the overall costs for the base and four policy cases, and Figure 4-6 shows how costs deviate from the ON case. The first column shows the internal net present cost of the scenario. This value represents the total cost of running the generation system through the end of the forecast period, including the cost of unserved energy.

Table 4-7. Costs for N Cases

\begin{tabular}{|c|c|c|c|c|c|c|c|c|c|c|c|c|}
\hline & \multirow{2}{*}{$\begin{array}{c}\text { NPC } \\
M \$(1995) \\
2006-2055 \\
\end{array}$} & \multirow{2}{*}{$\begin{array}{c}\text { ANPC } \\
\text { M\$ (1995) } \\
\\
2006-2055\end{array}$} & \multicolumn{4}{|c|}{$\begin{array}{c}\text { TSC per Generation } \\
\text { per year } \\
\text { ( } 6 / \mathrm{kWh})\end{array}$} & \multicolumn{5}{|c|}{$\begin{array}{c}\text { Subsidies to } \\
\text { B Cases } \\
\text { ( } ₫ / \mathrm{kWh})\end{array}$} & \multirow[b]{2}{*}{2030} \\
\hline & & & 2010 & 2015 & 2020 & 2025 & 2030 & 2010 & 2015 & 2020 & 2025 & \\
\hline ON & 132,002 & 132,002 & 1.6 & 2 & 2.2 & 2.5 & 2.7 & & & & & \\
\hline AN & 135,370 & 135,370 & 1.7 & 2.1 & 2.4 & 2.6 & 2.8 & & & & & \\
\hline BN & 132,001 & 139,506 & 1.6 & 2.1 & 2.5 & 2.7 & 2.8 & 2.7 & 2.0 & 1.8 & 1.5 & th \\
\hline DN & 148,382 & 148,382 & 1.8 & 2.2 & 2.6 & 2.8 & 3 & & & & & \\
\hline $\mathrm{HN}$ & 237,312 & 236,093 & 2.1 & 3.2 & 3.9 & 4.3 & 5.3 & & & & & \\
\hline
\end{tabular}

NPC (Net Present Cost)

ANPC (for Benefits and Emission Taxes Adjusted Net Present Cost)

TSC (Total Social Cost) 
Figure 4-6. Total Social Cost of Generation in Comparison to ON Case

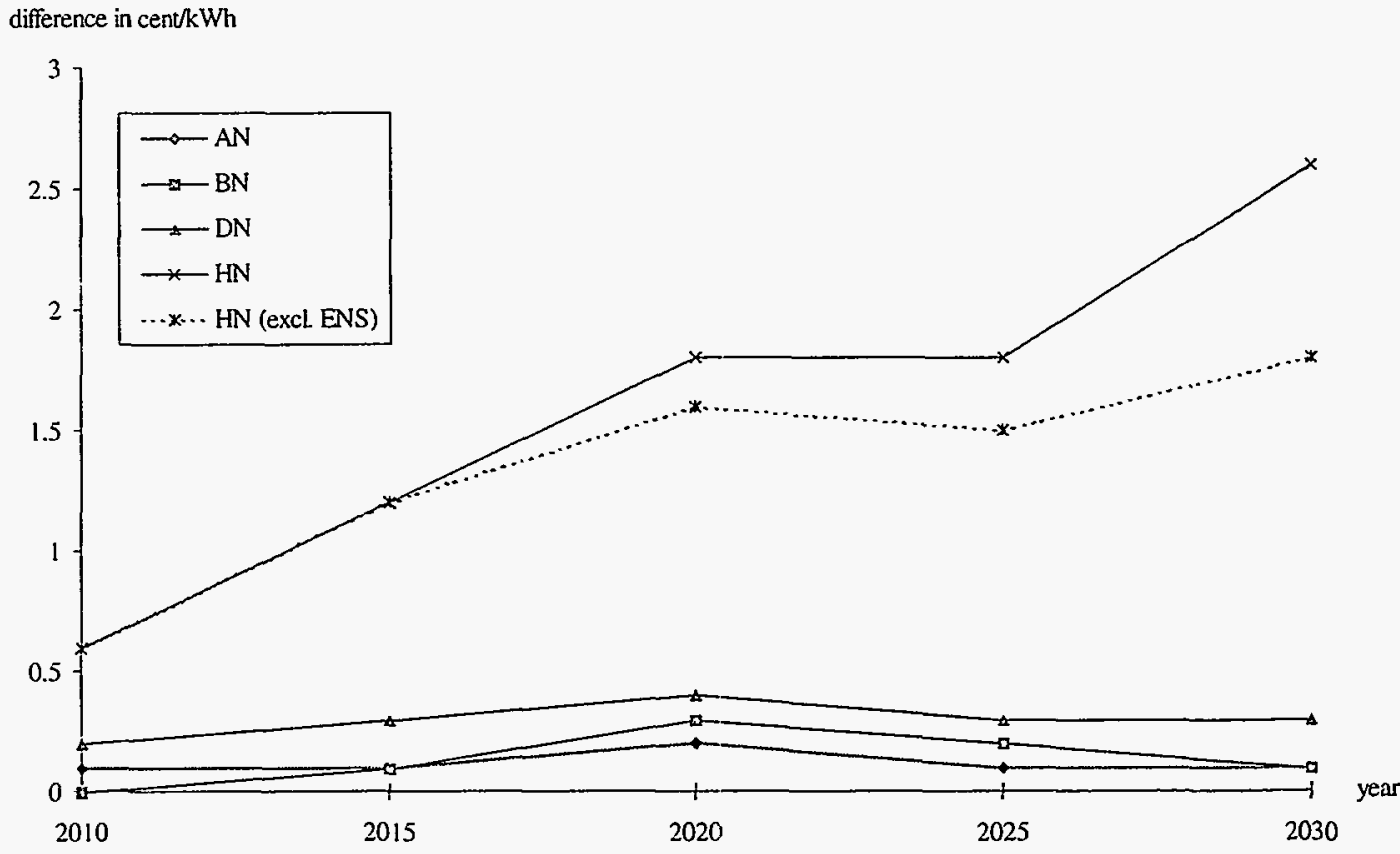

The second column reports an adjusted net present cost. The purpose of this value is to represent a more realistic picture of scenario costs by adjusting the NPC for the costs of subsidies and taxes faced by the electricity sector, which are transfer payments and not true economic costs. The AN and DN cases involve no tax or subsidy, so the adjustment is zero. However, in the $\mathrm{BN}$ case, because wind generators are receiving a subsidy, the true cost is higher than calculated internally by Elfin. On the other hand, true costs are lower in the carbon tax case because the tax revenue does not represent a true cost because the tax revenue is available for other purposes. Figure $4-8$ summarizes these results by reporting deviations for each policy scenario from the $0 \mathrm{~N}$ case. Again, the HN case stands out, and, as discussed above, has to be regarded with suspicion. Here however, it serves a useful purpose. Because costs are high in this simulation the amount on unserved energy is high, and this raises overall costs. In the figure the effect of this phenomenon is shown by reporting $\mathrm{HN}$ exclusive of the unserved energy cost. This just reinforces the notion that in Elfin, decisions are economic. In this simulation, a significant share of demand went unmet, and a cost was incurred as a result.

The following columns show the per-kWh generation costs after the adjustment. These are average production costs and do not reflect the costs of transmission, distribution, billing, etc. For reference, Table 4-8 shows the comparative emission and thermal dependency results, which have been discussed above. 


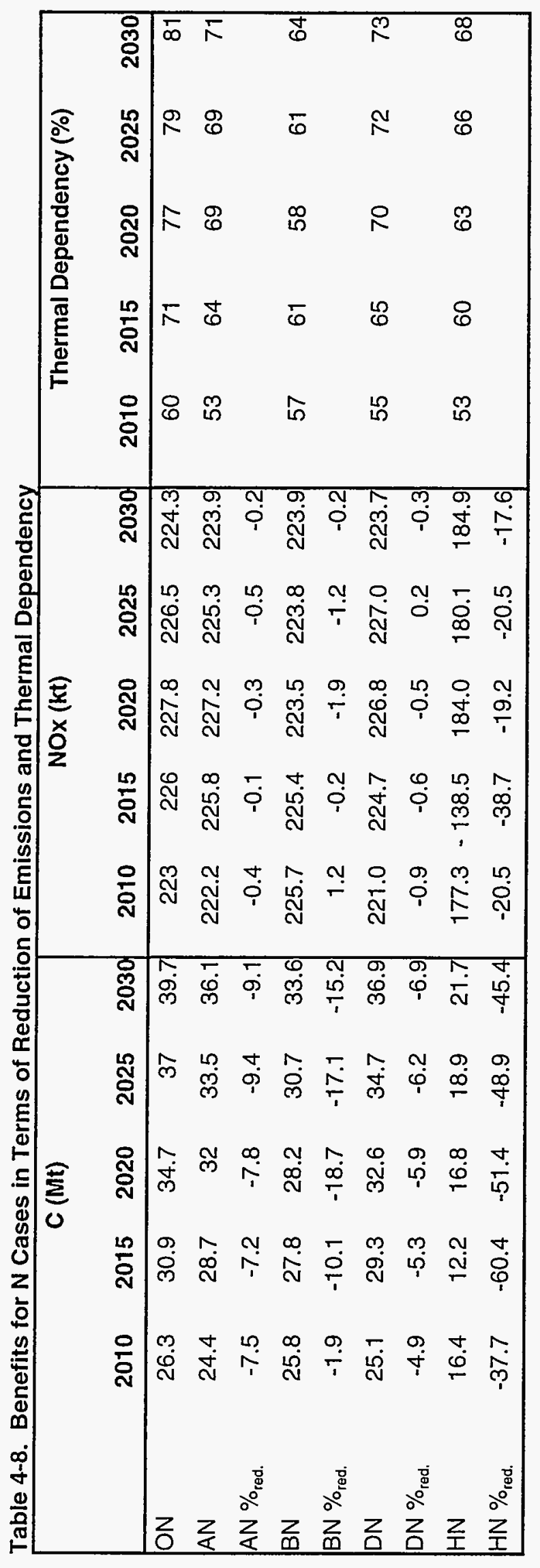


Before presenting these benefits and costs in graphical form, it would be interesting to focus briefly on market electricity prices. As has been emphasized above, these prices are the Holy Grail of competitive market simulation. With a reasonable estimate of prices in hand, other aspects of simple project analysis are relatively trivial, but without them no accurate revenue forecast is possible. Figures 4-7 and 4-8 show some simplified price results. In this instance, the simulation has been run using only three subperiods for each of 12 typical weeks. The peak subperiod is each afternoon from 12:00 to 18:00 and the weekend is 18:00 Friday to 8:00 Monday. All remaining hours are off peak. Remembering that in these simulations, all dispatch is assumed centralized, we will refer to these prices as pool prices in this section. In actual fact, of course most prices will be set by bilateral contracting, and PX prices will serve primarily as a basis for comparison.

Figure 4-7. ON Pool Price in 2025

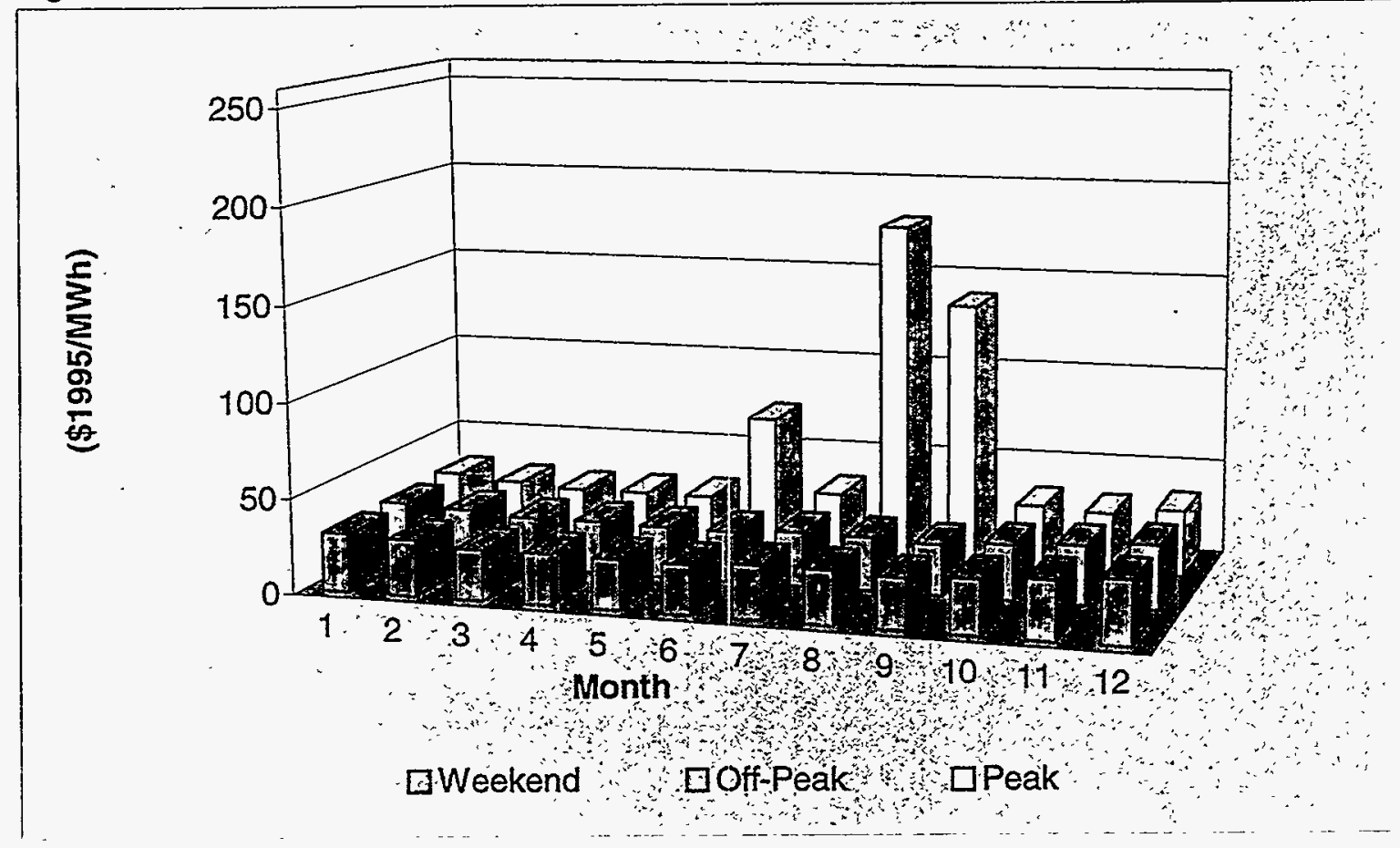

One immediately interesting aspect of the results is how flat pool prices are overall. Outside of the later summer peak periods, pool prices stay within the range of $\$ 26$ to 36 per MWh, the highest non-peak prices coming in the early winter period. The flatness of prices is somewhat of a surprise given the nature of the California electrical system. Load varies considerably, both diurnally and seasonally in the state, and the hydro resource, both in-state and imported, is also highly seasonal. However, the pool price appears to be dominated by the fact that traditional gas-fired resources almost always end up as the price-setting bidders, and, consequently, prices never collapse. 
Figure 4-8. AN Pool Price in 2025

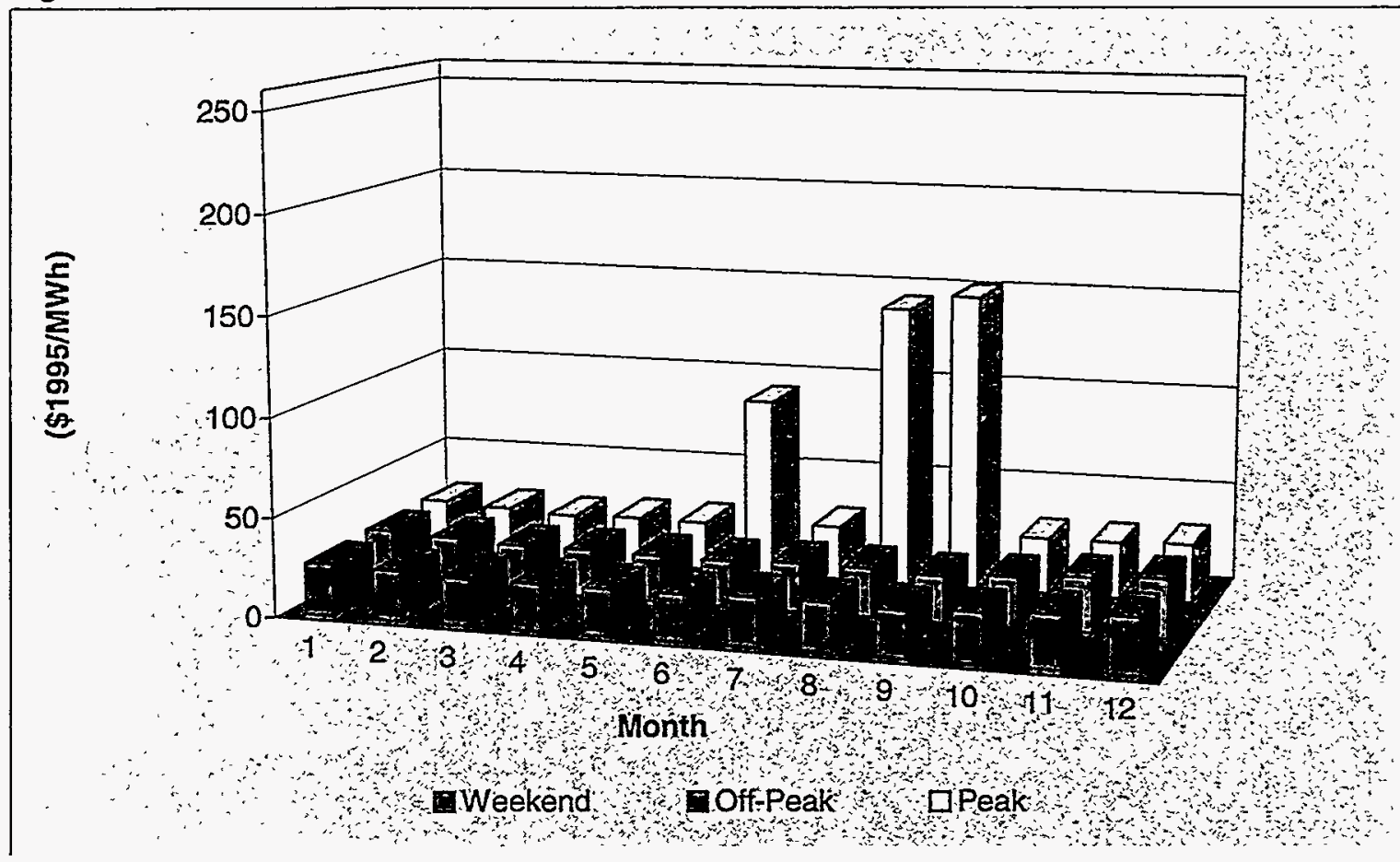

The second interesting aspect of the pool price results, quite obviously, is the extreme peak prices seen in the June to September period. The shortage of resources in this period is real, and quite clearly, none of the investment options we make available to Elfin can be profitably undertaken, despite these high prices. In other words, none of the peaking technologies available in these simulations, primarily solar and gas turbines, can be profitable despite the high peak pool prices, most likely because they appear in too few hours. It should also be noted that our simulations are incomplete in several ways that will tend to diminish the accuracy of on-peak pool price estimation. First, the peak pool price is heavily determined by the cost of unserved energy, as in all load duration curve based simulation. Second, imports together with other high cost options are treated quite crudely, and high cost bidders are likely to appear to peak periods that are not included in our simulation. Third, no demand response exists in the current version of Elfin. In a restructured industry, we expect more customers to face a real-time rate related to the pool price, and therefore, we can be sure that pool prices as high as these would result in load shifting. In ongoing work, a demand response module is being incorporated into Elfin that will allow demand in subsequent years to respond to high prices in any year.

Another obvious question that comes to mind is how well do these prices reflect actual retail prices as the ratepayer will see them. A reasonable rule-of-thumb for this time period, that is well beyond the transition, might be that transmission and distribution costs will remain as they are now, and these plus the pool price might represent a reasonable estimate of retail energy rates, although marketing costs could be a significant factor. Currently transmission and distribution cost about $4 \phi / \mathrm{kWh}$. 
Figure 4-8 reports equivalent data for the AN scenario. The general pattern of results remains the same, but pool prices overall appear lower. This result actually must be true because a large amount of wind capacity appears in this scenario, bidding into the pool at a zero price. While the pool price is still being set by gas resources, the effect of the large block of wind generation is that pool prices are somewhat suppressed. This result raises a very interesting question, which is how much does this reduced pool price compensate for the cost of the various policies. In the AN case, the 2025 year-round average revenue going to generators is $\$ 37.4$ per MWh compared to $\$ 44.1$ per MWh in the ON case. In other words, the consumer comes out clearly ahead as a result of the AN policy. Although production costs rise, as seen in Table 4-8, pool prices fall, meaning a transfer takes place from the generator to the consumer. In other policy cases, when a subsidy is being given to a zero marginal cost generator, the value of the subsidy is partially offset by the falling pool price resulting from increased renewable participation. While quite predictable, this is an interesting result that merits further study. It should also be noted that not all renewable generators operate at close to zero marginal cost. In the $\mathrm{DN}$ case, for example, pool prices rise slightly over the ON case. In the $\mathrm{BN}$ case, direct evaluation of the benefit of the falling pool price relative to the increase in production cost is make significantly more complex by the fluctuations in the effect across the forecast period, and a much more detailed analysis would be needed in this case.

Figure 4-9 summarizes the benefits and costs for the policy cases. All data are presented as percent deviations from the $\mathrm{ON}$ case. The positive values are the increases in costs. These represent the cost side of the policies. These are the total societal costs that represent true economic costs, free of transfers. The three subsequent indicators are all benefits, and are negative. In other words, falling thermal dependence and/or emissions is a benefit. As expected, the AN and BN cases have similar costs but BN delivers bigger benefits. This result is predictable because the total renewable construction is higher in the BN case, and because the additional renewable is wind in each case. This reinforces the earlier observation that the subsidy case is more effective than a purchase requirement in terms of total effect. However, development is less orderly. 
Figure 4-9. Percentage Deviation in Costs and Benefits from ON Case in Year 2025

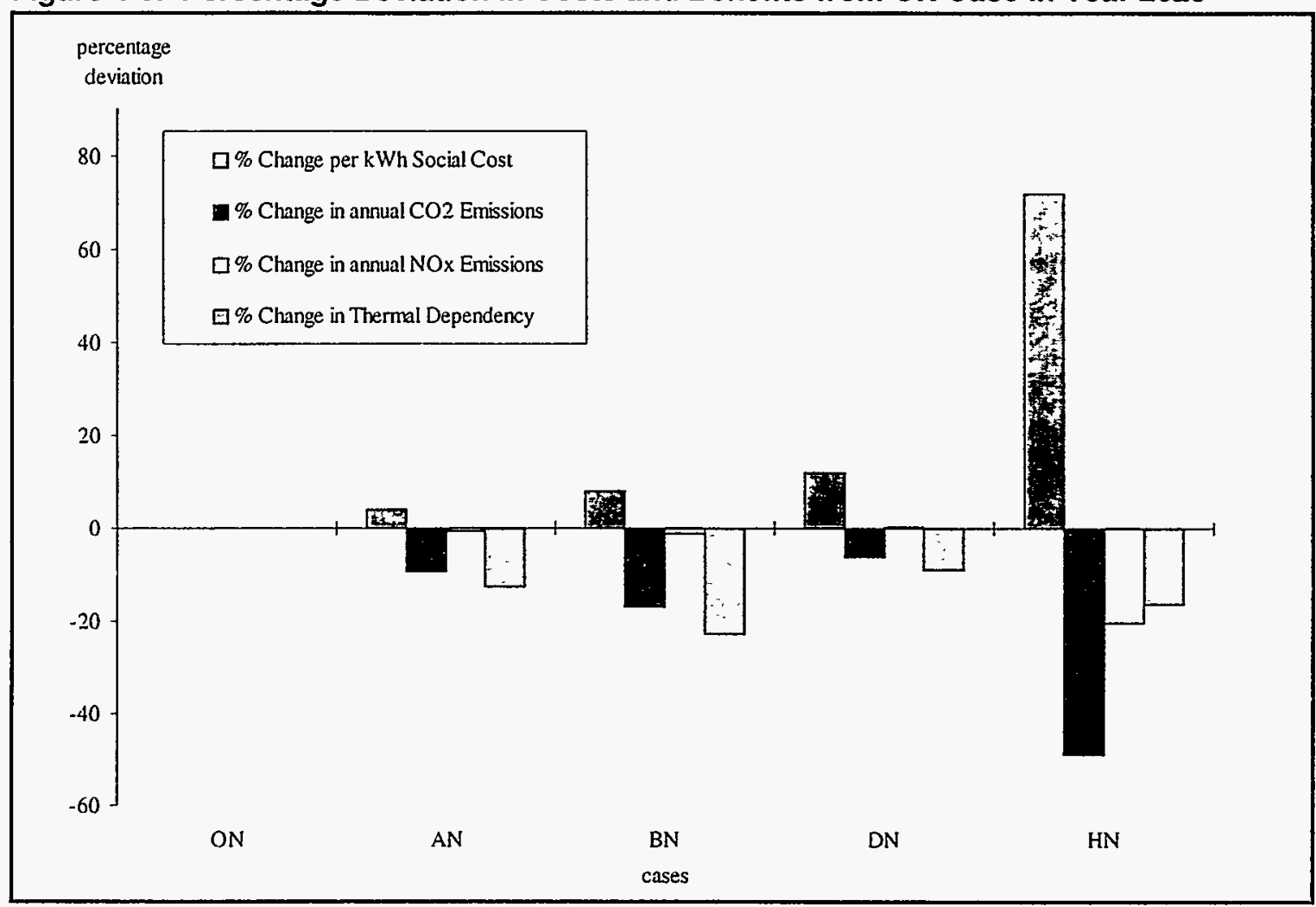




\section{Conclusions}

In this study, considerable progress has been made towards the goal of developing algorithms for simulating the operation of competitive electricity markets, and, specifically, of building a model capable of simulating the future operation of the competitive California market. Such models are useful both as planning and policymaking tools, and as a means of evaluating possible investments. Such models are particularly important to intermittent renewable generators because their revenue streams and the benefits they provide in terms of environmental benefits and reduced pool prices are hard to forecast.

The expansion planning logic of Elfin, based on the ITRE algorithm, has been enhanced so that it more clearly represents conditions in a competitive market. A new algorithm has been developed that permits ITRE to choose only the most profitable investments and then find combinations of new market entry that result in a sustainable equilibrium with no new profitable entry possible. The likely equilibrium is the one that results in the maximum return to investors. When entry has been determined, by incorporating non-energy payments into dispatch decisions, market prices can be derived using traditional algorithms.

The data sets of the incumbent utilities have been merged into one that contains all the key assets in California and those owned by California utilities but situated in neighboring states. Potential imports are represented by two single resources, one for the Northwest and one for the Southwest.

The new algorithms and the California data set have been used to forecast investments in generation in the future California market in the post-restructuring quarter century, 20062030. Under best-guess assumptions, no new renewable capacity is added and the state's thermal generating dependency increases to 81 percent by 2030 with natural gas consumption 3.5 times today's levels, and the overall carbon emissions of generation increasing from 113 to $126 \mathrm{~g} / \mathrm{kWh}$.

A 15 percent renewable purchase requirement lowers the 2030 thermal dependency to 71 percent and lowers carbon emissions by nine percent. Such a policy raises production costs but lowers market prices, so consumers benefit but generators lose by the policy intervention. The same level of purchase requirement with technology bands delivers much less benefits and incurs higher costs.

A direct subsidy to wind generators that averages $\$ 620 \mathrm{M}$ per year over the forecast period, but is fixed only in net present value terms, results in more benefits for similar costs. However, deployment of renewables is prone to a boom-and-bust cycle as developers tend to only invest during the time periods when it is clearly the most profitable. Therefore, a policy trade off exists between maximizing the benefits and achieving a sustained orderly development. 
This work represents a bold step towards simulation of competitive markets, but many technical problems remain to be solved. In our opinion, the key areas for future work fall into the two following areas:

\section{Algorithm Development}

Subsidy simulation algorithms need to be developed that can estimate the effects of subsidies in a stable fashion. Currently, the search for sustainable equilibriums with subsidies in place is unstable because of the interplay of various effects of a change in the subsidy, especially across time periods.

The search algorithm for MEPs performs satisfactorily for searches limited to small clusters of profit maxima, but needs to be enhanced such that it more effectively finds solutions that are remote from other local profit maxima.

In this work, transmission constraints have been assumed away, but a more realistic analysis would bring these into the analysis.

Current production cost modeling still functions without realistic account of demand response, a glaring deficiency given the effect that new load-shifting technologies and greater customer exposure to real-time prices might have.

Repowering of existing stations is one of the most likely forms of entry into the California market. Unfortunately, the economics of investments in repowering are quite different under a competitive market in which alternative uses of the site are not only possible but potentially more profitable than in power generation. Furthermore, repowering potential is particularly hard to incorporate in models because the possibilities are numerous at any one site and data local to the site is needed. New algorithms for retirement and repowering decision making are needed as is better data on repowering options.

\section{Data Enhancement}

The current data set focuses on in-state resources, whereas competition from out-of-state generators will be a key determinant of market conditions. The data set should be extended to incorporate these competitors.

The renewable technology options used in this study are quite simplistic. Now that more realistic simulation of market operations is possible, better data on the characteristics of the renewable resources in California and nearby is needed. 


\section{References}

Cadogan, John B., Brian Parsons, Joseph M. Cohen, and Bertrand L. Johnson, "Characterization of Wind Technology Progress."

California Energy Commission (CEC) 1995. “1994 Electricity Report.” CEC Nov. 1995.

CEC 1998a. "Renewable Energy Technology Program Guidebook." CEC Jan 1998, 5 vols.

CEC 1998b. "California Natural Gas End Use Price Forecast." Commissioners Jananne Sharpless and Michael C. More, 25 February 1998.

Deb, Rajat K., Richard S. Albert and Lie-Long Hsue. "Modeling Competitive Energy Market In California: Analysis of Restructuring. Report prepared for the CEC by LCG Consulting, 1997.

Electric Power Research Institute (EPRI) 1993. "TAG ${ }^{\mathrm{TM}}$ Technical Assessment Guide Volume 1: Electricity Supply_1993 (Revision 7)." TR-102276-V1R7. June.

EPRI 1997. "Renewable Energy Technology Characterizations." Joint project of EPRI and the U.S. Department of Energy, Office of Utility Technologies, TR-109496, December 1997.

Environmental Defense Fund (EDF). Electrical Financial Production Cost and Optimization: User's Manual, v. 3.0, August 1997.

Hadley, Stanton W., Lawrence J. Hill, and Robert D. Perlack 1993. "Report on the Study of the Tax and Rate Treatment of Renewable Energy Projects." Oak Ridge National Laboratory. ORNL-6772.

Kito, M. S. 1992. CPUC Report, October.

Klein, Joel. Interim Staff Market Clearing Price Forecast for the California Energy Market: Forecast Method and Analytic Issues. CEC, December 1977.

Marnay, Chris, and Steve Pickle. "Power Supply Expansion and the Nuclear Option in Poland." Contemporary Economic Policy, January 1998, vol. XVI(1).

Marnay, Chris, Suzie Kito, and Osman Sezgen. "Entry Into a Competitive Electricity Market: The Fate of Renewable Generators in the California Pool." Paper presented at the USAEEIAEE conference, International Energy Markets, Competition and Policy, Fairmont Hotel, San Francisco, CA, 7-10 September 1997. 
Pickle, S. and R. Wiser. 1997. "Green Power Marketing: Boosting Demand for Renewables" Public Utilities Fortnightly, December.

Sezgen, Osman, Chris Marnay, and Sarah Bretz. "Wind Generation in the Future Competitive California Power Market. Lawrence Berkeley National Laboratory. LBNL41134. March 1998.

U.S. Department of Energy (DOE) 1994. "Technology Characterizations." Draft. May. Andersen Consulting 1995. The Role of Broadband Communications in the Utility of the Future.

Wiser, R., S. Pickle, and C. Goldman 1996. "California Renewable Energy Policy and Implementation Issues-An Overview of Recent Regulatory and Legislative Action." Lawrence Berkeley National Laboratory. LBNL-39247. September.

Wiser, R. and S. Pickle. 1998. Selling Green Power in California: Product, Industry and Market Trends, LBNL-41807 May.

Wiser, R. and S. Pickle. 1997. Green Marketing, Renewables, and Free Riders: Increasing Customer Demand for a Public Good, LBNL-40632 September. 


\section{Detailed Results}

In this appendix we provide a more detailed set of figures and tables for each scenario modeled. Again, three environments for renewables were considered (neutral, good, and bad) and the policies modeled were:

- $\quad$ Policy 0: $\quad$ No policy (i.e., no new or existing policies present)

- Policy A: Non-hydro minimum renewable purchase requirement (set at $15 \%$ of total generation).

- Policy B: Surcharge policy (\$620M/a to lowest cost renewable)

- Policy D: Policy A's minimum renewable purchase requirement with technology bands (set at current market shares)

- Policy $\mathrm{H}: \quad$ Carbon tax $\left(3 \$ / t_{\mathrm{C}}\right)$

Labels for each policy and environment combination are then:

\begin{tabular}{|cccc|}
\hline & & Environment & \\
Policy & Neutral & Good & Bad \\
\hline None & $O N$ & $O G$ & $O B$ \\
A & $A N$ & $A G$ & $A B$ \\
B & $B N$ & $B G$ & \\
D & $D N$ & $D G$ & $D B$ \\
H & $H N$ & $H G$ & $H B$ \\
\hline
\end{tabular}


Figure A.1 Resource Mix Under Scenario ON

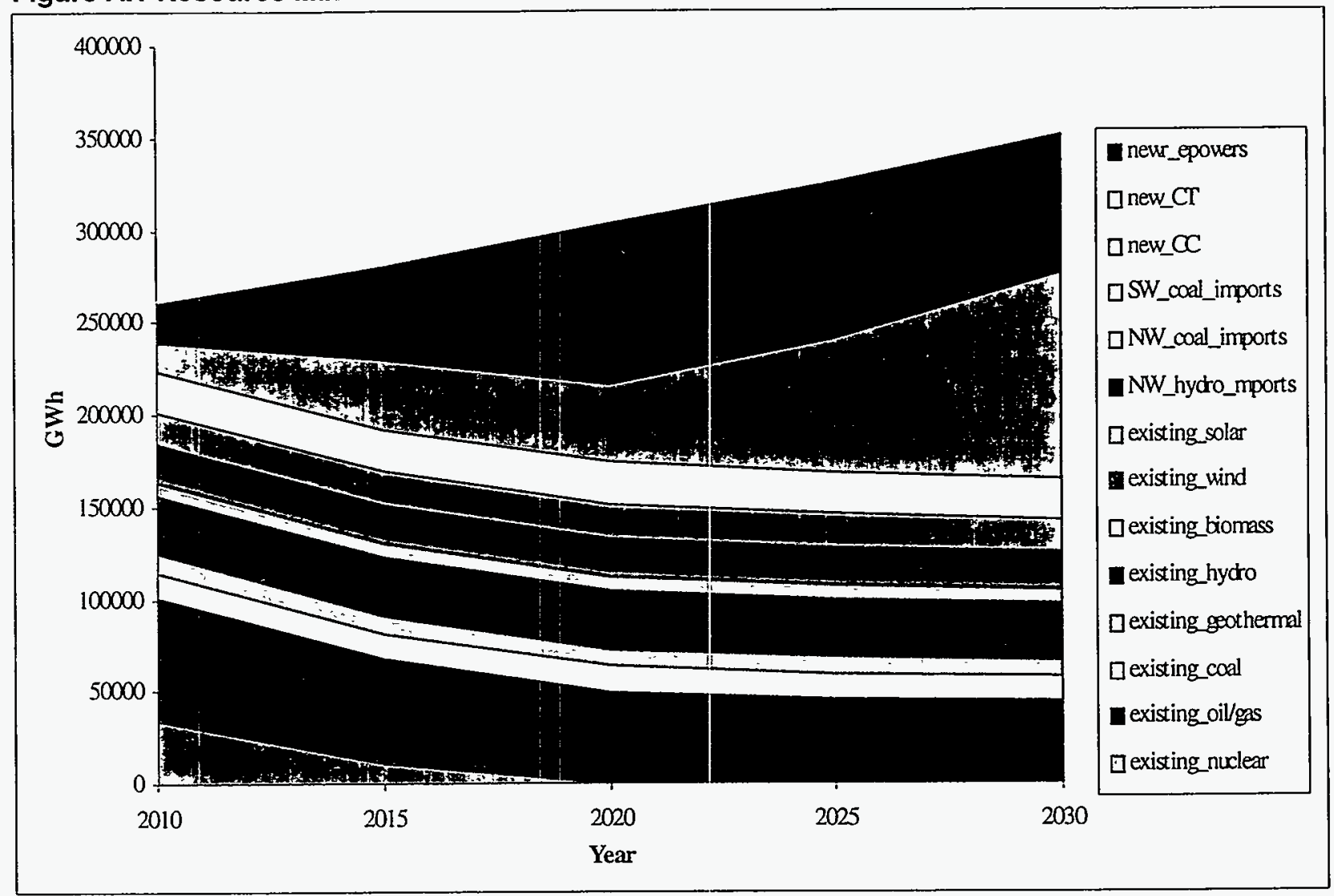

Table A.1 Resource Mix Under Scenario ON (GW/h/a)

\begin{tabular}{|c|c|c|c|c|c|}
\hline & 2010 & 2015 & 2020 & 2025 & 2030 \\
\hline existing_nuclear & 33936 & 10960 & 0 & 0 & 0 \\
\hline existing_oil/gas & 66411 & 56143 & 49044 & 45238 & 43900 \\
\hline existing_coal & 14121 & 14286 & 14444 & 14097 & 13995 \\
\hline existing_geothermal & 10463 & 9937 & 9414 & 8827 & 7820 \\
\hline existing_hydro & 31500 & 31508 & 31600 & 31509 & 31508 \\
\hline existing_biomass & 7245 & 7245 & 7264 & 7245 & 7245 \\
\hline existing_wind & 3069 & 3069 & 3076 & 3069 & 3069 \\
\hline existing_solar & 911 & 911 & 913 & $91 \mathrm{I}$ & 911 \\
\hline NW_hydro_mports & 16574 & 16575 & 16634 & 16575 & 16575 \\
\hline NW_coal_imports & 16881 & 18158 & 18487 & 18314 & 17636 \\
\hline$S W$ Coal_imports & 21713 & 22559 & 22815 & 22684 & 22173 \\
\hline new_CC & 16533 & 37485 & 42566 & 71928 & 111409 \\
\hline$n e w \_C T$ & 1022 & 961 & 1092 & 1666 & 1520 \\
\hline new_repowers & 19868 & 50414 & 85348 & 83049 & 72598 \\
\hline new_coal/nuke & 0 & 0 & 0 & 0 & 0 \\
\hline new_biom ass & 0 & 0 & 0 & 0 & 0 \\
\hline new_wind & 0 & 0 & 0 & 0 & 0 \\
\hline new_geothermal & 0 & 0 & 0 & 0 & 0 \\
\hline new_solar & 0 & 0 & 0 & 0 & 0 \\
\hline Other & 4 & 61 & 66 & 187 & 0 \\
\hline Pumped storage & 781 & 414 & 366 & 393 & 508 \\
\hline
\end{tabular}


Tables A-2 to A-6. Key Indicators for Scenario ON

\begin{tabular}{|c|c|c|c|c|c|}
\hline \multicolumn{6}{|c|}{ Construction (units) } \\
\hline & 2010 & 2015 & 2020 & 2025 & 2030 \\
\hline$\infty$ & 10 & 22 & 25 & 42 & 65 \\
\hline $\mathrm{CT}$ & 43 & 46 & 58 & 58 & 58 \\
\hline Wind & 0 & 0 & 0 & 0 & 0 \\
\hline Goo-thermal & 0 & 0 & 0 & 0 & 0 \\
\hline Solar-thermal & 0 & 0 & 0 & 0 & 0 \\
\hline Phato-voltaics & 0 & 0 & 0 & 0 & 0 \\
\hline Repover & 11 & 29 & 44 & 44 & 44 \\
\hline
\end{tabular}

Enissions (t)
\begin{tabular}{|l|rrrrr|}
\hline & \multicolumn{1}{|c}{2010} & 2015 & 2020 & 2025 & \multicolumn{1}{c|}{2030} \\
\hline NO & 222986 & 225962 & 227828 & 226539 & 2427 \\
SU & 82708 & 85247 & 86427 & 86016 & 84775 \\
PM & 9701 & 11930 & 13715 & 14819 & 15906 \\
RG & 33524 & 34899 & 36100 & 36684 & 37204 \\
CO & 68793 & 68741 & 69212 & 69399 & 69719 \\
CX & 26344706 & 30883172 & 34651154 & 37006603 & 39683706 \\
NG & 233432 & 179637 & 134195 & 126077 & 12607 \\
\hline
\end{tabular}

Thermal Usage
\begin{tabular}{|l|ccccc|}
\hline & 2010 & 2015 & 2020 & 2025 & 2030 \\
\hline$\%$ Thermal & $60 \%$ & $71 \%$ & $77 \%$ & $79 \%$ & $81 \%$ \\
EJ Cas & 0.640 & 0.933 & 1.187 & 1.362 & 1.563 \\
Billion m3 & 17 & 24 & 31 & 36 & 41 \\
\hline
\end{tabular}

Amulative Presert Values 2006-2055 (1995B. OY Milion\$)

\begin{tabular}{|ccccccc|}
\hline Production & Enission & Sharage & Fixed O\&M & Capital & Nat Present Cost \\
\hline 91429 & 0 & 0 & 12945 & 27628 & 132002 \\
\hline
\end{tabular}

Market Revenues and Costs 2006-2055 (1995RQY. Million\$)

\begin{tabular}{|rccccccccc|}
\hline Energy & Commit & Soin & Toxal Revenue & Fuel & Variable O\&M & Fixed O\&M & Capital & Total Cost & Ind Profit \\
\hline 218944 & 9203 & 1333 & 229480 & 85214 & 4862 & 12945 & 27628 & 130649 & 98832
\end{tabular}


Figure A-2. Resource Mix Under Scenario 0G

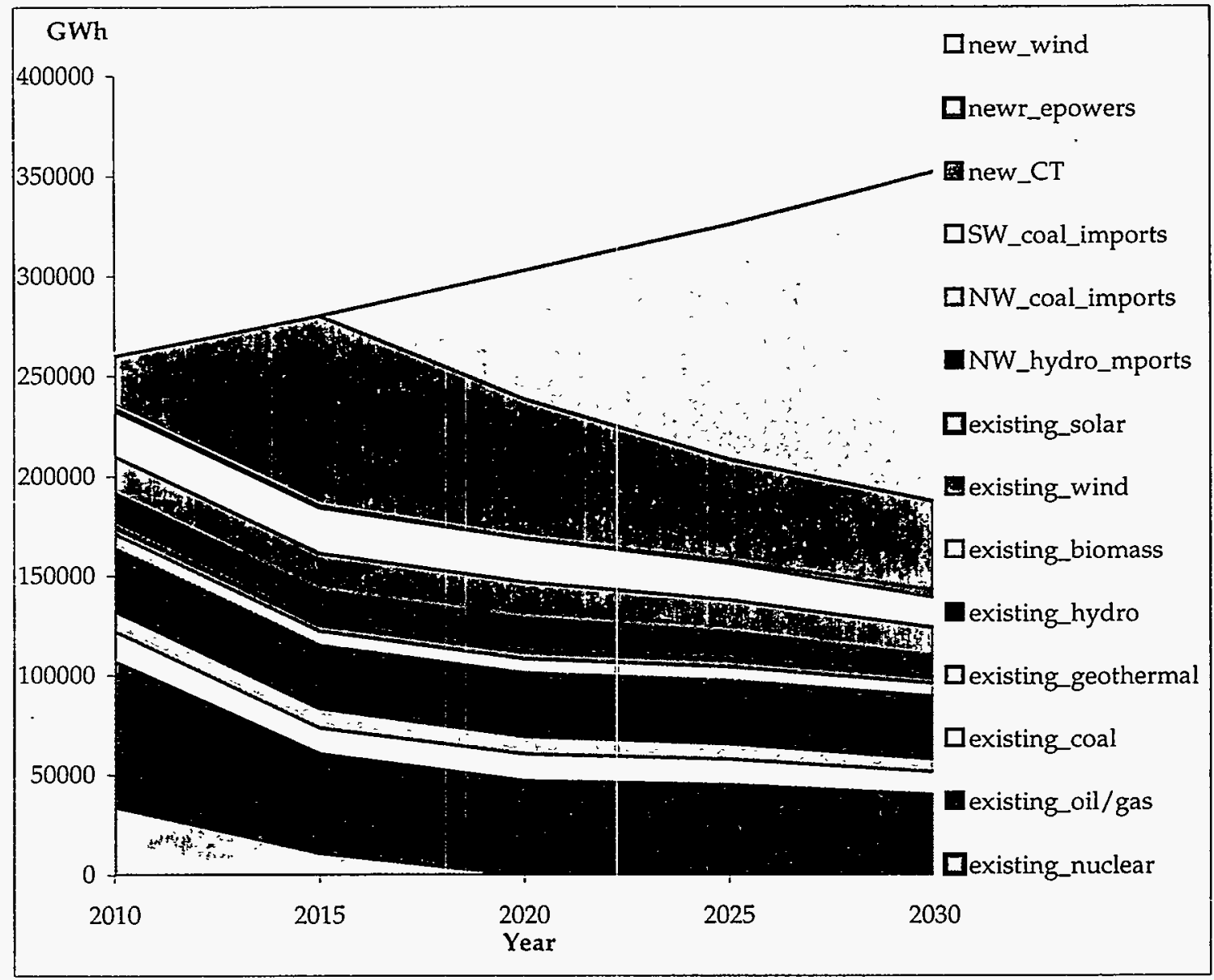


APPENDIX A

Table A-7. Resource Mix Under Scenario OG (GWh)

\begin{tabular}{|l|rrrrr|}
\hline & 2010 & 2015 & 2020 & 2025 & 2030 \\
\hline existing_nuclear & 33936 & 10960 & 0 & 0 & 0 \\
existing_oil/gas & 73200 & 49616 & 46947 & 44721 & 39791 \\
existing_coal & 15144 & 12970 & 13464 & 12900 & 11519 \\
existing_geotherm & 10366 & 9940 & 9049 & 8091 & 6500 \\
al & & & & & \\
existing_hydro & 31496 & 31511 & 31601 & 31471 & 31363 \\
existing_biomass & 7245 & 7245 & 7256 & 7125 & 6663 \\
existing_wind & 3069 & 3069 & 3075 & 2924 & 2534 \\
existing_solar & 911 & 911 & 913 & 883 & 796 \\
NW_hydro_mports & 16574 & 16575 & 16448 & 13779 & 10663 \\
NW_coal_imports & 18319 & 18465 & 18002 & 15779 & 13765 \\
SW_coal_imports & 22642 & 22776 & 21852 & 18298 & 15206 \\
new_cC & 0 & 0 & 0 & 0 & 0 \\
new_CT & 1474 & 1311 & 589 & 1590 & 3851 \\
newr_epowers & 25905 & 94891 & 69314 & 50645 & 44187 \\
new_coal/nuke & 0 & 0 & 0 & 0 & 0 \\
new_biomass & 0 & 0 & 0 & 0 & 0 \\
new_wind & 0 & 0 & 64345 & 117708 & 165422 \\
new_geothermal & 0 & 0 & 0 & 0 & 0 \\
new_solar & 0 & 0 & 0 & 0 & 0 \\
Other & 4 & 29 & 107 & 0 & 14 \\
Pumped storage & 866 & 423 & 1020 & 1961 & 2340 \\
\hline
\end{tabular}

Tables A-8 through A-12. Key Indicators for Scenario OG

A-8. Construction (units)

\begin{tabular}{|l|ccccc|}
\hline & 2010 & 2015 & 2020 & 2025 & 2030 \\
\hline & & & & & \\
CC & 0 & 0 & 0 & 0 & 0 \\
CT & 58 & 58 & 58 & 58 & 58 \\
Wind & 0 & 0 & 131 & 241 & 341 \\
Geo-thermal & 0 & 0 & 0 & 0 & 0 \\
Solar-thermal & 0 & 0 & 0 & 0 & 0 \\
PV & 0 & 0 & 0 & 0 & 0 \\
Repower & 12 & 42 & 42 & 42 & 42 \\
\hline
\end{tabular}


A-9. Emissions (t)

\begin{tabular}{|l|ccccc|}
\hline & 2010 & 2015 & 2020 & 2025 & 2030 \\
\hline NO & 228826 & 223672 & 222057 & 207683 & 187765 \\
SU & 87175 & 83368 & 82419 & 73463 & 63847 \\
PM & 9564 & 12203 & 10949 & 9774 & 8921 \\
RG & 33526 & 35012 & 34401 & 33193 & 31200 \\
CO & 69908 & 67683 & 66669 & 64955 & 60020 \\
CX & 26882477 & 30833779 & 27243183 & 23618085 & 21097815 \\
NG & 250777 & 149228 & 128664 & 124858 & 116044 \\
\hline
\end{tabular}

A-10. Thermal Usage

\begin{tabular}{|l|ccccc|}
\hline & 2010 & 2015 & 2020 & 2025 & 2030 \\
\hline$\%$ Thermal & $60 \%$ & $71 \%$ & $56 \%$ & $44 \%$ & $36 \%$ \\
Gas (EJ) & 0.634 & 0.947 & 0.704 & 0.548 & 0.495 \\
Billion $\left(\mathrm{m}^{\wedge} 3\right)$ & 17 & 25 & 18 & 14 & 13 \\
\hline
\end{tabular}

A-11. Cumulative Present Values 2006-2055 (19:95 B.O.Y Million \$)

\begin{tabular}{|cccccc|}
\hline Production & Emission & Shortage & Fixed O\&M & Capital & Net Cost \\
\hline & & & & & \\
$\$ 67,705$ & $\$ 0$ & $\$ 0$ & $\$ 28,745$ & $\$ 56,871$ & $\$ 153,320$ \\
\hline
\end{tabular}

A-12. Market Revenues and Costs 2006-2055 (1995 B.O.Y. Million \$)

\begin{tabular}{|cccccc|}
\hline Energy & Commit & Spin & Total Fev. & Fuel & Var. O\&M \\
\hline & & & & & \\
$\$ 234,407$ & $\$ 7,745$ & $\$ 1,229$ & $\$ 243,381$ & $\$ 63,522$ & $\$ 3,739$ \\
\hline
\end{tabular}

\begin{tabular}{|cccc|}
\hline Fixed O\&M & Capital & Total Cost $^{\circ}$ & Ind. Profit \\
\hline & & & \\
$\$ 28,745$ & $\$ 56,871$ & $\$ 152,876$ & $\$ 90,505$ \\
\hline
\end{tabular}


Figure A-3. Resource Mix Under Scenario 0B

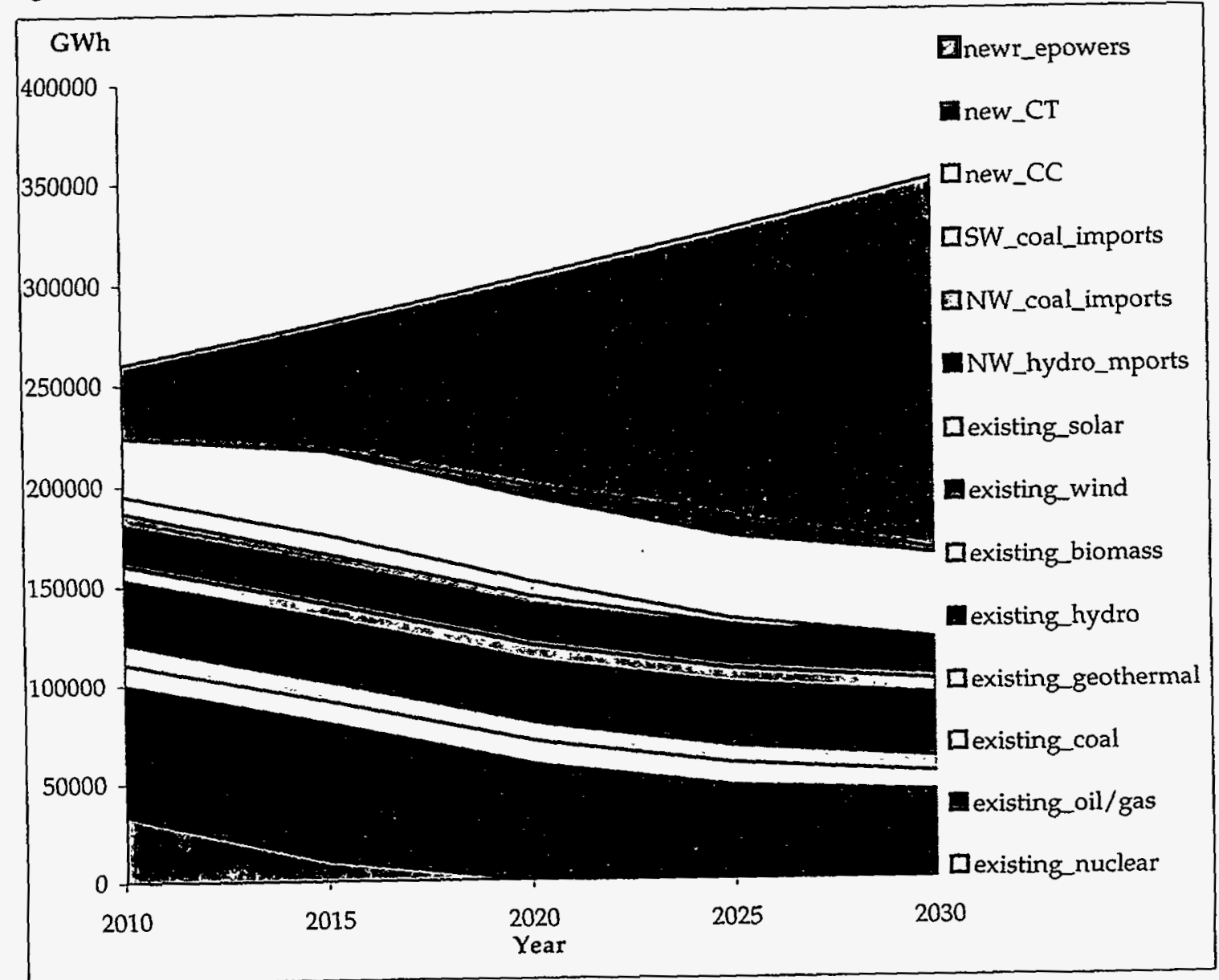


Table A-13. Resource Mix under Scenario OB (GWh)

\begin{tabular}{|l|rrrrr|}
\hline & 2010 & 2015 & 2020 & 2025 & 2030 \\
\hline existing_nuclear & 33936 & 10960 & 0 & 0 & 0 \\
existing_oil/gas & 66454 & 69451 & 59010 & 47257 & 43900 \\
existing_coal & 10909 & 11320 & 11822 & 11435 & 9716 \\
existing_geotherm & 10439 & 9935 & 9414 & 8827 & 7820 \\
al & & & & & \\
existing_hydro & 31507 & 31505 & 31596 & 31507 & 31512 \\
existing_biomass & 7245 & 7245 & 7264 & 7245 & 7245 \\
existing_wind & 3069 & 3069 & 3076 & 3069 & 3069 \\
existing_solar & 911 & 911 & 913 & 911 & 911 \\
NW_hydro_mports & 16575 & 16575 & 16634 & 16575 & 16575 \\
NW_coal_imports & 5877 & 4567 & 3945 & 1452 & 72 \\
SW_coal_imports & 8236 & 9589 & 7376 & 2962 & 245 \\
new_cC & 28930 & 41806 & 42129 & 41600 & 42265 \\
new_CT & 27 & 820 & 6136 & 9635 & 2443 \\
newr_epowers & 36039 & 62447 & 103416 & 142759 & 184638 \\
new_coal/nuke & 0 & 0 & 0 & 0 & 0 \\
new_biomass & 0 & 0 & 0 & 0 & 0 \\
new_wind & 0 & 0 & 0 & 0 & 0 \\
new_geothermal & 0 & 0 & 0 & 0 & 0 \\
new_solar & 0 & 0 & 0 & 0 & 0 \\
Other & 0 & 56 & 9 & 24 & 4 \\
Pumped storage & 443 & 371 & 362 & 361 & 358 \\
\hline
\end{tabular}

Tables A-14 through A-18. Key Indicators for Scenario OB

A-14. Construction (units)

\begin{tabular}{|l|ccccc|}
\hline & 2010 & 2015 & 2020 & 2025 & 2030 \\
\hline & 17 & 24 & 24 & 24 & 25 \\
CC & 9 & 43 & 71 & 71 & 71 \\
Wind & 0 & 0 & 0 & 0 & 0 \\
Geo-thermal & 0 & 0 & 0 & 0 & 0 \\
Solar-thermal & 0 & 0 & 0 & 0 & 0 \\
PV & 0 & 0 & 0 & 0 & 0 \\
Repower & 22 & 26 & 38 & 53 & 77 \\
\hline
\end{tabular}




\section{A-15. Emissions ( $t$ )}

\begin{tabular}{|l|ccccc|}
\hline & 2010 & 2015 & 2020 & 2025 & 2030 \\
\hline NO & 177499 & 181858 & 177836 & 164306 & 151726 \\
SU & 48942 & 50413 & 48892 & 39318 & 27849 \\
PM & 9660 & 11667 & 13733 & 15197 & 16115 \\
RG & 33877 & 35356 & 36746 & 37629 & 38000 \\
CO & 69278 & 71406 & 71931 & 71419 & 70822 \\
CX & 24261221 & 29463608 & 33252907 & 35256617 & 37253430 \\
NG & 244801 & 224099 & 158584 & 126077 & 126077 \\
\hline
\end{tabular}

A-16. Thermal Usage

\begin{tabular}{|l|ccccc|}
\hline & 2010 & 2015 & 2020 & 2025 & 2030 \\
\hline$\%$ Thermal & $60 \%$ & $71 \%$ & $77 \%$ & $79 \%$ & $81 \%$ \\
Gas (EJ) & 0.847 & 1.190 & 1.488 & 1.728 & 1.958 \\
Billion $\left(\mathrm{m}^{\wedge} 3\right)$ & 22 & 31 & 39 & 45 & 51 \\
\hline
\end{tabular}

A-17. Cumulative Present Values 2006-2055 (1995

B.O.Y Million \$)

\begin{tabular}{|cccccc|}
\hline Production & Emission & Shortage & Fixed O\&M & Capital & Net Cost \\
\hline$\$ 66,551$ & $\$ 0$ & $\$ 0$ & $\$ 12,118$ & $\$ 23,831$ & $\$ 102,500$ \\
\hline
\end{tabular}

A-18. Market Revenues and Costs 2006-2055 (1995

B.O.Y. Million \$)

\begin{tabular}{|cccccc|}
\hline Energy & Commit & Spin & Total Rev. & Fuel & Var. O\&M \\
\hline & & & & & \\
$\$ 185,520$ & $\$ 13,907$ & $\$ 980$ & $\$ 200,406$ & $\$ 58,037$ & $\$ 8,287$ \\
\hline
\end{tabular}

\begin{tabular}{|cccc|}
\hline Fixed O\&M & Capital & Total Cost & Ind. Profit \\
\hline & & & \\
$\$ 12,118$ & $\$ 23,831$ & $\$ 102,273$ & $\$ 98,133$ \\
\hline
\end{tabular}


Figure A-4. Resource Mix Under Scenario AN

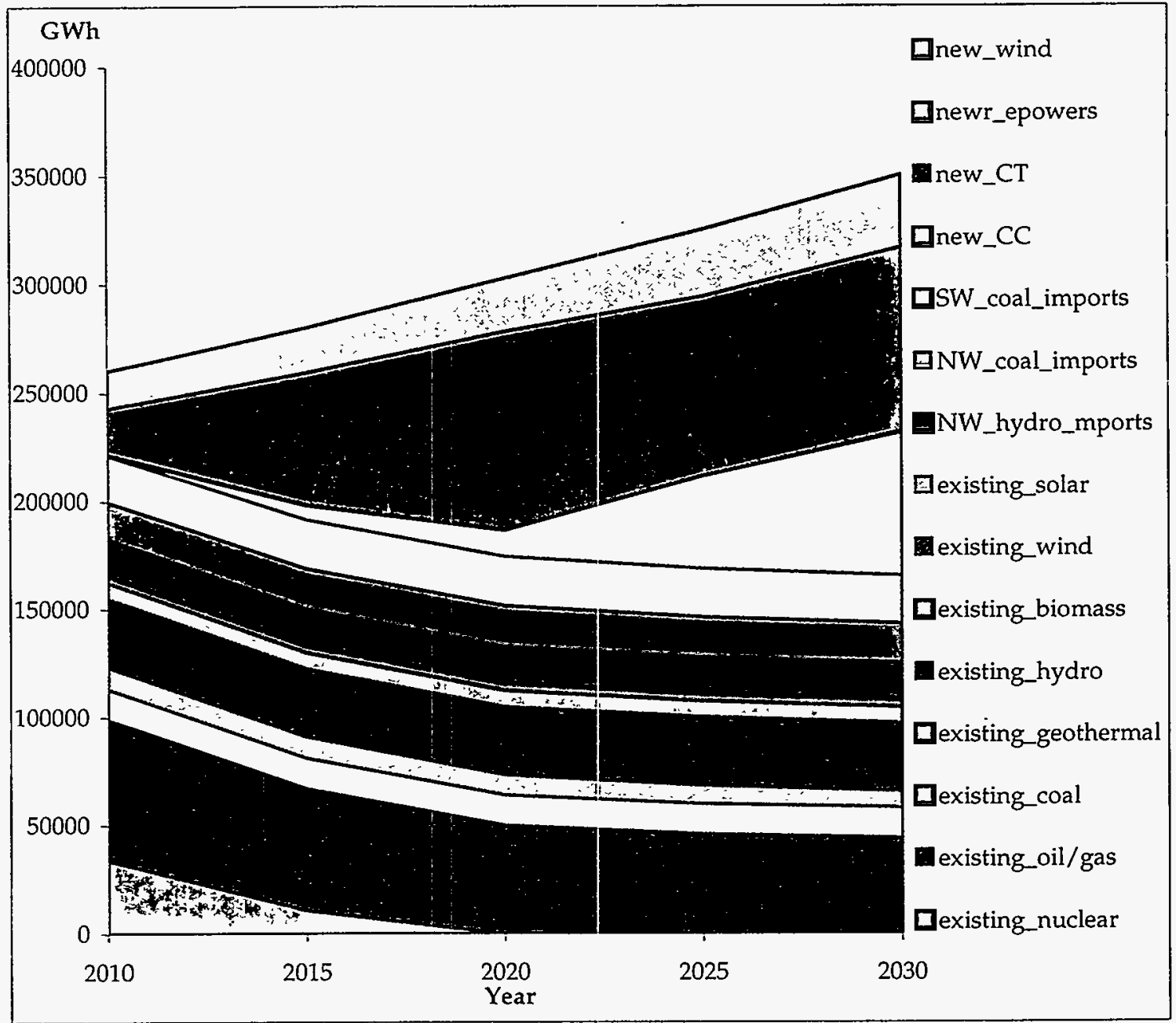


Table A-19. Resource Mix under Scenario AN (GWh)

\begin{tabular}{|l|rrrrr|}
\hline & 2010 & 2015 & 2020 & 2025 & 2030 \\
\hline existing_nuclear & 33936 & 10960 & 0 & 0 & 0 \\
existing_oil/gas & 64988 & 56062 & 49854 & 45804 & 43900 \\
existing_coal & 14289 & 14257 & 14207 & 13955 & 14102 \\
existing_geotherm & 10445 & 9937 & 9414 & 8822 & 7820 \\
al & & & & & \\
existing_hydro & 31501 & 31509 & 31601 & 31510 & 31509 \\
existing_biomass & 7245 & 7245 & 7264 & 7245 & 7245 \\
existing_wind & 3069 & 3069 & 3076 & 3069 & 3069 \\
existing_solar & 911 & 911 & 913 & 911 & 911 \\
NW_hydro_mports & 16521 & 16575 & 16634 & 16575 & 16575 \\
NW_coal_imports & 16872 & 18308 & 18482 & 18194 & 17911 \\
SW_coal_imports & 21498 & 22580 & 22806 & 22388 & 22102 \\
new_CC & 0 & 6611 & 12072 & 42757 & 66395 \\
new_cT & 849 & 672 & 549 & 575 & 1031 \\
newr_epowers & 20925 & 60846 & 91191 & 82405 & 84293 \\
new_coal/nuke & 0 & 0 & 0 & 0 & 0 \\
new_biomass & 0 & 0 & 0 & 0 & 0 \\
new_wind & 17231 & 20672 & 24637 & 31008 & 33469 \\
new_geothermal & 0 & 0 & 0 & 0 & 0 \\
new_solar & 0 & 0 & 0 & 0 & 0 \\
Other & 3 & 43 & 62 & 77 & 0 \\
Pumped storage & 880 & 366 & 361 & 389 & 442 \\
\hline
\end{tabular}

Tables A-20 through A-24. Key Indicators for Scenario AN

A-20. Construction

\begin{tabular}{|l|ccccc|}
\hline & 2010 & 2015 & 2020 & 2025 & 2030 \\
\hline CC & & & & & \\
CT & 0 & 4 & 7 & 25 & 39 \\
Wind & 39 & 41 & 41 & 41 & 41 \\
Geo-thermal & 35 & 42 & 50 & 63 & 68 \\
Solar-thermal & 0 & 0 & 0 & 0 & 0 \\
PV & 0 & 0 & 0 & 0 & 0 \\
Repower & 0 & 0 & 0 & 0 & 0 \\
\hline
\end{tabular}


A-21. Emissions ( $t$ )

\begin{tabular}{|l|ccccc|}
\hline & 2010 & 2015 & 2020 & 2025 & 2030 \\
\hline NO & 222178 & 225815 & 227198 & 225297 & 223901 \\
SU & 82134 & 85301 & 86025 & 85135 & 84823 \\
PM & 8984 & 11067 & 12647 & 13465 & 14476 \\
RG & 33074 & 34381 & 35487 & 35934 & 36323 \\
CO & 68000 & 68069 & 68575 & 68582 & 68629 \\
CX & 24372114 & 28666873 & 31962740 & 33522160 & 36067691 \\
NG & 232244 & 176894 & 137484 & 126077 & 126077 \\
\hline
\end{tabular}

A-22. Thermal Usage

\begin{tabular}{|l|ccccc|}
\hline & 2010 & 2015 & 2020 & 2025 & 2030 \\
\hline$\%$ Thermal & $53 \%$ & $64 \%$ & $69 \%$ & $69 \%$ & $71 \%$ \\
Gas (EJ) & 0.501 & 0.777 & 1.002 & 1.125 & 1.309 \\
Billion $\left(\mathrm{m}^{\wedge} 3\right)$ & 13 & 20 & 26 & 29 & 34 \\
\hline
\end{tabular}

\section{A-23. Cumulative Present Values 2006-2055 (1995 B.O.Y Million \$)}

\begin{tabular}{|cccccc|}
\hline Production & Emission & Shortage & Fixed O\&M & Capital & Net Cost \\
\hline \multirow{2}{*}{$\$ 9,066$} & $\$ 0$ & $\$ 0$ & $\$ 16,836$ & $\$ 39,468$ & $\$ 135,370$ \\
\hline
\end{tabular}

A-24. Market Revenues and Costs 2006-2055 (1995 B.O.Y. Million \$)

\begin{tabular}{|cccccc|}
\hline Energy & Commit & Spin & Total Rev. & Fuel & Var. O\&M \\
\hline & & & & & \\
$\$ 214,934$ & $\$ 9,079$ & $\$ 1,066$ & $\$ 225,079$ & $\$ 72,712$ & $\$ 4,958$ \\
\hline
\end{tabular}

\begin{tabular}{|cccc|}
\hline Fixed O\&M & Capital & Total Cost & Ind. Profit \\
\hline & & & \\
$\$ 16,836$ & $\$ 39,468$ & $\$ 133,974$ & $\$ 91,105$ \\
\hline
\end{tabular}


Figure A-5. Resource Mix Under Scenario AG

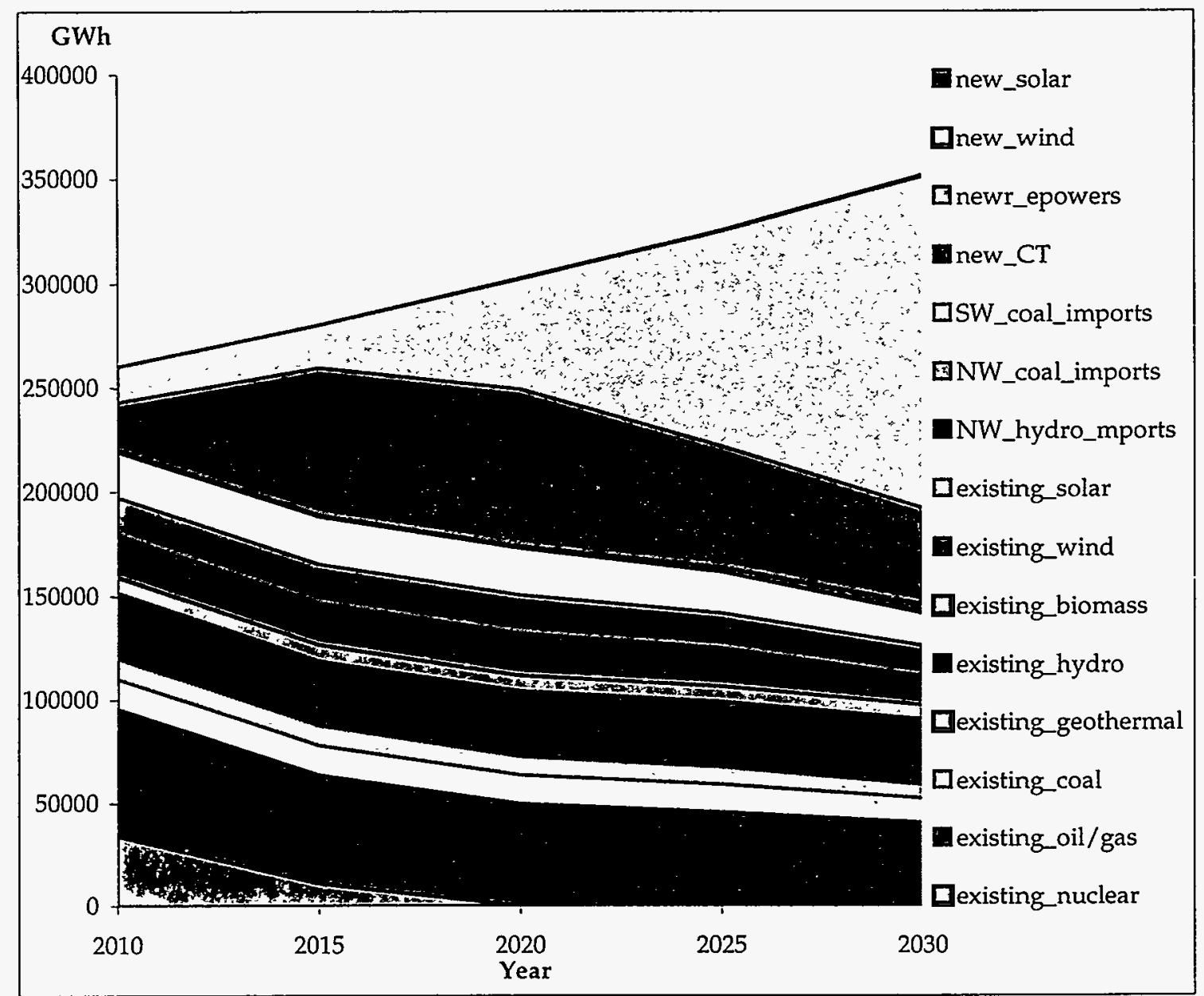


Table A-25. Resource Mix Under Scenario AG (GWh)

\begin{tabular}{|l|rrrrr|}
\hline & 2010 & 2015 & 2020 & 2025 & 2030 \\
\hline existing_nuclear & 33936 & 10960 & 0 & 0 & 0 \\
existing_oil/gas & 61607 & 52773 & 49720 & 45588 & 40344 \\
existing_coal & 14817 & 14317 & 14050 & 13599 & 11965 \\
existing_geotherm & 10186 & 9618 & 9076 & 8346 & 6823 \\
al & & & & & \\
existing_hydro & 31497 & 31509 & 31599 & 31493 & 31388 \\
existing_biomass & 7245 & 7245 & 7264 & 7211 & 6710 \\
existing_wind & 3069 & 3069 & 3076 & 3020 & 2602 \\
existing_solar & 911 & 911 & 913 & 906 & 869 \\
NW_hydro_mports & 16524 & 16575 & 16612 & 14888 & 11094 \\
NW_coal_imports & 17578 & 18453 & 18345 & 16675 & 14214 \\
SW_coal_imports & 21961 & 22742 & 22405 & 19825 & 15761 \\
new_cC & 0 & 0 & 0 & 0 & 0 \\
new_CT & 869 & 604 & 963 & 2515 & 4485 \\
newr_epowers & 23007 & 70802 & 75174 & 57731 & 45504 \\
new_coal/nuke & 0 & 0 & 0 & 0 & 0 \\
new_biomass & 0 & 0 & 0 & 0 & 0 \\
new_wind & 17232 & 20672 & 53101 & 103592 & 159790 \\
new_geothermal & 0 & 0 & 0 & 0 & 0 \\
new_solar & 0 & 0 & 342 & 340 & 338 \\
Other & 1 & 30 & 232 & 15 & 27 \\
Pumped storage & 1329 & 439 & 792 & 1874 & 2530 \\
\hline
\end{tabular}

Tables A-26 through A-30. Key Indicators for Scenario AG

A-26. Construction (units)

\begin{tabular}{|l|ccccc|}
\hline & 2010 & 2015 & 2020 & 2025 & 2030 \\
\hline & & & & & \\
CC & 0 & 0 & 0 & 0 & 0 \\
CT & 41 & 41 & 41 & 41 & 41 \\
Wind & 35 & 42 & 72 & 212 & 329 \\
Geo-thermal & 0 & 0 & 0 & 0 & 0 \\
Solar-thermal & 0 & 0 & 0 & 0 & 0 \\
PV & 0 & 0 & 4 & 4 & 4 \\
Repower & 12 & 38 & 40 & 40 & 40 \\
\hline
\end{tabular}


A-27. Emissions ( $t$ )

\begin{tabular}{|l|ccccc|}
\hline & 2010 & 2015 & 2020 & 2025 & 2030 \\
\hline NO & 224373 & 226219 & 225491 & 215382 & 191962 \\
SU & 84734 & 85960 & 84461 & 78073 & 66226 \\
PM & 9105 & 11209 & 11391 & 10383 & 9162 \\
RG & 33110 & 34458 & 34757 & 33889 & 31639 \\
CO & 67582 & 67700 & 67715 & 66193 & 61025 \\
CX & 24475132 & 28720813 & 28716385 & 25396181 & 21789267 \\
NG & 213427 & 159996 & 135355 & 125876 & 117116 \\
\hline
\end{tabular}

A-28. Thermal Usage

\begin{tabular}{|l|ccccc|}
\hline & 2010 & 2015 & 2020 & 2025 & 2030 \\
\hline$\%$ Thermal & $53 \%$ & $64 \%$ & $59 \%$ & $48 \%$ & $37 \%$ \\
Gas (EJ) & 0.488 & 0.775 & 0.785 & 0.621 & 0.514 \\
Billion $\left(\mathrm{m}^{\wedge} 3\right)$ & 13 & 20 & 20 & 16 & 13 \\
\hline
\end{tabular}

A-29. Cumulative Present Values 2006-2055 (1995 B.O.Y Million \$)

\begin{tabular}{|cccccc|}
\hline Production & Emission & Shortage & Fixed O\&M & Capital & Net Cost \\
\hline$\$ 64,094$ & $\$ 0$ & $\$ 0$ & $\$ 29,429$ & $\$ 58,380$ & $\$ 151,904$ \\
\hline
\end{tabular}

A-30. Market Revenues and Costs 2006-2055 (1995 B.O.Y. Million \$)

\begin{tabular}{|c|c|c|c|c|c|}
\hline Energy & Commit & Spin & Total Rev. & Fuel & Var. O\&M \\
\hline$\$ 251,315$ & $\$ 14,303$ & $\$ 1,858$ & $\$ 267,477$ & $\$ 59,908$ & $\$ 3,389$ \\
\hline & Fixed O\&M & Capital & Total Cost & Ind. Profit & \\
\hline & $\$ 29,429$ & $\$ 58,380$ & $\$ 151,107$ & $\$ 116,369$ & \\
\hline
\end{tabular}




\section{APPENDIX A}

Figure A-6. Resource Mix Under Scenario AB

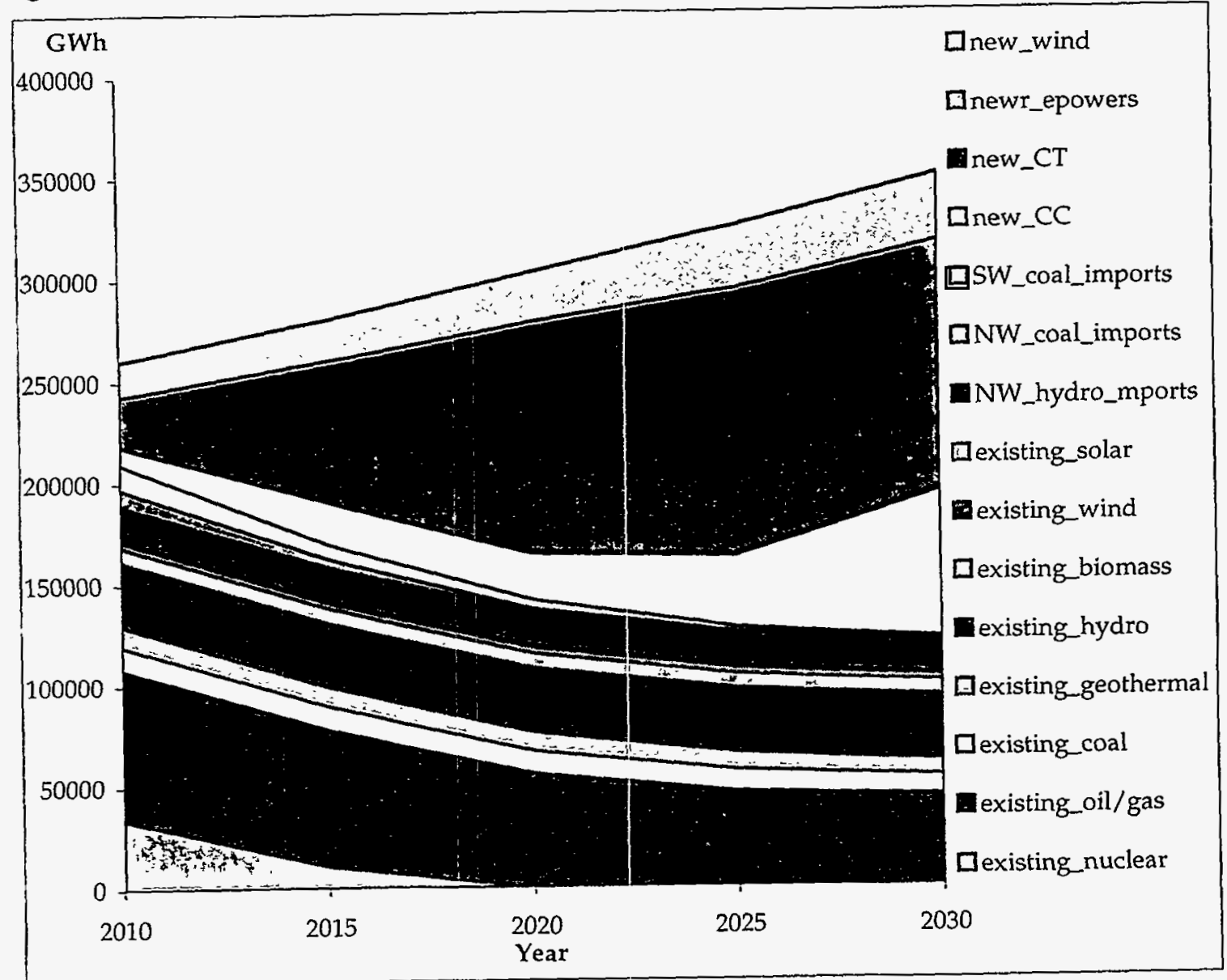


Table A-31. Resource Mix under Scenario AB (GWh)

\begin{tabular}{|l|rrrrr|}
\hline & 2010 & 2015 & 2020 & 2025 & 2030 \\
\hline existing_nuclear & 33936 & 10960 & 0 & 0 & 0 \\
existing_oil/gas & 74048 & 66934 & 55471 & 45937 & 43900 \\
existing_coal & 11741 & 11537 & 11397 & 10739 & 9782 \\
existing_geotherm & 10423 & 9927 & 9413 & 8826 & 7820 \\
al & & & & & \\
existing_hydro & 31502 & 31505 & 31596 & 31508 & 31509 \\
existing_biomass & 7245 & 7245 & 7264 & 7245 & 7245 \\
existing_wind & 3069 & 3069 & 3076 & 3069 & 3069 \\
existing_solar & 911 & 911 & 913 & 911 & 911 \\
NW_hydro_mports & 16516 & 16575 & 16634 & 16575 & 16575 \\
NW_coal_imports & 7804 & 3822 & 1265 & 390 & 228 \\
SW_coal_imports & 12360 & 7303 & 4398 & 2069 & 834 \\
new_CC & 8617 & 20799 & 22817 & 34768 & 72327 \\
new_CT & 521 & 401 & 1405 & 1640 & 2086 \\
newr_epowers & 24265 & 68582 & 112452 & 130550 & 120674 \\
new_coal/nuke & 0 & 0 & 0 & 0 & 0 \\
new_biomass & 0 & 0 & 0 & 0 & 0 \\
new_wind & 17232 & 20672 & 24637 & 31008 & 33469 \\
new_geothermal & 0 & 0 & 0 & 0 & 0 \\
new_solar & 0 & 0 & 0 & 0 & 0 \\
Other & 1 & 18 & 14 & 32 & 23 \\
Pumped storage & 525 & 384 & 364 & 364 & 410 \\
\hline
\end{tabular}

Tables A-32 through A-36. Key Indicators for Scenario AB

A-32. Construction (units)

\begin{tabular}{|l|ccccc|}
\hline & 2010 & 2015 & 2020 & 2025 & 2030 \\
\hline & & & & & \\
CC & 5 & 12 & 13 & 20 & 43 \\
CT & 33 & 36 & 44 & 44 & 44 \\
Wind & 35 & 42 & 50 & 63 & 68 \\
Geo-thermal & 0 & 0 & 0 & 0 & 0 \\
Solar-thermal & 0 & 0 & 0 & 0 & 0 \\
PV & 0 & 0 & 0 & 0 & 0 \\
Repower & 12 & 30 & 45 & 57 & 57 \\
\hline
\end{tabular}


A-33. Emissions ( $t$ )

\begin{tabular}{|l|ccccc|}
\hline & 2010 & 2015 & 2020 & 2025 & 2030 \\
\hline NO & 190555 & 175291 & 167033 & 158537 & 152858 \\
SU & 57508 & 47226 & 40602 & 34365 & 28971 \\
PM & 8761 & 10843 & 12642 & 13599 & 14498 \\
RG & 33308 & 34813 & 36139 & 36629 & 36996 \\
CO & 69593 & 70418 & 70543 & 69656 & 69558 \\
CX & 23193838 & 26873604 & 29817279 & 31067270 & 33233060 \\
NG & 268848 & 220397 & 150687 & 126077 & 126077 \\
\hline
\end{tabular}

A-34. Thermal Usage

\begin{tabular}{|l|ccccc|}
\hline & 2010 & 2015 & 2020 & 2025 & 2030 \\
\hline$\%$ Thermal & $53 \%$ & $64 \%$ & $69 \%$ & $69 \%$ & $71 \%$ \\
Gas (EJ) & 0.677 & 1.051 & 1.323 & 1.469 & 1.662 \\
Billion $\left(\mathrm{m}^{\wedge} 3\right)$ & 18 & 27 & 35 & 38 & 43 \\
\hline
\end{tabular}

A-35. Cumulative Present Values 2006-2055 (1995

B.O.Y Million \$)

\begin{tabular}{|cccccc|}
\hline Production & Emission & Shortage & Fixed O\&M & Capital & Net Cost \\
\hline$\$ 56,998$ & $\$ 0$ & $\$ 0$ & $\$ 17,457$ & $\$ 39,819$ & $\$ 114,275$ \\
\hline
\end{tabular}

A-36. Market Revenues and Costs 2006-2055 (1995

B.O.Y. Million \$)

\begin{tabular}{|cccccc|}
\hline Energy & Commit & Spin & Total Rev. & Fuel & Var. O\&M \\
\hline & & & & & \\
$\$ 156,846$ & $\$ 14,824$ & $\$ 884$ & $\$ 172,555$ & $\$ 50,216$ & $\$ 6,425$ \\
\hline
\end{tabular}

\begin{tabular}{|cccc|}
\hline Fixed O\&M & Capital & Total Cost & Ind. Profit \\
\hline & & & \\
$\$ 17,457$ & $\$ 39,819$ & $\$ 113,919$ & $\$ 58,635$ \\
\hline
\end{tabular}


Figure A-7. Resource Mix Under Scenario BN

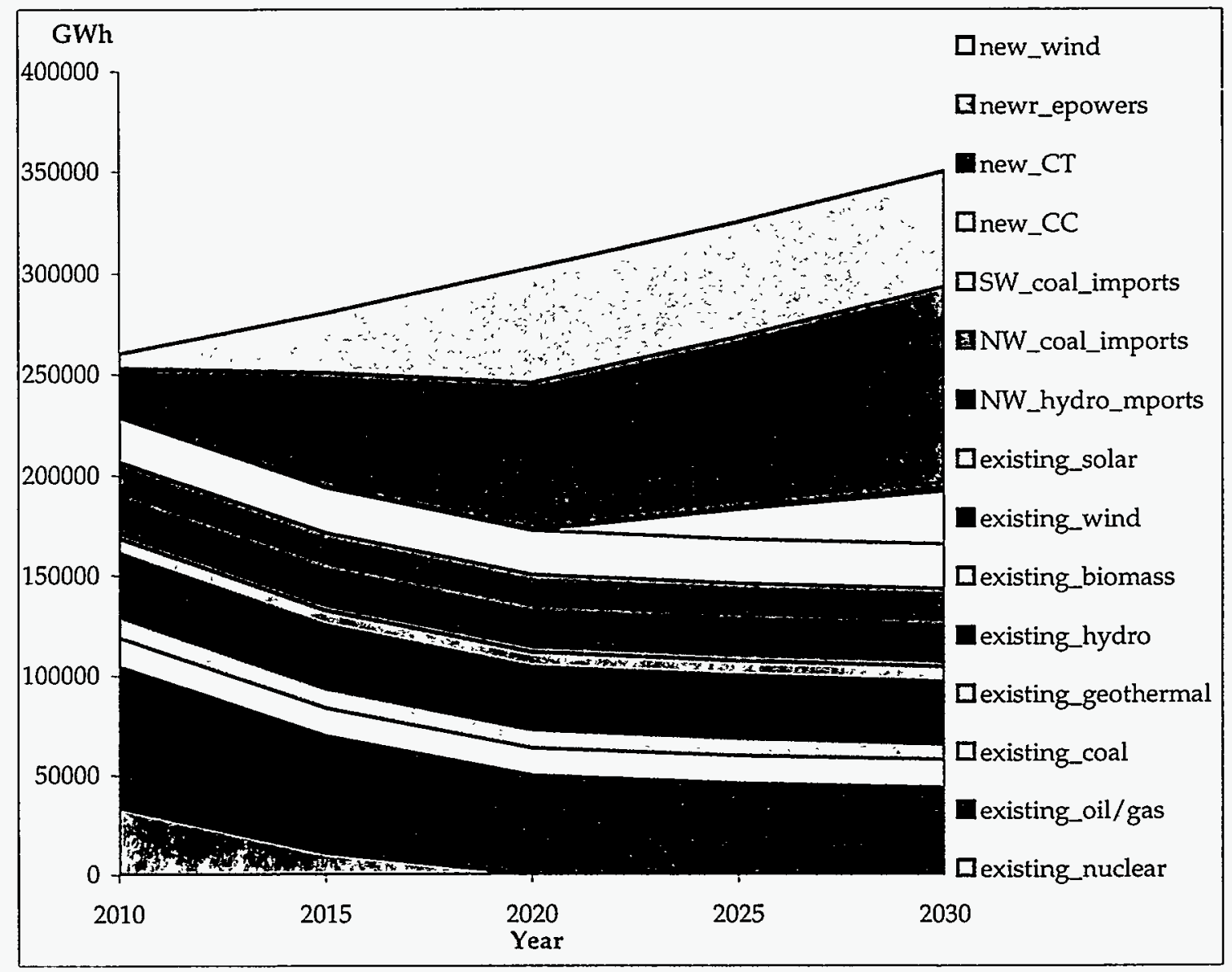


Table A-37. Resource Mix Under Scenario BN (GWh)

\begin{tabular}{|l|rrrrr|}
\hline & 2010 & 2015 & 2020 & 2025 & 2030 \\
\hline existing_nuclear & 33936 & 10960 & 0 & 0 & 0 \\
existing_oil/gas & 70785 & 58830 & 49985 & 45971 & 43900 \\
existing_coal & 14543 & 14267 & 13751 & 13876 & 14024 \\
existing_geotherm & 10477 & 9801 & 9195 & 8815 & 7820 \\
al & & & & & \\
existing_hydro & 31499 & 31507 & 31599 & 31508 & 31510 \\
existing_biomass & 7245 & 7245 & 7264 & 7245 & 7245 \\
existing_wind & 3069 & 3069 & 3076 & 3069 & 3069 \\
existing_solar & 911 & 911 & 913 & 911 & 911 \\
NW_hydro_mports & 16573 & 16574 & 16588 & 16563 & 16573 \\
NW_coal_imports & 17657 & 18183 & 18061 & 18040 & 18219 \\
SW_coal_imports & 22149 & 22414 & 22014 & 22007 & 22232 \\
new_CC & 0 & 0 & 0 & 14811 & 26545 \\
new_CT & 1175 & 1082 & 787 & 1370 & 1759 \\
newr_epowers & 23299 & 55865 & 72505 & 84115 & 99596 \\
new_coal/nuke & 0 & 0 & 0 & 0 & 0 \\
new_biomass & 0 & 0 & 0 & 0 & 0 \\
new_wind & 6904 & 29532 & 57029 & 56978 & 56994 \\
new_geothermal & 0 & 0 & 0 & 0 & 0 \\
new_solar & 0 & 0 & 0 & 0 & 0 \\
Other & 5 & 40 & 24 & 72 & 0 \\
Pumped storage & 702 & 478 & 460 & 603 & 605 \\
\hline
\end{tabular}

Tables A-38 through A-42. Key Indicators for Scenario BN

A-38. Construction (units)

\begin{tabular}{|l|ccccc|}
\hline & 2010 & 2015 & 2020 & 2025 & 2030 \\
\hline & & & & & \\
CC & 0 & 0 & 0 & 9 & 16 \\
CT & 47 & 49 & 49 & 49 & 49 \\
Wind & 14 & 60 & 116 & 116 & 116 \\
Geo-thermal & 0 & 0 & 0 & 0 & 0 \\
Solar-thermal & 0 & 0 & 0 & 0 & 0 \\
PV & 0 & 0 & 0 & 0 & 0 \\
Repower & 12 & 30 & 42 & 47 & 53 \\
\hline
\end{tabular}


A-39. Emissions ( $t$ )

\begin{tabular}{|l|ccccc|}
\hline & 2010 & 2015 & 2020 & 2025 & 2030 \\
\hline NO & 225727 & 225427 & 223521 & 223805 & 223894 \\
SU & 84254 & 84720 & 83565 & 84126 & 84455 \\
PM & 9294 & 10610 & 11199 & 12377 & 13502 \\
RG & 33327 & 34143 & 34589 & 35281 & 35730 \\
CO & 69243 & 68195 & 67424 & 67827 & 67872 \\
CX & 25842860 & 27774071 & 28185354 & 30696316 & 33640414 \\
NG & 249285 & 186661 & 137874 & 126070 & 126077 \\
\hline
\end{tabular}

A-40. Thermal Usage

\begin{tabular}{|l|ccccc|}
\hline & 2010 & 2015 & 2020 & 2025 & 2030 \\
\hline$\%$ Thermal & $57 \%$ & $61 \%$ & $58 \%$ & $61 \%$ & $64 \%$ \\
Gas (EJ) & 0.585 & 0.717 & 0.762 & 0.937 & 1.137 \\
Billion (m^3) & 15 & 19 & 20 & 24 & 30 \\
\hline
\end{tabular}

A-41. Cumulative Present Values 2006-2055 (1995 B.O.Y Million \$)

\begin{tabular}{|cccccc|}
\hline Production & Emission & Shortage & Fixed O\&M & Capital & Net Cost \\
\hline & & & & & \\
$\$ 67,004$ & $\$ 0$ & $\$ 0$ & $\$ 19,177$ & $\$ 42,820$ & $\$ 132,001$ \\
\hline
\end{tabular}

A-42. Market Revenues and Costs 2006-2055 (1995 B.O.Y. Million \$)

\begin{tabular}{|cccccc|}
\hline Energy & Commit & Spin & Total Rev. & Fuel & Var. O\&M \\
$\$ 219,672$ & $\$ 9,202$ & $\$ 1,054$ & $\$ 229,928$ & $\$ 67,588$ & $-\$ 2,048$ \\
\hline
\end{tabular}

\begin{tabular}{|cccc|}
\hline Fixed O\&M & Capital & Total Cost & Ind. Profit \\
\hline & & & \\
$\$ 19,177$ & $\$ 45,820$ & $\$ 130,536$ & $\$ 99,392$ \\
\hline
\end{tabular}


Figure A-8. Resource Mix Under Scenario BG

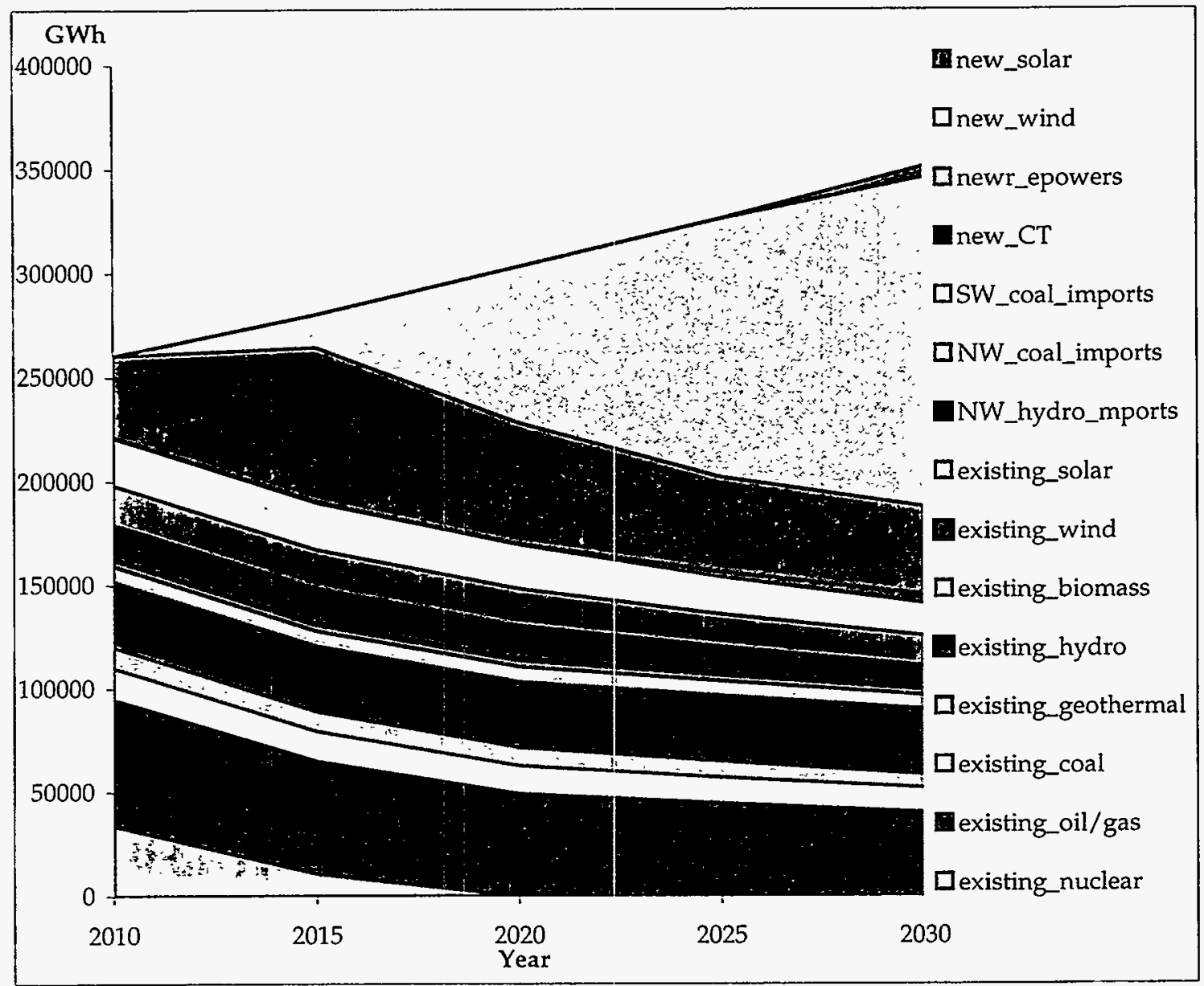


APPENDIXA

Table A-43. Resource Mix Under Scenario BG (GWh)

\begin{tabular}{|l|rrrrr|}
\hline & 2010 & 2015 & 2020 & 2025 & 2030 \\
\hline existing_nuclear & 33936 & 10960 & 0 & 0 & 0 \\
existing_oil/gas & 61077 & 54313 & 49213 & 44562 & 40319 \\
existing_coal & 15177 & 14323 & 13701 & 12632 & 11793 \\
existing_geotherm & 10394 & 9744 & 8930 & 7969 & 6655 \\
al & & & & & \\
existing_hydro & 31499 & 31509 & 31597 & 31452 & 31382 \\
existing_biomass & 7245 & 7245 & 7264 & 7072 & 6725 \\
existing_wind & 3069 & 3069 & 3072 & 2890 & 2600 \\
existing_solar & 911 & 911 & 913 & 897 & 817 \\
NW_hydro_mports & 16575 & 16575 & 16023 & 13028 & 10918 \\
NW_coal_imports & 18395 & 18463 & 17534 & 15304 & 14187 \\
SW_coal_imports & 22675 & 22761 & 21215 & 17736 & 15543 \\
new_CC & 0 & 0 & 0 & 0 & 0 \\
new_CT & 728 & 698 & 671 & 2827 & 4532 \\
newr_epowers & 38564 & 73372 & 57872 & 45293 & 41965 \\
new_coal/nuke & 0 & 0 & 0 & 0 & 0 \\
new_biomass & 0 & 0 & 0 & 0 & 0 \\
new_wind & 0 & 16243 & 74967 & 124268 & 158702 \\
new_geothermal & 0 & 0 & 0 & 0 & 0 \\
new_solar & 0 & 0 & 0 & 0 & 5229 \\
Other & 3 & 81 & 82 & 13 & 21 \\
Pumped storage & 761 & 394 & 1300 & 1976 & 2542 \\
\hline
\end{tabular}

Tables A-44 through A-48. Key Indicators for Scenario BG

A-44. Construction (units)

\begin{tabular}{|l|ccccc|}
\hline & 2010 & 2015 & 2020 & 2025 & 2030 \\
\hline CC & & & & & \\
CT & 0 & 0 & 0 & 0 & 0 \\
Wind & 36 & 36 & 36 & 36 & 36 \\
Geo-thermal & 0 & 33 & 153 & 255 & 327 \\
Solar-thermal & 0 & 0 & 0 & 0 & 0 \\
PV & 0 & 0 & 0 & 0 & 0 \\
Repower & 19 & 0 & 0 & 0 & 62 \\
\hline
\end{tabular}


APPENDIX A

A-45. Emissions ( $t$ )

\begin{tabular}{|l|ccccc|}
\hline & 2010 & 2015 & 2020 & 2025 & 2030 \\
\hline NO & 227852 & 226449 & 220817 & 204607 & 190926 \\
SU & 87345 & 85409 & 81125 & 71564 & 65406 \\
PM & 9897 & 11344 & 10452 & 9523 & 8977 \\
RG & 33622 & 34562 & 34170 & 32893 & 31523 \\
CO & 68177 & 68081 & 66879 & 64408 & 60856 \\
CX & 26511775 & 29272982 & 26130936 & 22904290 & 21264936 \\
NG & 211359 & 164898 & 134337 & 124211 & 117082 \\
\hline
\end{tabular}

A-46. Thermal Usage

\begin{tabular}{|l|ccccc|}
\hline & 2010 & 2015 & 2020 & 2025 & 2030 \\
\hline$\%$ Thermal & $60 \%$ & $66 \%$ & $53 \%$ & $42 \%$ & $36 \%$ \\
Gas (EJ) & 0.606 & 0.814 & 0.636 & 0.519 & 0.486 \\
Billion $\left(\mathrm{m}^{\wedge} 3\right)$ & 16 & 21 & 17 & 14 & 13 \\
\hline
\end{tabular}

A-47. Cumulative Present Values 2006-2055 (1995 B.O.Y Million \$)

\begin{tabular}{|cccccc|}
\hline Production & Emission & Shortage & Fixed O\&M & Capital & Net Cost \\
64953 & 0 & 0 & 28601 & 56894 & 150449 \\
\hline
\end{tabular}

A-48. Market Revenues and Costs 2006-2055 (1995 B.O.Y. Million \$)

\begin{tabular}{|cccccc|}
\hline Energy & Commit & Spin & Total Rev. & Fuel & Var. O\&M \\
\hline & & & & & \\
287549 & 15550 & 2576 & 305676 & 62223 & 1377 \\
\hline
\end{tabular}

\begin{tabular}{|cccc|}
\hline Fixed O\&M & Capital & Total Cost & Ind. Profit \\
\hline & & & \\
28,601 & 56,894 & 149,096 & 156,579 \\
\hline
\end{tabular}


Figure A-9. Resource Mix Under Scenario DN

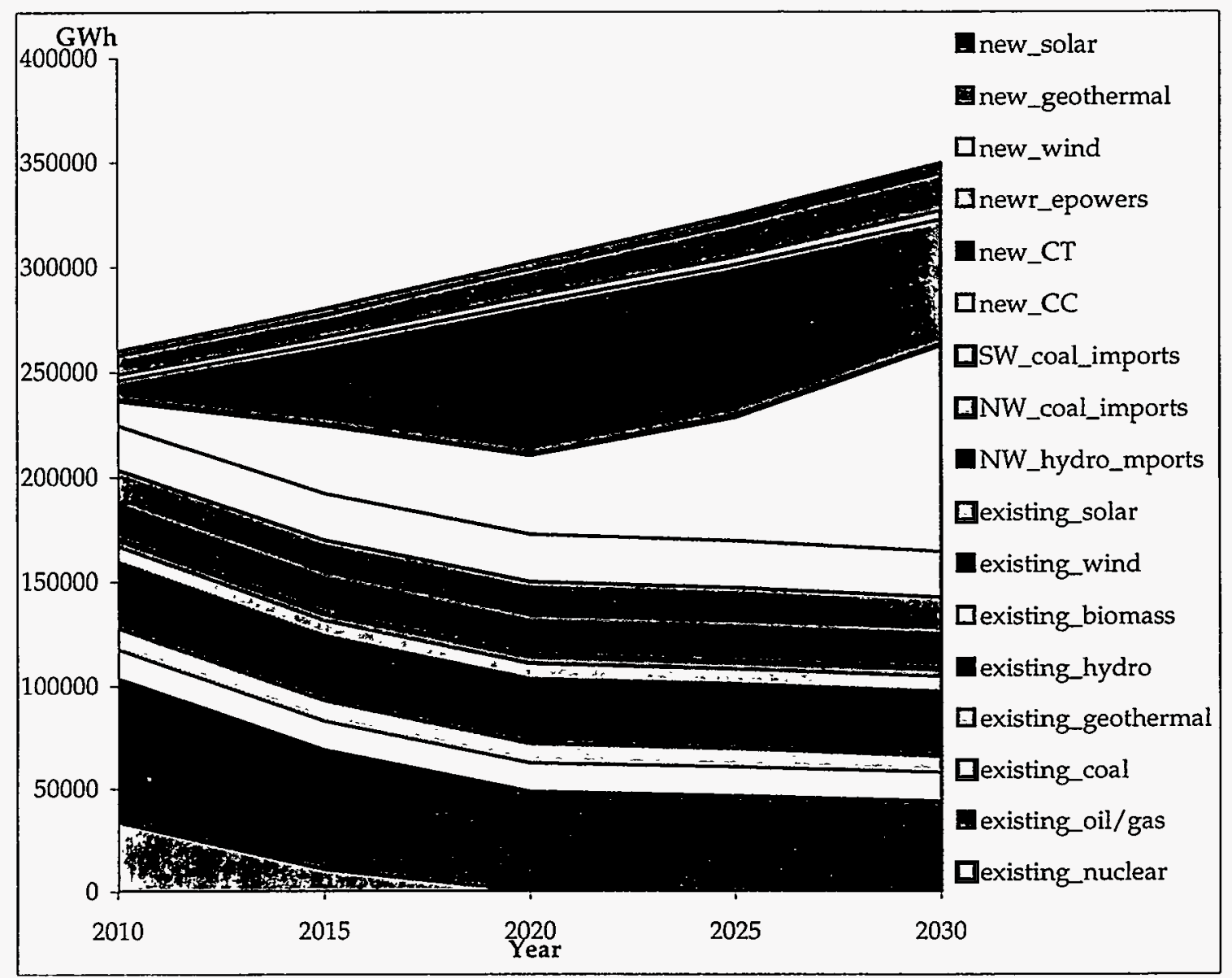


Table A-49. Resource Mix Under Scenario DN (GWh)

\begin{tabular}{|l|rrrrr|}
\hline & 2010 & 2015 & 2020 & 2025 & 2030 \\
\hline existing_nuclear & 33936 & 10960 & 0 & 0 & 0 \\
existing_oil/gas & 69866 & 57962 & 48560 & 46456 & 43900 \\
existing_coal & 14196 & 14083 & 14021 & 14086 & 14054 \\
existing_geotherm & 10438 & 9931 & 9413 & 8825 & 7820 \\
al & & & & & \\
existing_hydro & 31497 & 31507 & 31600 & 31508 & 31508 \\
existing_biomass & 7245 & 7245 & 7264 & 7245 & 7245 \\
existing_wind & 3069 & 3069 & 3076 & 3069 & 3069 \\
existing_solar & 911 & 911 & 913 & 911 & 911 \\
NW_hydro_mports & 16561 & 16575 & 16634 & 16575 & 16575 \\
NW_coal_imports & 15957 & 17716 & 18398 & 18153 & 17214 \\
SW_coal_imports & 21062 & 22237 & 22761 & 22551 & 21780 \\
new_CC & 11665 & 32404 & 37604 & 58859 & 98161 \\
new_CT & 1173 & 988 & 1004 & 1497 & 1028 \\
newr_epowers & 8806 & 37977 & 71286 & 71392 & 59040 \\
new_coal/nuke & 0 & 0 & 0 & 0 & 0 \\
new_biomass & 56 & 64 & 114 & 410 & 956 \\
new_wind & 2466 & 2958 & 3454 & 3942 & 4435 \\
new_geothermal & 8822 & 10379 & 12870 & 15147 & 17741 \\
new_solar & 2571 & 3225 & 3731 & 4458 & 5061 \\
Other & 26 & 97 & 63 & 213 & 0 \\
Pumped storage & 1043 & 478 & 378 & 411 & 737 \\
\hline
\end{tabular}

Tables A-50 through A-54. Key Indicators for Scenario DN A-50. Construction (units)

\begin{tabular}{|l|ccccc|}
\hline & 2010 & 2015 & 2020 & 2025 & 2030 \\
\hline CC & 7 & 19 & 22 & 34 & 57 \\
CT & 35 & 38 & 50 & 50 & 50 \\
Wind & 5 & 6 & 7 & 8 & 9 \\
Geo-thermal & 11 & 13 & 16 & 19 & 22 \\
Solar-thermal & 7 & 9 & 10 & 12 & 14 \\
PV & 9 & 10 & 12 & 14 & 15 \\
Bio & 6 & 6 & 8 & 9 & 10 \\
Repower & 5 & 23 & 38 & 38 & 38 \\
\hline
\end{tabular}


A-51. Emissions ( $\mathrm{t}$ )

\begin{tabular}{|l|ccccc|}
\hline & 2010 & 2015 & 2020 & 2025 & 2030 \\
\hline NO & 221040 & 224704 & 226766 & 227021 & 223665 \\
SU & 80959 & 84140 & 86072 & 85646 & 83984 \\
PM & 9070 & 11240 & 12989 & 14311 & 15893 \\
RG & 33118 & 34468 & 35551 & 36231 & 36495 \\
CO & 68923 & 68579 & 68504 & 69277 & 69138 \\
CX & 25066855 & 29260940 & 32596073 & 34721397 & 36949270 \\
NG & 245648 & 185091 & 134294 & 126077 & 126077 \\
\hline
\end{tabular}

A-52. Thermal Usage

\begin{tabular}{|l|ccccc|}
\hline & 2010 & 2015 & 2020 & 2025 & 2030 \\
\hline$\%$ Thermal & $55 \%$ & $65 \%$ & $70 \%$ & $72 \%$ & $73 \%$ \\
Gas (EJ) & 0.550 & 0.813 & 1.028 & 1.177 & 1.347 \\
Billion (m^3) & 14 & 21 & 27 & 31 & 35 \\
\hline
\end{tabular}

A-53. Cumulative Present Values 2006-2055 (1995 B.O.Y Million \$)

\begin{tabular}{|cccccc|}
\hline Production & Emission & Shortage & Fixed O\&M & Capital & Net Cost \\
\hline$\$ 88,168$ & $\$ 0$ & $\$ 0$ & $\$ 17,494$ & $\$ 42,719$ & $\$ 148,382$ \\
\hline
\end{tabular}

A-54. Market Revenues and Costs 2006-2055 (1995 B.O.Y. Million \$)

\begin{tabular}{|cccccc|}
\hline Energy & Commit & Spin & Total Rev. & Fuel & Var. O\&M \\
\hline & & & & & \\
$\$ 225,047$ & $\$ 12,396$ & $\$ 1,539$ & $\$ 238,983$ & $\$ 82,258$ & $\$ 4,469$ \\
\hline
\end{tabular}

\begin{tabular}{|cccc|}
\hline Fixed O\&M & Capital & Total Cost & Ind. Profit \\
\hline & & & \\
$\$ 17,494$ & $\$ 42,719$ & $\$ 146,941$ & $\$ 92,042$ \\
\hline
\end{tabular}


Figure A-10. Resource Mix Under Scenario DG

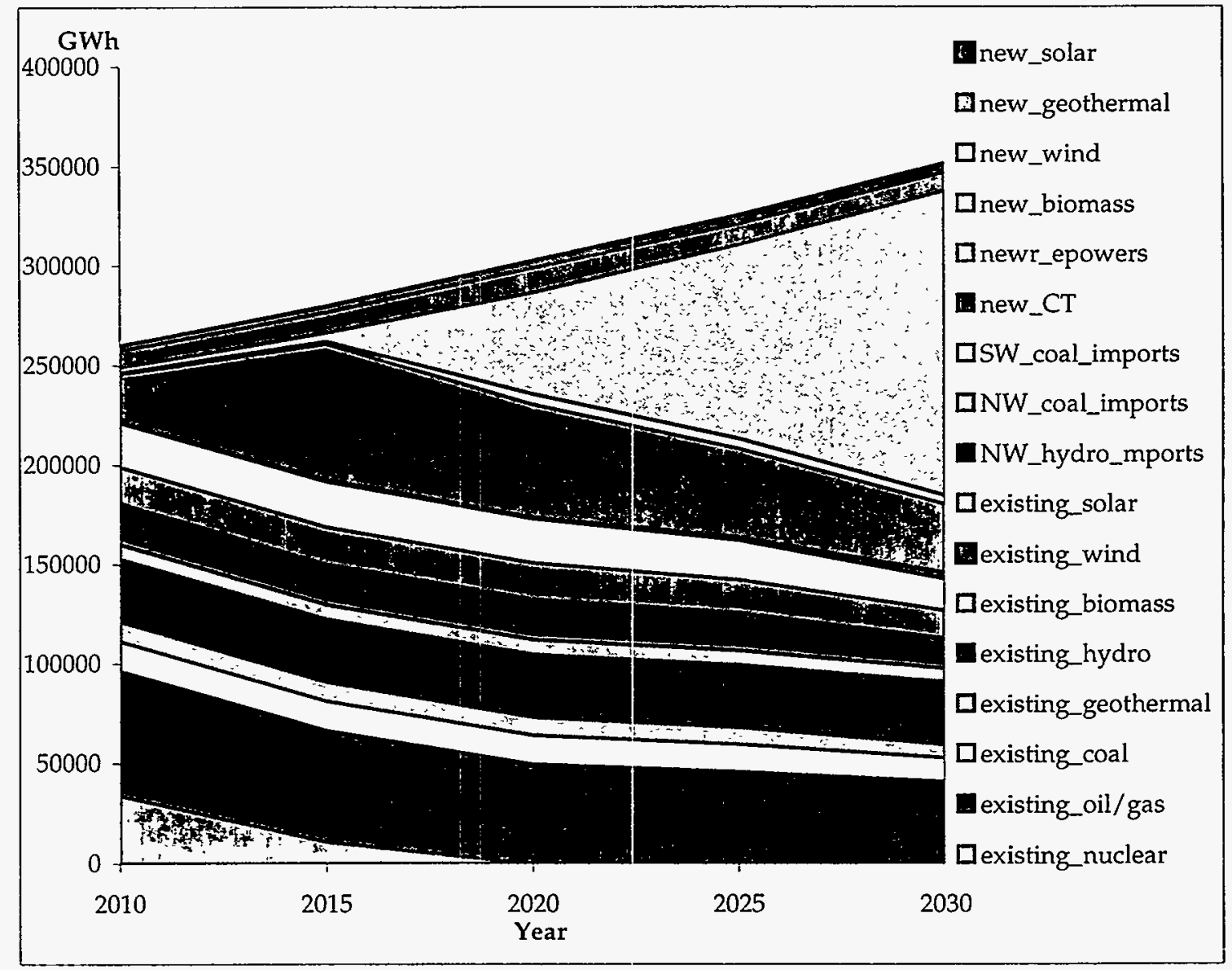


Table A-55. Resource Mix Under Scenario DG (GWh)

\begin{tabular}{|l|rrrrr|}
\hline & 2010 & 2015 & 2020 & 2025 & 2030 \\
\hline existing_nuclear & 33936 & 10960 & 0 & 0 & 0 \\
existing_oil/gas & 62368 & 55356 & 49348 & 45654 & 40695 \\
existing_coal & 14979 & 14734 & 14510 & 13867 & 11855 \\
existing_geotherm & 10257 & 9932 & 9305 & 8448 & 6910 \\
al & & & & & \\
existing_hydro & 31498 & 31506 & 31597 & 31497 & 31398 \\
existing_biomass & 7245 & 7245 & 7264 & 7229 & 6781 \\
existing_wind & 3069 & 3069 & 3076 & 3035 & 2713 \\
existing_solar & 911 & 911 & 913 & 907 & 877 \\
NW_hydro_mports & 16573 & 16575 & 16567 & 15091 & 11458 \\
NW_coal_imports & 18027 & 18464 & 18110 & 16501 & 14124 \\
SW_coal_imports & 22425 & 22774 & 22096 & 19932 & 15693 \\
new_CC & 0 & 0 & 0 & 0 & 0 \\
new_CT & 632 & 1202 & 936 & 1894 & 3460 \\
newr_epowers & 24019 & 68169 & 56596 & 44114 & 33968 \\
new_coal/nuke & 0 & 0 & 0 & 0 & 0 \\
new_biomass & 651 & 1399 & 5254 & 4959 & 4403 \\
new_wind & 2466 & 4436 & 51144 & 97795 & 153679 \\
new_geothermal & 8663 & 10136 & 12240 & 10256 & 9094 \\
new_solar & 2680 & 3302 & 3833 & 4569 & 4670 \\
Other & 1 & 90 & 162 & 11 & 11 \\
Pumped storage & 1199 & 380 & 1007 & 1800 & 2384 \\
\hline
\end{tabular}

Tables A-56 through A-60. Key Indicators for Scenario DG

A-56. Construction (units)

\begin{tabular}{|l|ccccc|}
\hline & 2010 & 2015 & 2020 & 2025 & 2030 \\
\hline & & & & & \\
CC & 0 & 0 & 0 & 0 & 0 \\
CT & 41 & 44 & 44 & 44 & 44 \\
Wind & 5 & 9 & 104 & 200 & 316 \\
Geo-thermal & 11 & 13 & 16 & 19 & 22 \\
Solar-thermal & 7 & 9 & 10 & 12 & 14 \\
PV & 9 & 10 & 12 & 14 & 15 \\
Repower & 12 & 31 & 33 & 33 & 33 \\
\hline
\end{tabular}


A-57. Emissions (t)

\begin{tabular}{|l|ccccc|}
\hline & 2010 & 2015 & 2020 & 2025 & 2030 \\
\hline NO & 226815 & 228363 & 229180 & 220215 & 195893 \\
SU & 86232 & 86459 & 85440 & 79507 & 66336 \\
PM & 10030 & 12967 & 17226 & 16080 & 14212 \\
RG & 33175 & 34497 & 34431 & 33787 & 31659 \\
CO & 67958 & 68496 & 68283 & 67075 & 62160 \\
CX & 25101437 & 29310753 & 27044122 & 24325920 & 20775604 \\
NG & 217551 & 173320 & 133604 & 125987 & 117704 \\
\hline
\end{tabular}

A-58. Thermal Usage

\begin{tabular}{|l|ccccc|}
\hline & 2010 & 2015 & 2020 & 2025 & 2030 \\
\hline$\%$ Thermal & $54 \%$ & $64 \%$ & $53 \%$ & $43 \%$ & $34 \%$ \\
Gas (EJ) & 0.500 & 0.787 & 0.630 & 0.502 & 0.410 \\
Billion $\left(\mathrm{m}^{\wedge} 3\right)$ & 13 & 21 & 16 & 13 & 11 \\
\hline
\end{tabular}

A-59. Cumulative Present Values 2006-2055 (1995 B.O.Y Million \$)

\begin{tabular}{|lccccc|}
\hline Production & Emission & Shortage & Fixed O\&M & Capital & Net Cost \\
\hline 65,670 & $\$ 0$ & $\$ 0$ & $\$ 31,942$ & $\$ 64,578$ & $\$ 162,191$ \\
\hline
\end{tabular}

A-60. Market Revenues and Costs 2006-2055 (1995 B.O.Y. Million \$)

\begin{tabular}{|c|c|c|c|c|c|}
\hline Energy & Commit & Spin & Total Rev. & Fuel & Var. O\&M \\
\hline$\$ 250,817$ & $\$ 19,678$ & $\$ 1,872$ & $\$ 272,368$ & $\$ 61,281$ & $\$ 3,771$ \\
\hline & Fixed O\&M & Capital & Total Cost & Ind. Profit & \\
\hline & $\$ 31,942$ & $\$ 64,578$ & $\$ 161,576$ & $\$ 110,794$ & \\
\hline
\end{tabular}


Figure A-11. Resource Mix Under Scenario DB

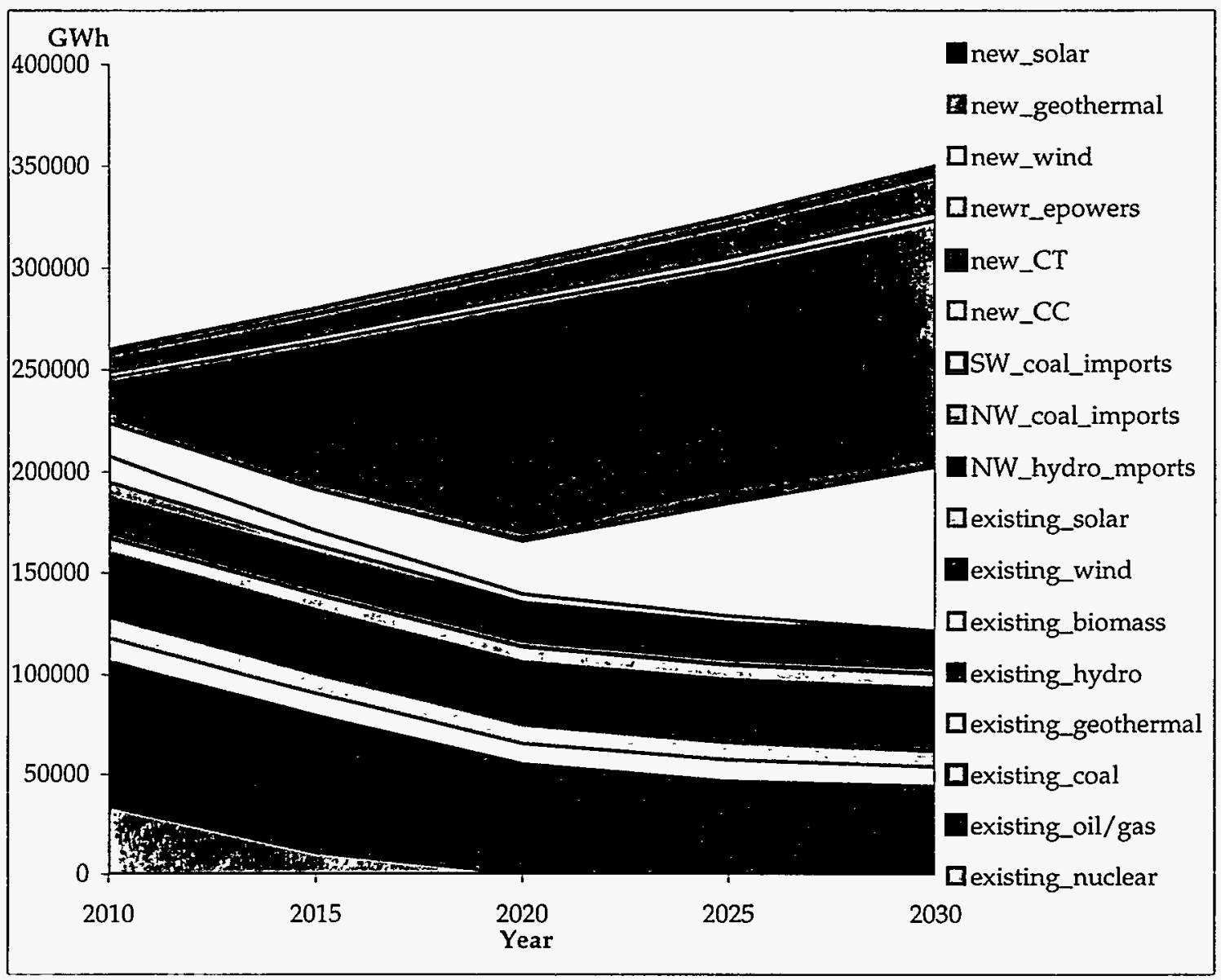


Table A-61. Resource Mix Under Scenario DB (GWh)

\begin{tabular}{|l|rrrrr|}
\hline & 2010 & 2015 & 2020 & 2025 & 2030 \\
\hline existing_nuclear & 33936 & 10960 & 0 & 0 & 0 \\
existing_oil/gas & 72706 & 68045 & 54786 & 46452 & 43900 \\
existing_coal & 11507 & 11423 & 10471 & 10671 & 9912 \\
existing_geotherm & 10439 & 9938 & 9414 & 8826 & 7820 \\
al & & & & & \\
existing_hydro & 31502 & 31504 & 31593 & 31507 & 31510 \\
existing_biomass & 7245 & 7245 & 7264 & 7245 & 7245 \\
existing_wind & 3069 & 3069 & 3076 & 3069 & 3069 \\
existing_solar & 911 & 911 & 913 & 911 & 911 \\
NW_hydro_mports & 16563 & 16575 & 16634 & 16575 & 16575 \\
NW_coal_imports & 7299 & 3777 & 1197 & 736 & 139 \\
SW_coal_imports & 12400 & 7395 & 3929 & 2755 & 377 \\
new_CC & 16421 & 20338 & 26331 & 55724 & 81146 \\
new_CT & 479 & 407 & 1558 & 4722 & 1473 \\
newr_epowers & 21790 & 72008 & 115547 & 112356 & 119305 \\
new_coal/nuke & 0 & 0 & 0 & 0 & 0 \\
new_biomass & 11 & 18 & 12 & 34 & 13 \\
new_wind & 2466 & 2958 & 3454 & 3942 & 4436 \\
new_geothermal & 8880 & 10494 & 12951 & 15337 & 17759 \\
new_solar & 2551 & 3148 & 3606 & 4354 & 4846 \\
Other & 1 & 37 & 14 & 59 & 11 \\
Pumped storage & 492 & 364 & 361 & 366 & 373 \\
\hline
\end{tabular}

Tables A-62 through A-66. Key Indicators for Scenario DB

A-62. Construction (units)

\begin{tabular}{|l|ccccc|}
\hline & 2010 & 2015 & 2020 & 2025 & 2030 \\
\hline & & & & & \\
CC & 10 & 12 & 15 & 32 & 50 \\
CT & 27 & 30 & 42 & 42 & 42 \\
Wind & 5 & 6 & 7 & 8 & 9 \\
Geo-thermal & 11 & 13 & 16 & 19 & 22 \\
Solar-thermal & 7 & 9 & 10 & 12 & 14 \\
PV & 9 & 10 & 12 & 14 & 15 \\
Repower & 11 & 30 & 45 & 45 & 57 \\
\hline
\end{tabular}


A-63. Emissions ( $t$ )

\begin{tabular}{|l|ccccc|}
\hline & 2010 & 2015 & 2020 & 2025 & 2030 \\
\hline NO & 189864 & 175807 & 164275 & 160946 & 152254 \\
SU & 56089 & 46659 & 36735 & 35766 & 28834 \\
PM & 8923 & 11030 & 12834 & 14009 & 14803 \\
RG & 33361 & 34972 & 36272 & 36834 & 37165 \\
CO & 69468 & 70851 & 70579 & 70233 & 69897 \\
CX & 23689766 & 27619192 & 30430917 & 32398537 & 34269989 \\
NG & 263281 & 219570 & 148020 & 126077 & 126077 \\
\hline
\end{tabular}

A-64. Thermal Usage

\begin{tabular}{|l|ccccc|}
\hline & 2010 & 2015 & 2020 & 2025 & 2030 \\
\hline$\%$ Thermal & $55 \%$ & $65 \%$ & $71 \%$ & $72 \%$ & $73 \%$ \\
Gas (EJ) & 0.704 & 1.085 & 1.370 & 1.524 & 1.711 \\
Billion $\left(\mathrm{m}^{\wedge} 3\right)$ & 18 & 28 & 36 & 40 & 45 \\
\hline
\end{tabular}

A-65. Cumulative Present Values 2006-2055 (1995 B.O.Y Million \$)

\begin{tabular}{|cccccc|}
\hline Production & Emission & Shortage & Fixed O\&M & Capital & Net Cost \\
\hline$\$ 62,600$ & $\$ 0$ & $\$ 0$ & $\$ 17,637$ & $\$ 44,212$ & $\$ 124,450$ \\
\hline
\end{tabular}

A-66. Market Revenues and Costs 2006-2055 (1995 B.O.Y. Million \$)

\begin{tabular}{|c|c|c|c|c|c|}
\hline Energy & Commit & Spin & Total Rev. & Fuel & Var. O\&M \\
\hline$\$ 156,848$ & $\$ 15,364$ & $\$ 1,023$ & $\$ 173,237$ & $\$ 55,630$ & $\$ 6,659$ \\
\hline
\end{tabular}

\begin{tabular}{|cccc|}
\hline Fixed O\&M & Capital & Total Cost & Ind. Profit \\
\hline & & & \\
$\$ 17,637$ & $\$ 44,212$ & $\$ 124,139$ & $\$ 49,097$ \\
\hline
\end{tabular}


Figure A-12. Resource Mix Under Scenario HN

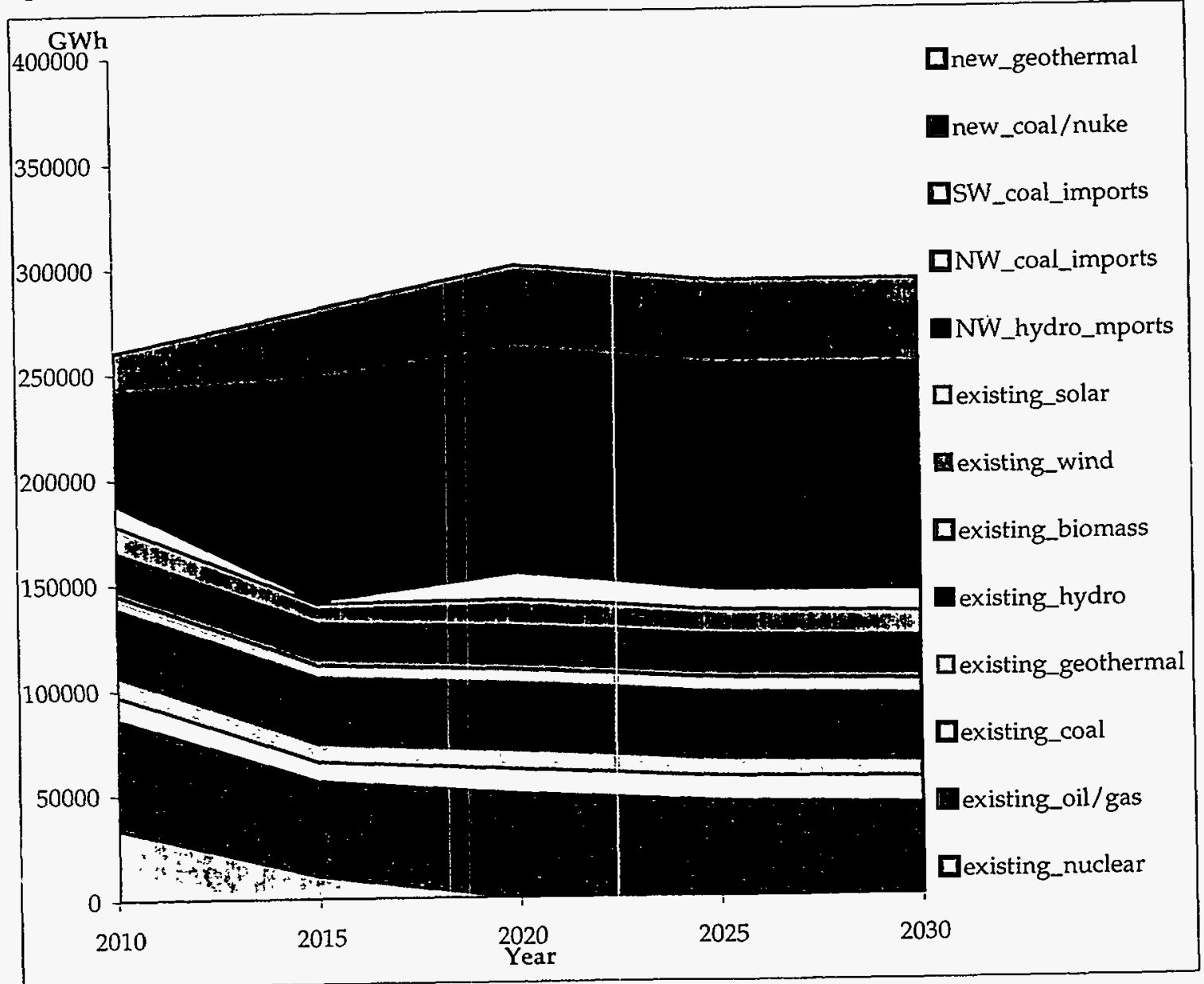


Table A-67. Resource Mix Under Scenario HN (GWh)

\begin{tabular}{|l|rrrrr|}
\hline & 2010 & 2015 & 2020 & 2025 & 2030 \\
\hline existing_nuclear & 33936 & 10960 & 0 & 0 & 0 \\
existing_oil/gas & 52360 & 45144 & 49455 & 45072 & 43466 \\
existing_coal & 10921 & 9347 & 11826 & 12003 & 12610 \\
existing_geotherm & 9961 & 8817 & 9062 & 8585 & 7813 \\
al & & & & & \\
existing_hydro & 31498 & 31494 & 31586 & 31489 & 31462 \\
existing_biomass & 6536 & 5684 & 6486 & 6762 & 7023 \\
existing_wind & 3069 & 3063 & 3075 & 3069 & 3069 \\
existing_solar & 911 & 909 & 912 & 910 & 911 \\
NW_hydro_mports & 16552 & 15778 & 16575 & 16558 & 16568 \\
NW_coal_imports & 12502 & 9258 & 12750 & 11447 & 11586 \\
SW_coal_imports & 10254 & 1404 & 12555 & 9810 & 10600 \\
new_CC & 0 & 0 & 0 & 29907 & 53072 \\
new_CT & 0 & 0 & 0 & 0 & 0 \\
newr_epowers & 0 & 0 & 0 & 0 & 0 \\
new_coal/nuke & 53290 & 105530 & 106740 & 106914 & 107358 \\
new_biomass & 0 & 0 & 0 & 0 & 0 \\
new_wind & 0 & 0 & 0 & 0 & 0 \\
new_geothermal & 18848 & 33244 & 39663 & 39931 & 40107 \\
new_solar & 0 & 0 & 0 & 0 & 0 \\
Other & 81 & 462 & 2202 & 2174 & 2353 \\
Pumped storage & 1884 & 2527 & 2502 & 2342 & 2473 \\
\hline
\end{tabular}

Tables A-68 through A-72. Key Indicators for Scenario HN

A-68. Construction (units)

\begin{tabular}{|l|ccccc|}
\hline & 2010 & 2015 & 2020 & 2025 & 2030 \\
\hline CC & 0 & 0 & 0 & 22 & 38 \\
CT & 0 & 0 & 0 & 0 & 0 \\
Wind & 0 & 0 & 0 & 0 & 0 \\
Geo-thermal & 25 & 50 & 50 & 50 & 50 \\
Solar-thermal & 0 & 0 & 0 & 0 & 0 \\
PV & 0 & 0 & 0 & 0 & 0 \\
Nuclear & 12 & 24 & 24 & 24 & 24 \\
Repower & 0 & 0 & 0 & 0 & 0 \\
\hline
\end{tabular}


A-69. Emissions ( $t$ )

\begin{tabular}{|l|ccccc|}
\hline & 2010 & 2015 & 2020 & 2025 & 2030 \\
\hline NO & 177294 & 138479 & 184038 & 180111 & 184892 \\
SU & 54490 & 35160 & 60033 & 56308 & 59132 \\
PM & 6486 & 5240 & 6637 & 7909 & 9034 \\
RG & 30232 & 27665 & 30389 & 31796 & 32777 \\
CO & 59002 & 50883 & 58308 & 60912 & 63005 \\
CX & 16421002 & 12220729 & 16840799 & 18903321 & 21679018 \\
NG & 174045 & 140593 & 140219 & 125327 & 125830 \\
\hline
\end{tabular}

A-70. Thermal Usage

\begin{tabular}{|l|ccccc|}
\hline & 2010 & 2015 & 2020 & 2025 & 2030 \\
\hline$\%$ Thermal & $53 \%$ & $60 \%$ & $63 \%$ & $66 \%$ & $68 \%$ \\
Gas (EJ) & 0.230 & 0.165 & 0.176 & 0.360 & 0.519 \\
Billion $\left(\mathrm{m}^{\wedge} 3\right)$ & 6 & 4 & 5 & 9 & 14 \\
\hline
\end{tabular}

A-71. Cumulative Present Values 2006-2055 (1995 B.0.Y Million \$)

\begin{tabular}{|cccccc|}
\hline Production & Emission & Shortage & Fixed O\&M & Capital & Net Cost \\
\hline$\$ 138,631$ & $\$ 0$ & $\$ 0$ & $\$ 31,207$ & $\$ 67,351$ & $\$ 237,190$ \\
\hline
\end{tabular}

A-72. Market Revenues and Costs 2006-2055 (1995 B.O.Y. Million \$)

\begin{tabular}{|c|c|c|c|c|c|}
\hline Energy & Commit & Spin & Total Rev. & Fuel & Var. O\&M \\
\hline$\$ 1,481,163$ & $\$ 10,646$ & $\$ 8,291$ & $\$ 1,500,101$ & $\$ 79,304$ & $\$ 5,852$ \\
\hline
\end{tabular}

\begin{tabular}{|cccc|}
\hline Fixed O\&M & Capital & Total Cost & Ind. Profit \\
\hline & & & \\
$\$ 31,207$ & $\$ 67,351$ & $\$ 183,716$ & $\$ 1,316,384$ \\
\hline
\end{tabular}


Figure A-13. Resource Mix Under Scenario HG

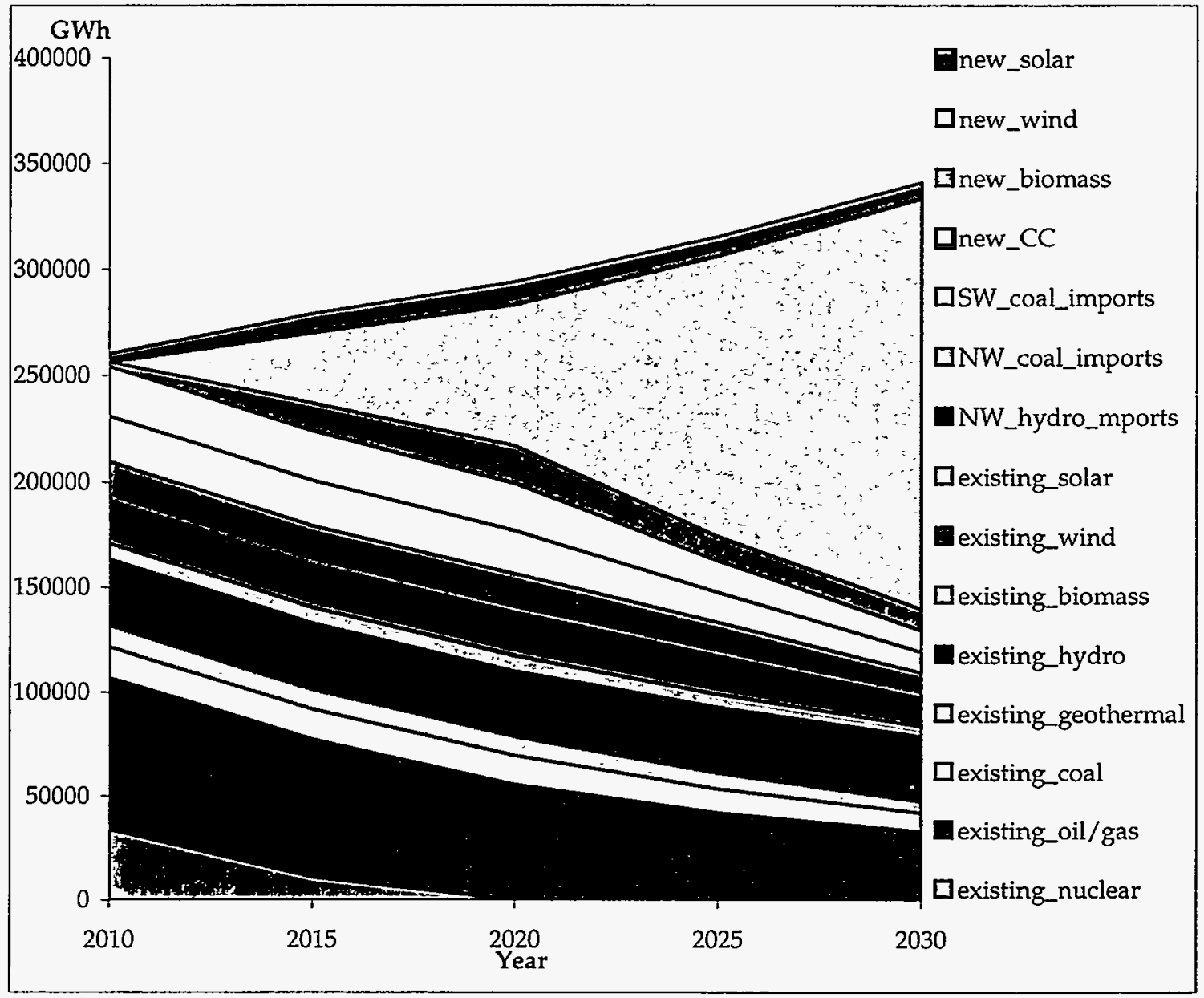


Table A-73. Resource Mix Under Scenario HG (GWh)

\begin{tabular}{|l|rrrrr|}
\hline & 2010 & 2015 & 2020 & 2025 & 2030 \\
\hline existing_nuclear & 33936 & 10960 & 0 & 0 & 0 \\
existing_oil/gas & 73172 & 66415 & 55672 & 41930 & 32831 \\
existing_coal & 14869 & 14470 & 14055 & 11665 & 9109 \\
existing_geotherm & 10051 & 9661 & 9184 & 7763 & 5816 \\
al & & & & & \\
existing_hydro & 31496 & 31498 & 31444 & 31322 & 31081 \\
existing_biomass & 7244 & 7236 & 7151 & 6122 & 4797 \\
existing_wind & 3069 & 3069 & 3076 & 2972 & 2348 \\
existing_solar & 911 & 911 & 913 & 897 & 744 \\
NW_hydro_mports & 16575 & 16575 & 16633 & 14960 & 10590 \\
NW_coal_imports & 18456 & 18412 & 18261 & 15639 & 12296 \\
SW_coal_imports & 21161 & 21569 & 20690 & 14299 & 9889 \\
new_CC & 23352 & 23201 & 22252 & 15290 & 10156 \\
new_CT & 0 & 0 & 0 & 0 & 0 \\
newr_epowers & 0 & 0 & 0 & 0 & 0 \\
new_coal/nuke & 0 & 0 & 0 & 0 & 0 \\
new_biomass & 2187 & 12831 & 17639 & 11412 & 10064 \\
new_wind & 0 & 33437 & 66609 & 132283 & 194198 \\
new_geothermal & 0 & 0 & 0 & 0 & 0 \\
new_solar & 3929 & 8949 & 10642 & 8871 & 7378 \\
Other & 136 & 1293 & 1093 & 1004 & 493 \\
Pumped storage & 1756 & 1948 & 2612 & 2516 & 2763 \\
\hline
\end{tabular}

Tables A-74 through A-78. Key Indicators for Scenario HG

A-74. Construction (units)

\begin{tabular}{|l|ccccc|}
\hline & 2010 & 2015 & 2020 & 2025 & 2030 \\
\hline CC & 15 & 15 & 15 & 15 & 15 \\
CT & 0 & 0 & 0 & 0 & 0 \\
Wind & 0 & 68 & 136 & 272 & 408 \\
Geo-thermal & 0 & 0 & 0 & 0 & 0 \\
Solar-thermal & 15 & 30 & 30 & 30 & 30 \\
PV & 0 & 0 & 0 & 0 & 0 \\
Bio & 36 & 36 & 36 & 36 & 36 \\
Repower & 0 & 0 & 0 & 0 & 0 \\
\hline
\end{tabular}


A-75. Emissions ( $t)$

\begin{tabular}{|l|ccccc|}
\hline & 2010 & 2015 & 2020 & 2025 & 2030 \\
\hline NO & 227143 & 235185 & 235545 & 194649 & 157271 \\
SU & 84625 & 85514 & 83694 & 65490 & 49612 \\
PM & 12019 & 25513 & 31403 & 21793 & 18457 \\
RG & 33367 & 33943 & 33969 & 30357 & 26375 \\
CO & 70398 & 71924 & 71027 & 58286 & 45590 \\
CX & 26127316 & 25570417 & 23991051 & 18147924 & 13770713 \\
NG & 246190 & 197899 & 148432 & 116535 & 96503 \\
\hline
\end{tabular}

\section{A-76. Thermal Usage}

\begin{tabular}{|l|ccccc|}
\hline & 2010 & 2015 & 2020 & 2025 & 2030 \\
\hline$\%$ Thermal & $58 \%$ & $51 \%$ & $44 \%$ & $31 \%$ & $22 \%$ \\
Gas (EJ) & 0.597 & 0.513 & 0.399 & 0.237 & 0.155 \\
Billion $\left(\mathrm{m}^{\wedge} 3\right.$ ) & 16 & 13 & 10 & 6 & 4 \\
\hline
\end{tabular}

A-77. Cumulative Present Values 2006-2055 (1995 B.O.Y Million \$)

\begin{tabular}{|cccccc|}
\hline Production & Emission & Shortage & Fixed O\&M & Capital & Net Cost \\
\hline & & & & & \\
$\$ 144,646$ & $\$ 0$ & $\$ 0$ & $\$ 37,222$ & $\$ 75,953$ & $\$ 257,823$ \\
\hline
\end{tabular}

A-78. Market Revenues and Costs 2006-2055 (1995 B.O.Y. Million \$)

\begin{tabular}{|cccccc|}
\hline Energy & Commit & Spin & Total Rev. & Fuel & Var. O\&M \\
\hline & & & & & \\
$\$ 1,306,863$ & $\$ 21,987$ & $\$ 7,084$ & $\$ 1,335,935$ & $\$ 61,939$ & $\$ 3,442$ \\
\hline
\end{tabular}

\begin{tabular}{|cccc|}
\hline Fixed O\&M & Capital & Total Cost & Ind. Profit \\
\hline & & & \\
$\$ 37,222$ & $\$ 75,953$ & $\$ 178,558$ & $\$ 1,157,377$ \\
\hline
\end{tabular}


Figure A-14. Resource Mix Under Scenario HB3

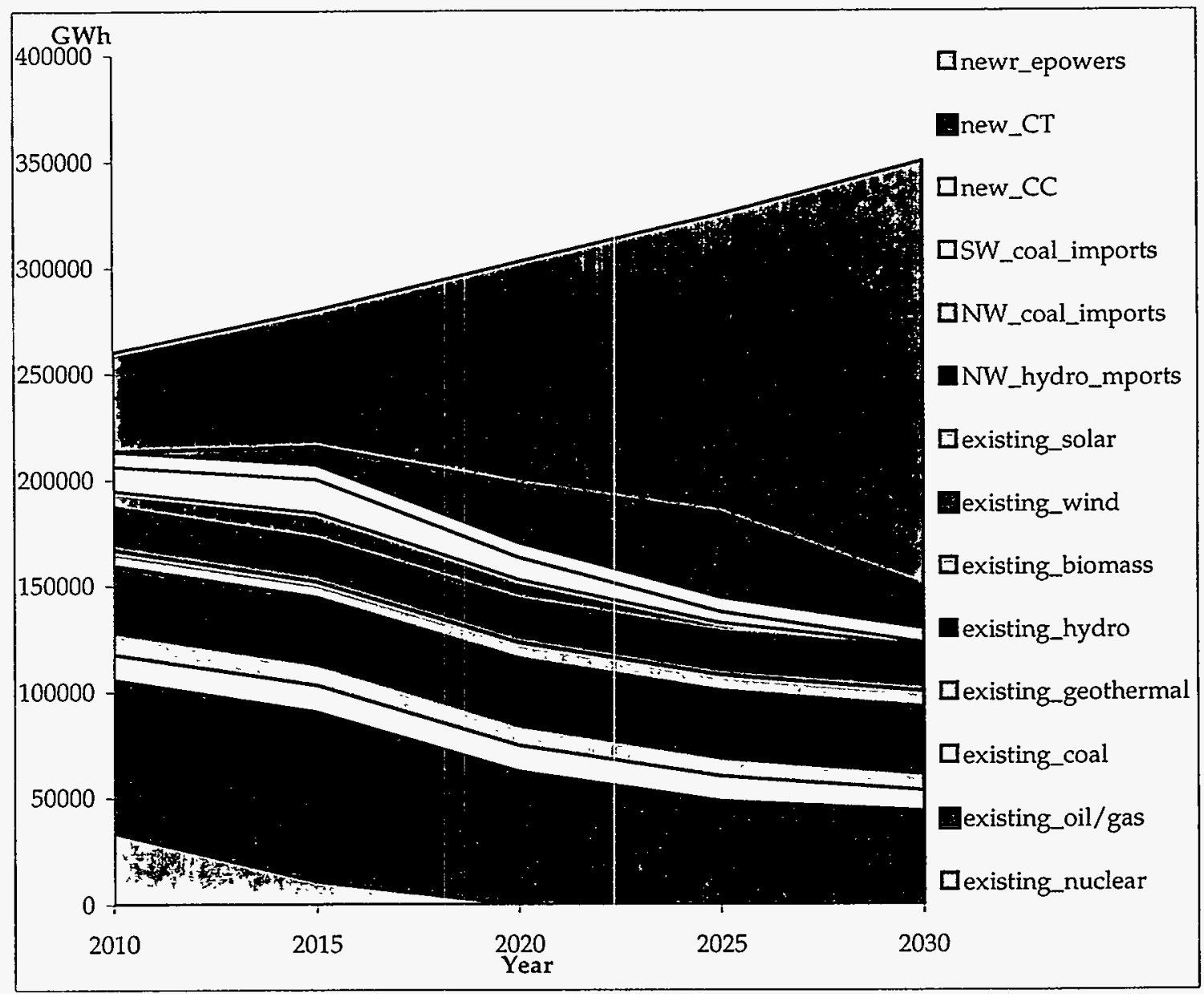


Table A-79. Resource Mix Under Scenario HB (GWh)

\begin{tabular}{|l|rrrrr|}
\hline & 2010 & 2015 & 2020 & 2025 & 2030 \\
\hline existing_nuclear & 33936 & 10960 & 0 & 0 & 0 \\
existing_oil/gas & 71895 & 79705 & 62461 & 48414 & 43900 \\
existing_coal & 11898 & 12605 & 12433 & 11772 & 9666 \\
existing_geotherm & 10484 & 9940 & 9414 & 8827 & 7820 \\
al & & & & & \\
existing_hydro & 31506 & 31510 & 31601 & 31510 & 31511 \\
existing_biomass & 7245 & 7245 & 7264 & 7245 & 7244 \\
existing_wind & 3069 & 3069 & 3076 & 3069 & 3069 \\
existing_solar & 911 & 911 & 913 & 911 & 911 \\
NW_hydro_mports & 16575 & 16575 & 16634 & 16575 & 16575 \\
NW_coal_imports & 7349 & 11844 & 8906 & 4171 & 1089 \\
SW_coal_imports & 11619 & 16017 & 10664 & 5027 & 1338 \\
new_CC & 6996 & 7002 & 7022 & 7002 & 6740 \\
new_CT & 258 & 8623 & 27816 & 40026 & 20340 \\
newr_epowers & 46391 & 64208 & 104526 & 140646 & 200131 \\
new_coal/nuke & 0 & 0 & 0 & 0 & 0 \\
new_biomass & 0 & 0 & 0 & 0 & 0 \\
new_wind & 0 & 0 & 0 & 0 & 0 \\
new_geothermal & 0 & 0 & 0 & 0 & 0 \\
new_solar & 0 & 0 & 0 & 0 & 0 \\
Other & 1 & 31 & 29 & 90 & 34 \\
Pumped storage & 371 & 363 & 362 & 362 & 361 \\
\hline
\end{tabular}

Tables A-80 through A-84. Key Indicators for Scenario HB

A-80. Construction (units)

\begin{tabular}{|l|ccccc|}
\hline & 2010 & 2015 & 2020 & 2025 & 2030 \\
\hline CC & 4 & 4 & 4 & 4 & 4 \\
CT & 27 & 77 & 102 & 102 & 102 \\
Wind & 0 & 0 & 0 & 0 & 0 \\
Geo-thermal & 0 & 0 & 0 & 0 & 0 \\
Solar-thermal & 0 & 0 & 0 & 0 & 0 \\
PV & 0 & 0 & 0 & 0 & 0 \\
Bio & 0 & 0 & 0 & 0 & 0 \\
Repower & 22 & 22 & 34 & 46 & 70 \\
\hline
\end{tabular}


A-81. Emissions ( $\mathrm{t}$ )

\begin{tabular}{|l|ccccc|}
\hline & 2010 & 2015 & 2020 & 2025 & 2030 \\
\hline NO & 188540 & 205647 & 191219 & 172346 & 155255 \\
SU & 56669 & 68563 & 58087 & 44900 & 29989 \\
PM & 9588 & 11591 & 14137 & 15875 & 16535 \\
RG & 33742 & 35140 & 36973 & 38063 & 38241 \\
CO & 69777 & 72809 & 72989 & 72329 & 71084 \\
CX & 25006726 & 31144145 & 35011739 & 37259209 & 38481713 \\
NG & 266286 & 234874 & 161701 & 126077 & 126077 \\
\hline
\end{tabular}

A-82. Thermal Usage

\begin{tabular}{|l|ccccc|}
\hline & 2010 & 2015 & 2020 & 2025 & 2030 \\
\hline$\%$ Thermal & $60 \%$ & $71 \%$ & $77 \%$ & $79 \%$ & $81 \%$ \\
Gas (EJ) & 0.818 & 1.132 & 1.514 & 1.811 & 2.018 \\
Billion $\left(\mathrm{m}^{\wedge} 3\right)$ & 21 & 30 & 40 & 47 & 53 \\
\hline
\end{tabular}

A-83. Cumulative Present Values 2006-2055 (1995 B.O.Y Million \$)

\begin{tabular}{|cccccc|}
\hline Production & Emission & Shortage & Fixed O\&M & Capital & Net Cost \\
\hline$\$ 71,130$ & $\$ 0$ & $\$ 0$ & $\$ 10,171$ & $\$ 21,110$ & $\$ 102,412$ \\
\hline
\end{tabular}

A-84. Market Revenues and Costs 2006-2055 (1995 B.O.Y. Million \$)

\begin{tabular}{|cccccc|}
\hline Energy & Commit & Spin & $\begin{array}{c}\text { Total } \\
\text { Revenue }\end{array}$ & Fuel & $\begin{array}{c}\text { Variable } \\
\text { O\&M }\end{array}$ \\
\hline$\$ 168,077$ & $\$ 14,713$ & $\$ 1,544$ & $\$ 184,335$ & $\$ 62,202$ & $\$ 8,561$ \\
\hline
\end{tabular}

\begin{tabular}{|llll|}
\hline Fixed O\&M & Capital & Total Cost & Profit \\
\hline & & & \\
$\$ 10,171$ & $\$ 21,110$ & $\$ 102,046$ & $\$ 82,288$ \\
\hline
\end{tabular}




\section{The Expansion Planning Logic of Elfin}

\section{B.1 Traditional Cost-Minimizing Capacity Expansion Planning}

The tradition of electric utility expansion planning using production cost models is based on the paradigm of the centralized, vertically integrated company, and applies cost-minimizing assumptions. The objective function is a grand net present cost function, $\mathrm{C}$, which is the discounted cost of all utility operations from the beginning to the end of the planning period at time T. This cost function is the sum of several components as follows:

$$
C=\sum_{t=1}^{T}\left[\frac{\sum_{n=1}^{N} c^{g}{ }_{n, t}+c^{u}{ }_{t}+c^{e}{ }_{t}}{(1+d)^{t}}\right]
$$

Within the Elfin context, $C$ can be considered total net present cost, and $c_{n, t}^{g}$ as the costs of running various $n$ generating assets available to system. The denominator is the familar discounting term at a discount rate of $d$. The social cost of leaving energy unserved, that is, of letting the lights go out, is $c^{\mu}{ }_{r}$. Within traditional dispatch logic, resources are dispatched to meet load irrespective of cost. That is, demand is seen as fixed, and the need to meet it as absolute. No demand response of any type exists, although an interruptible load might be considered a supply-side asset. In other words, $c^{\mu}{ }_{t}$ does not appear in the dispatch cost function meaning service cannot be interrupted on economic grounds alone. Elfin, unlike most expansion planning models, takes a more social welfare oriented approach to expansion planning. New capacity is built only if and only if it lowers cost, including the cost of not serving customers. Unserved load is treated no differently than other costs. The external costs of power generation, such as uninternalized environmental damage is represented by $c^{e}$. These costs can be included in Elfin simulations if, appropriate values are specified by the user.

Each $c_{n, t}^{\mathrm{g}}$ term can be thought of as a sum of the various elements of operating cost for a generator. These costs are normally summarized by categories of costs as follows:

$$
c_{n, t}^{\mathrm{g}}=\text { fuel costs + variable O\&M (including labor) + fixed O\&M + capital costs + other }
$$

The other category can be a negative, if, for example, there is some subsidy, such as a renewables production credit, for which the resource is eligible. 


\section{B.2 The MC-ITRE Algorithm}

In expansion planning, keeping the search area within the limits of computational tractability is accomplished by representing potential new additions as a small number of generic alternatives. Elfin uses multiple algorithms for solving the expansion planning problem but here we focus on just one alternative, MC-ITRE. The MC-ITRE algorithm searches on the $C$ cost surface as follows:

1. A table is built of the per MW net present value (NPV) of adding or deleting each generic resource in each year of the planning period.

2. Elfin adds new units up to a user-specified limit of the available expansion options.

3. Elfin then recalculates the table with the chosen additions in place. This operation completes one iteration.

4. The next iteration is commenced and Elfin again searches for cost reducing additions and reductions. On this and all subsequent iterations, Elfin also tests the benefits of deleting prior additions from the plan.

5. When no further cost reducing additions or deletions can be found, searching ceases. However, the final lowest cost plan is further tested by swapping in and out construction choices to verify that the plan is truly is lowest cost.

This search algorithm has proven to be quite stable and efficient. Some tricks are used to avoid getting trapped in a local cost minimum, but, in general, costs fall quickly as the iterations progress and a minimum is found that can be verified to be a reasonable minimum by the simple swapping of resource options in search of lower costs.

\section{B.3 Towards a Competitive Expansion Logic}

While traditional dispatch logic may persist in competitive market systems, clearly, expansion decision making will be performed in quite a different way from what the current centralized utility paradigm encourages. Investment decision making will be decentralized and based on individual investor returns rather than net present system operating cost. The goal here is to move Elfin's expansion planning logic incrementally towards a credible model of a competitive market system, of the kind proposed for California. The key change made to Elfin's expansion planning logic for the purposes of this study is a move away from the omnipotent centralized cost minimizing view of the old logic and towards a competitive paradigm driven by the decentralized entry decisions of new generating technologies. Remembering that the intent of expansion planning models is not the accurate simulation of 
actual operations, but rather the approximation of outcomes at a level sufficient only for mid to long run forecasting (beyond 5 years), and that computational burdens must be kept to a minimum to enable lengthy search procedures to complete, the basic logic of the approach is three-pronged.

1. It is assumed that either an ISO will continue to run system unit commitment and dispatch in a similar way as territorial utilities operate today, or competitive pressure will lead towards similar minimum cost solutions. Therefore, simulation of actual operations need be only modestly revised. (Section 4 , below.)

2. The most important determinant of capacity construction under a competitive regime is free entry as far as is profitable. (Section 5 , below.)

3. The search algorithm must be similar to the current one so that changes to Elfin are manageable and understandable. (Section 7, below.)

\section{B.4 Market Dispatch Logic}

A key initial assumption made here is that overall unit commitment and dispatch will tend towards the same sort of result current models would achieve for the same system and demand; that is, the cost minimum solution subject to constraints imposed by limits on various operations will be the outcome of both traditional and ISO dispatch unit commitment. The significant difference is the manner in which investments in new capacity are made. Elfin does not currently have good multi-area modeling capability that might be used to simulate the effect of local transmission constraints, and, therefore, strategic bidding is assumed non-existent. The modifications required to Elfin are manageable and need only address the fact that payments from the market will diverge from the simple minimum cost in the following minor ways.

1. An energy payment accrues to each generator that produces during a period. The payment is equal to the generators output times a weighted market price. The weighted market price is the sum of bid prices of generators that emerged as the marginal one dispatched during the period weighted by the share of the time each was marginal.

2. A commit payment is assumed to exist. This payment is made to the last generator committed during a period if it fails to break even from its market revenues. The payment simply makes this last generator whole and is given to all generators who are committed during the period.

3. A spin payment is assumed to exist. This payment is made to any generator whose output was curtailed to meet the spinning requirement even though it bid below the 
market price. The payment is specific to the generator ramped down and is equal to the lost revenue that it would have collected if it had been free to generate.

Consequently, the revenue stream obtained by any generator is the sum of three payment types, although the energy payment is by far the largest of the three.

\section{B.5 How Much Entry Will Occur}

A net present profit function can be written for the industry as follows:

$$
\pi^{\mathrm{i}}=\pi^{\mathrm{x}}+\pi^{\mathrm{e}}
$$

where, $\pi^{i}=$ profits of the industry as a whole

$\pi^{\mathrm{x}}=$ profits of existing generating assets, and

$\pi^{\mathrm{e}}=$ profits earned by entering generating assets

The paradigm adopted is one of competing technologies. Consider first the profits accruing to exiting capacity, $\pi^{\mathrm{i}}$. Given that dispatch in this study almost follows the traditional rules and no strategic bidding exists, existing generating capacity is essentially passive. It has no control over its profit function and passively accepts its lot. If its net present market revenues exceed its net present costs, then it generates profits, otherwise not. However, since these generating assets are typically largely depreciated and bid into the market at their marginal cost including variable O\&M, only failure to cover fixed O\&M results in losses. In a sense, existing assets have no entry decisions to make. Their profits will most likely be highest if no entry occurs, thereby pushing up market prices, and vice-versa. The one complication is that in some cases, the retirement of existing units is linked to repowers at the same site. From this perspective, this amounts to a unit being removed from the existing term of the profit function as its repower appears in the entering term. For the repower to be profitable, the overall profitability of the site must exceed the profit stream at the site were the existing plant to remain in place.

The focus here, of course, is on profits accruing to entering capacity, $\pi^{\mathrm{e}}$. Note that, from a modeling point of view, entering capacity never becomes existing capacity. Entering capacity covers all capacity built throughout the study period. There are two fundamental assumptions governing entry. First, entry by at least one technology is unrestricted, and second, investors as a group will try to establish the pattern of new entry that will result in their own maximum profit.

Consider a breakdown of the entering capacity net present profit function by technology and year of construction. That is, capacity net present profit function by technology and year of construction. That is, 


$$
\pi^{e}=\sum_{h=1}^{H} \sum_{t=1}^{T} \pi_{h, t}
$$

where, $\quad h=$ entering technologies, i.e. nuclear, gas combined cycle, wind, etc. and $\quad t=$ the years of the study period

The net present profit function for any technology built in any year, $\pi_{\mathrm{h}, \mathrm{l}}$, depends on how much total capacity is built which will determine the revenue stream from market payments, and, of course, on the costs of the technology. This perspective essentially treats the construction of units of one given technology in one given year as a separate competitor. Since all units of a given technology are identical, and clearly more capacity lowers the market price, we can picture this profit function as follows.

In Figure B-1, the first two units of technology $h$ built in year $t$ generate profits and the net present profit function stays positive. If the third unit is built, however, the profit function turns negative. By the rule that all profitable entry occurs, this industry will build two units in this year. This rule is equivalent to saying that while we are looking at one technology as represented by one industry, it is, nonetheless, a competitive industry and it cannot increase

Figure B-1. Technology Profit Function

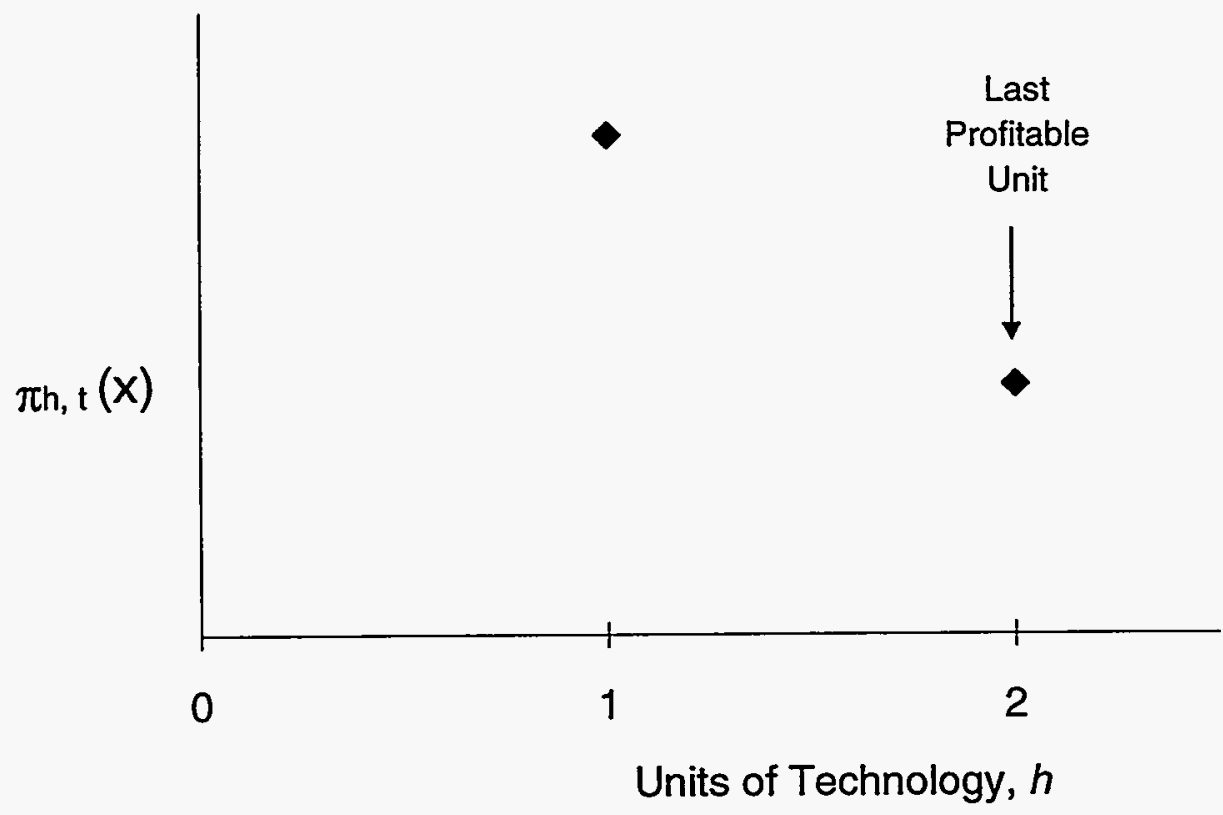


profits by restricting entry. Further, all producers in this industry are homogeneous; that is, all plants built are identical. However, for at least two reasons, positive profits can exist. First, the lumpiness of this and all other technologies precludes entry to the point of zero profits. This phenomenon makes careful specification of generic resources imperative. The realities of limited computation time require the use of as small a number of generic options as possible, and the specification of large generic resources. However, if resources are specified as too large, artificial lumpiness is being introduced. This is a particularly big problem with renewable technologies, such as wind, which, obviously, could be built on quite small scales. And second, since the Elfin algorithm looks at all years in deciding which additions to choose, not absolutely all profitable entry is made in every year. Elfin chooses the most profitable entry throughout the forecast period, which means that in the short-run, entry will not continue to the zero profit point. Note that the value of the net present profit function is much more complex than it seems because it depends not only on the build of this technology but also on the decisions made by all other technologies regarding their builds.

$$
\pi_{h, t}\left[X_{h, t}, P\left(X_{h, t}, Y_{h, t}, Z_{t}\right), C_{h, t}\right]
$$

That is, the net present profit for technology $h$ in year $t$ depends not only on $\mathrm{X}_{\mathrm{h}, \mathrm{t}}$, the number of units of technology $h$ built in year $t$, but also on the stream of expected market revenues, $P$, which depends of the capacity of technology $h$ built in all years, $X_{h, t}$, and the capacity build decisions of all other entrant technologies in all years, $Y_{h, t}$, and on the existing capacity stock in all years, $Z_{t}$, and the net present costs of construction and operation, $\mathrm{C}_{\mathrm{h}, \mathrm{t}^{*}}$.

The profit function of entering technologies, $\pi^{\mathrm{e}}$, can be further broken down into those technologies that have limited entry and those which are unlimited. The later category are the true generic resources. How many units of these technologies are built is entirely at the discretion of the model. And, each simulation must contain at least one unlimited technology if entry is to be truly free. The limited entry technologies are more troubling. For example, consider a specific type of geothermal site on which no more than two generating units can be constructed. This technology will benefit if the two units are built and yield profits, but, assuming that they are built, they will benefit the most if further entry is limited. Therefore, it seems at first blush that these technologies must be excluded from consideration in the same way that existing technologies are excluded. However, this is not so. The key to this paradox is that entry can still occur, even though not of this specific technology. Investors will seek the entry combination that results in maximum profit including the limited entry technologies. Even though a plan in which both of the limited entry technology units are built may seem inadmissable, in fact it is. A combination of new construction under which no further new capacity can be profitably built; that is, no additional entry is possible, is called a market equilibrium plan (MEP). Obviously, multiple MEPs exist for any combination of expansion alternatives. 


\section{B.6 Finding the Best Plan}

Once as many of the MEPs as possible have been identified, choosing a winner from them is trivial. In as much as those investing in the industry will choose the plan that maximizes their private profit, the plan with the highest $\pi^{\mathrm{e}}$ must be selected.

\section{B.7 Revised Algorithm}

Given the goal of approximating a market system with free entry rather than traditional cost minimization, the following adjusted MC-ITRE algorithm has been developed and implemented in Elfin:

1. Because there is good reason to believe that MEPs lie close to the minimum cost point, and because minimum cost searches are efficient and stable, the minimum cost point is found.

2. Beginning at the minimum cost point, the first step in the algorithm, then is to build a table akin to the MC-ITRE table that shows whether any entry by a given technology in a given year can be profitable, given all other entry (and exit) decisions. The basic format of MC-ITRE is retained. For example, all decisions are made in discrete one-year time steps. If there is potentially profitable entry, then it assumed to take place.

3. This process continues until all the entrant profit functions are positive, but if a unit of any technology anywhere is built, then the profit function of its industry turns negative; that is, given the response of all other technologies, the last unit built loses money, which, because by definition, all units of a given technology are homogeneous, means they all lose money.

4. Unfortunately, because the profit surface is craggy but fairly level, numerous combinations of construction may meet this basic criterion. Therefore, the search algorithm must make subsequent searches in such a way that as many candidate plans as possible are identified in an unbiased manner.

5. When Elfin finds itself searching in a place it has visited before, searching ceases.

6. A swap step attempts to find new productive areas for searching.

7. When as many MEPs as possible have been found, the one with the highest entrant profit is selected as the winner. 


\section{B.8 Conclusion}

A variation on the MC-ITRE algorithm has been developed to simulate entry into a competitive electricity market. Estimates are made of the profitability of construction of one new unit of generating capacity for each candidate technology. The most profitable capacity in the most profitable year is built first and the future operation of the system resimulated with the additions in place. Subsequent iterations add more profitable entry until no more is possible, combination of investments called an MEP. The choice between multiple MEPs is made so as to maximize overall profits to entrants. This algorithm has been implemented in Elfin together with a system of energy, commit, and spin payments. 


\section{Resource Options}

\section{C.1 Overview}

In this appendix, we summarize the ranges of costs and operational parameters that were found in the literature for the 12 potential new resource additions modeled in this project and the assumptions that we ultimately used to model these resources.

\section{C.2 Ranges of Costs and Other Operational Parameters}

In this section, we describe the range of cost and other parameters we found in the literature for the 12 resource options that we included in our data set. The primary sources for this information were EPRI (1993), U.S. DOE (1994), and the resource characteristics of California utilities found in the Elfin data sets created for the 1994 Electricity Report. In each section, we summarize costs and other parameters in a table to facilitate side-by-side comparison of the range of cost and other parameters that we found from these various sources. We have converted all of the cost figures to 1995 dollars using the Gross Domestic Product (GDP) implicit price deflator and assume that natural gas costs will be the same for new units as for existing ones. In most cases, we found very wide ranges of costs for these 12 technologies and, thus, we have represented the resource options with base case, high, and low capital costs. We have also chosen representative parameters from the ranges presented for plant size, plant life, variable O\&M, fixed O\&M, heat rates, fuel costs, forced outage rates, and maintenance rates. The costs and other parameters ultimately selected for inclusion in this analysis are presented in Section C.3.3.

\section{C.2.1 Gas Combined Cycle}

We found a wide range of costs for combined cycle (CC) technologies, with capital costs ranging from approximately $\$ 600 / \mathrm{kW}$ to $\$ 1,400 / \mathrm{kW}$ (see Table C- 1 ). Siting differences explain at least some of these differences. Construction of CCs at existing sites with appropriate infrastructure tends to cost less than new sites, with potentially more stringent permit requirements and possible public opposition. For this study, we use a range of different capital costs: $\$ 600 / \mathrm{kW}$ for the base case, $\$ 500 / \mathrm{kW}$ for the low-cost case, and $\$ 800 / \mathrm{kWh}$ for the high-cost case. The base case of $\$ 600 / \mathrm{kW}$ is consistent with EPRI (1993), SDG\&E ER94 data, and Hadley, Hill, and Perlack (1993). The low-cost assumption assumes technical progress by 2005 , which is the year in which we consider resource additions. In addition, we use the other data elements specified by EPRI (e.g., $225 \mathrm{MW}$ for plant size, $30 \frac{\mathrm{s}}{\mathrm{kW} \cdot \mathrm{a}}$ for fixed O\&M, etc.). EPRI's variable and fixed O\&M costs differ from the utilities' because EPRI assumes that more of the O\&M costs are fixed and the utilities assume that 
more are variable. The fuel for this and all gas-fired technologies is ordinary natural gas, priced equally for all technologies.

Table C-1. Gas Combined Cycle Costs and Other Parameters

\begin{tabular}{|c|c|c|c|c|c|}
\hline Dâta Elements & $\begin{array}{l}\text { EPRITag (1993) } \\
\text { ETCC 16.3 }\end{array}$ & $\begin{array}{l}\text { ERgA SCE } \\
\text { option } \\
\text { Existing site In } \\
\text { Basin }\end{array}$ & $\begin{array}{l}\text { ER94SCE } \\
\text { Opton \#10, New } \\
\text { Site outtof-Basin }\end{array}$ & $\begin{array}{l}\text { ERga SDG\& } \\
\text { Optlon } 13 \\
\text { In-county cc }\end{array}$ & $\begin{array}{l}\text { Ep SDG\&E } \\
\text { Option \#10, Out- } \\
\text { of County,CC }\end{array}$ \\
\hline $\begin{array}{l}\text { Capital Costs } \\
(1995 \$ / \mathrm{kW})\end{array}$ & 623 & 979 & 1384 & 702 (692 for 2 ) & 794 (911 for 2$)$ \\
\hline $\begin{array}{l}\text { Fixed O\&M Costs } \\
\left(1995 \frac{\mathrm{s}}{\mathrm{kW} \cdot a}\right)\end{array}$ & 27.8 & 10.2 & 10.2 & 8.84 & 8.85 \\
\hline $\begin{array}{l}\text { Variable O\&M } \\
\text { Costs } \\
(1995 \$ / k W h)\end{array}$ & 0.0004 & $\begin{array}{r}0.0027 \\
(0.87 \% \text { real esc.) }\end{array}$ & $\begin{array}{r}0.0027 \\
(0.87 \% \text { real esc.) }\end{array}$ & $\begin{array}{r}0.0040 \\
(0.66 \% \text { real esc.) }\end{array}$ & $\begin{array}{r}0.0040 \\
(0.66 \% \text { real esc.) }\end{array}$ \\
\hline $\begin{array}{l}\text { Heat Rate (AHR } \\
\text { kJ/kWh) - Block } \\
\text { Size (MW) }\end{array}$ & $\begin{array}{r}11,089-56 \\
8,778-113 \\
7,934-169 \\
7,702-225 \\
7,934-A A\end{array}$ & $\begin{array}{l}8,810-124 \\
8,388-157 \\
7,702-210\end{array}$ & $\begin{array}{l}9,443-115 \\
9,021-146 \\
8,229-195\end{array}$ & $\begin{array}{r}11,848-44 \\
8,552-131 \\
7,808-218 \\
8,156-292 \\
7,770-366 \\
7,723-436\end{array}$ & $\begin{array}{r}11,896-43 \\
8,616-129 \\
7,840-216 \\
8,189-289 \\
7,801-362 \\
7,755-428\end{array}$ \\
\hline $\begin{array}{l}\text { Forced Outage } \\
\text { Rate }\end{array}$ & $4.6 \%$ & $3 \%$ & $3 \%$ & $4.2 \%$ & $4.2 \%$ \\
\hline Maintenance Rate & $6.9 \%$ & $5 \%$ & $5 \%$ & $4.2 \%$ & $4.2 \%$ \\
\hline $\begin{array}{l}\text { Unit Capacity } \\
\text { (MW) }\end{array}$ & 225 & 210 & 195 & $\begin{array}{l}472 \text { (NC) } \\
436 \text { (DC) }\end{array}$ & $\begin{array}{l}464 \text { (NC) } \\
428 \text { (DC) }\end{array}$ \\
\hline Plant Life (a) & 30 & 29 & 29 & 30 & 30 \\
\hline
\end{tabular}

+We have converted all of the figures into 1995 dollars using the GDP Implicit Price Deflator.

++ Natural gas fuel costs will be the same for existing and new units in the Elfin model.

+++ Heat Rate and Block Sizes for SDG\&E are summer values (June to October).

$\mathrm{AA}=$ Average Annual

$\mathrm{NC}=$ net capacity

$\mathrm{DC}=$ dependable capacity for reliability calculations

\section{C.2.2 Repowers}

As discussed elsewhere in this report, repowers are one of the most important yet difficult to characterize capacity options. On reason repowers are inherently problematic resources in capacity expansion modeling is because repower projects are unique to specific sites and equipment, whereas the computational constraints of modeling dictate that expansion options be as small a set of generic options as possible. In other words, it is inherently difficult to represent repower resources as a generic option. In addition, possible repower options at any one site are numerous and, obviously, the choice of any one project will have a major impact on other projects. For the purposes of this study, the data used for repowers was a low-end 
estimate made on the basis of green field gas-fired combined cycle technology and ER94 data on potential repowers. The fuel is ordinary natural gas.

\section{C.2.3 Gas Combustion Turbine}

We also found a wide range of costs for gas combustion turbines (see Table C-2). We use $\$ 450 / \mathrm{kW}$ as the base-case option, $\$ 350 / \mathrm{kW}$ for the low-cost option, and $\$ 600 / \mathrm{kW}$ for the high-cost option. The base-case costs are consistent with EPRI (1993), the low cost are consistent with Hadley, Hill, and Perlack (1993), and the high costs are consistent with SCE's ER94 data set. The low-cost assumption assumes technical progress by 2005 , which is the year in which we consider resource additions. We use EPRI operational parameters (e.g., fixed and variable O\&M, plant capacity, etc.), except for forced outage and maintenance rates, where we use SCE's values. EPRI's variable O\&M costs are substantially lower than the utilities'.

Table C-2. Gas Combustion Turbine Costs and Other Parameters

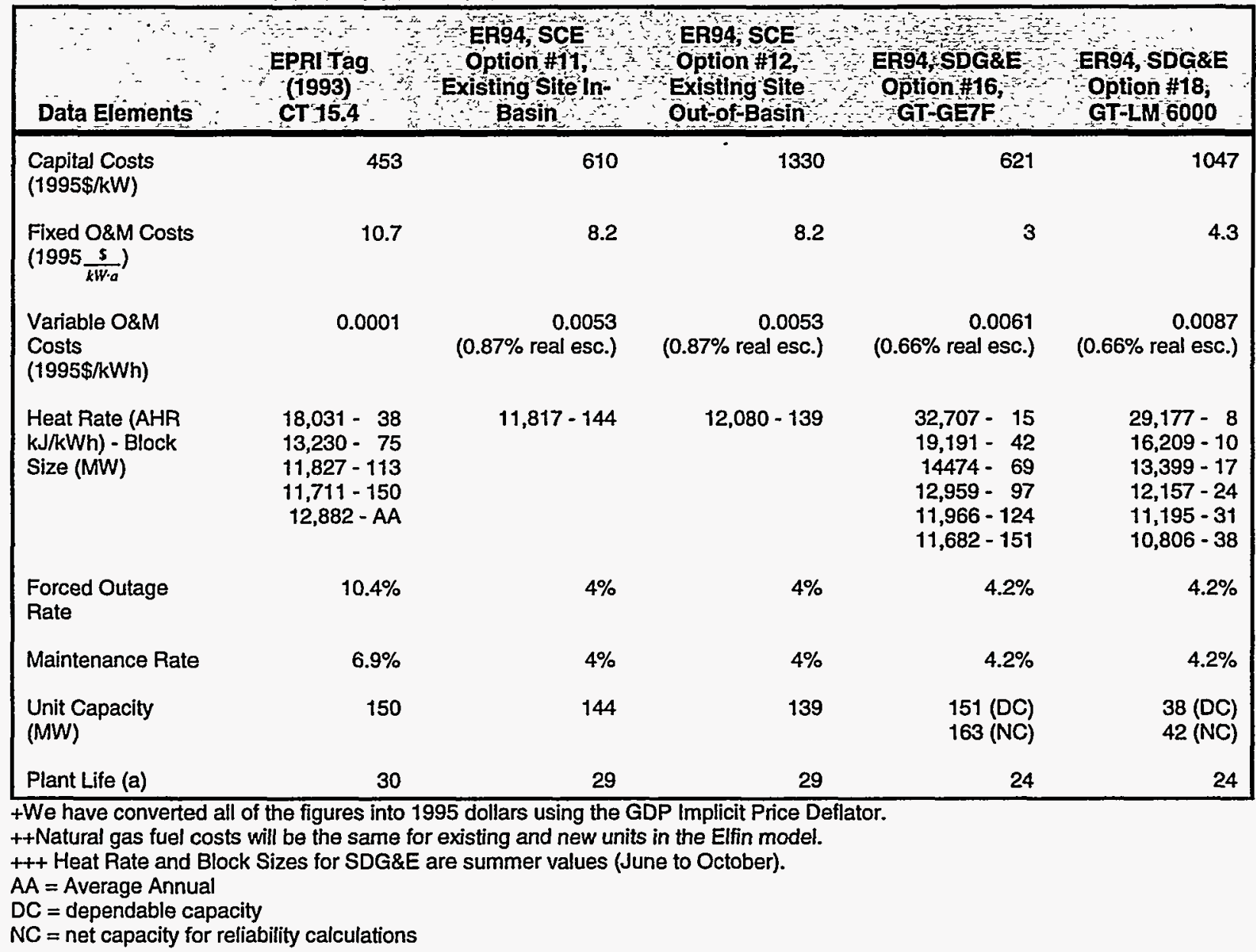




\section{C.2.4 Wind}

Wind capital costs range from a low of $\$ 620 / \mathrm{kW}$ in 2005 to a high of $\$ 1,600 / \mathrm{kW}$ for at least one SDG\&E option. In addition, DOE (1996) estimates that capital costs will move from a current $\$ 825 / \mathrm{kW}$ to $\$ 625 / \mathrm{kW}$ in 2030 . The ranges we use in our analysis differ slightly from those found in Table C-3. For the base-case capital costs, we assume that capital costs are $\$ 900 / \mathrm{kW}$ in 1995 and fall to $\$ 600 / \mathrm{kW}$ in 2030 . These costs are generally consistent with DOE (1996), EPRI (1993), Wiser and Kahn (1996), Hadley, Hill, and Perlack (1993), Hamrin and Rader (1993), and Williams and Bateman (1995). For low capital costs, we assume that capital costs fall from $\$ 800 / \mathrm{kW}$ in 1995 to $\$ 500 / \mathrm{kW}$ in 2026 . For the high cost, we assume that current prices of approximately $\$ 900 / \mathrm{kW}$ remain constant. We assume fixed O\&M costs of $26 \frac{\mathrm{s}}{k W \cdot a}$, no variable costs, maintenance rates of 2.5 percent, forced outage rates of zero percent, and a nameplate capacity of $250 \mathrm{MW}$.

Table C-3. Wind Plant Costs and Other Parameters

\begin{tabular}{|c|c|c|c|c|c|c|}
\hline Data Elements & $\begin{array}{c}\text { EPRi Tag } \\
\text { (1993) } \\
\text { Wind 24.1 } \\
\text { (1995 Costs) }\end{array}$ & $\begin{array}{c}\text { Eppl Tag } \\
\text { (1993) Wind } \\
24.1 \\
(2005 \text { Costs) }\end{array}$ & $\begin{array}{l}\text { ER94 SCE } \\
\text { Option \#21 }\end{array}$ & $\begin{array}{l}\text { ER94ScE } \\
\text { Optioñ } 20\end{array}$ & $\begin{array}{c}\text { ERg4 } \\
\text { SDG\&E } \\
\text { Optión \#28 }\end{array}$ & $\begin{array}{l}\text { EP94 SDG } 8 E \\
\text { Option } 142\end{array}$ \\
\hline $\begin{array}{l}\text { Capital Costs } \\
\text { (1995\$/kW) }\end{array}$ & 860 & 620 & 1159 & 969 & 1632 & 957 \\
\hline $\begin{array}{l}\text { Fixed O\&M Costs } \\
\left(1995 \frac{\mathrm{s}}{\mathrm{kW} \cdot a}\right)\end{array}$ & 26.4 & 26.4 & 15.5 & 15.5 & 71.8 & 2.6 \\
\hline $\begin{array}{l}\text { Variable O\&M } \\
\text { Costs } \\
(1995 \$ / \mathrm{kWh})\end{array}$ & 0 & 0 & $\begin{array}{r}0.0082 \\
(0.87 \% \text { real } \\
\text { esc. })\end{array}$ & $\begin{array}{r}0.0082 \\
(0.87 \% \text { real } \\
\text { esc. })\end{array}$ & $\begin{array}{r}0.014 \\
(0.66 \% \text { real } \\
\text { esc) }\end{array}$ & $\begin{array}{r}0.014 \\
(0.66 \% \text { real } \\
\text { esc) }\end{array}$ \\
\hline Load Shape & & & & & see WIN1 & see USWP \\
\hline $\begin{array}{l}\text { Forced Outage } \\
\text { Rate }\end{array}$ & & & $2.5 \%$ & $2.5 \%$ & $5.8 \%$ & $5.8 \%$ \\
\hline $\begin{array}{l}\text { Maintenance } \\
\text { Rate }\end{array}$ & & & $2.5 \%$ & $2.5 \%$ & $4.8 \%$ & $4.8 \%$ \\
\hline $\begin{array}{l}\text { Plant Capacity } \\
\text { (MW) }\end{array}$ & 50 (NC) & 50 (NC) & $\begin{array}{r}50(D C) \\
250(N C)\end{array}$ & $\begin{array}{r}50(\mathrm{DC}) \\
250(\mathrm{NC})\end{array}$ & $\begin{array}{l}11 \text { (DC) } \\
75 \text { (NC) }\end{array}$ & $\begin{array}{l}12 \text { (DC) } \\
80 \text { (NC) }\end{array}$ \\
\hline Plant Life (a) & 30 & 30 & 29 & 29 & 20 & 50 \\
\hline
\end{tabular}

+We have converted all of the figures into 1995 dollars using the GDP Implicit Price Deflator.

++ EPRI Tag O\&M numbers are expected to decline in the future. We have used 1995 and 2005 capital costs $\mathrm{DC}=$ dependable capacity

NC $=$ net capacity for reliability calculation 


\section{C.2.5 Wind with Combustion Turbine Backup}

There were no existing capital costs or operational parameters for a wind plant backed up by a combustion turbine (CT). We combined the costs of a wind and a CT plant for the capital cost options. We assume that costs fall from $\$ 1,350$ to $\$ 1,050$ in 2030 for the base case, that costs fall from $\$ 1,150$ to $\$ 850$ in 2030 for the low-cost case, and that costs remain constant to $\$ 1,500 / \mathrm{kW}$ for the high-cost case. We assume a $250 \mathrm{MW}$ facility, with maintenance and forced outage rates of four percent, no variable O\&M costs, and fixed costs O\&M costs of 40 $\frac{s}{\mathrm{k} W \mathrm{a}}$. We assume no fuel costs when the wind plants are generating energy and a heat rate of 12,000 units when the CT is operating and using gas. Emissions are the same as for the CT provided above.

\section{C.2.6 Geothermal}

Table C-4. Geothermal Costs and Other Parameters

\begin{tabular}{|c|c|c|c|c|c|c|}
\hline Data Elements & $\begin{array}{l}\text { EPRI Tag } \\
\text { (1993) } \\
\text { Binary 21.1 }\end{array}$ & $\begin{array}{l}\text { EPRIJag } \\
\text { (1993) } \\
\text { Dual Flash } \\
\text { 21.2 }\end{array}$ & $\begin{array}{r}\text { ER } 945 \mathrm{SC} \\
\text { Option } 435 \\
\text { Binany }\end{array}$ & $\begin{array}{l}\text { ERg4 SCE } \\
\text { Option t22, } \\
\text { Duál Flash }\end{array}$ & $\begin{array}{l}\text { ER94 SDG\&E } \\
\text { Option } 24, \\
\text { Binary }\end{array}$ & $\begin{array}{l}\text { ER94 SDG\&E } \\
\text { Option } \# 26, \\
\text { Dual Flash }\end{array}$ \\
\hline Capital Costs & 2158 & 1275 & 4658 & 4244 & 4359 & 3891 \\
\hline Fixed O\&M Costs & 51.5 & 39.1 & 192.2 & 268.5 & 192.2 & 107.2 \\
\hline $\begin{array}{l}\text { Variable O\&M } \\
\text { Costs }\end{array}$ & 0 & 0 & $\begin{array}{r}0.0015 \\
(0.87 \% \text { real } \\
\text { esc })\end{array}$ & $\begin{array}{r}0.0068 \\
(0.87 \% \text { real } \\
\text { esc) }\end{array}$ & $\begin{array}{r}0.015 \\
(0.66 \% \text { real } \\
\text { esc) }\end{array}$ & $\begin{array}{r}0.0099 \\
(0.66 \% \text { real } \\
\text { esc) }\end{array}$ \\
\hline $\begin{array}{l}\text { Heat Rate (AHR } \\
\text { kJ/kWh) - Block } \\
\text { Size (MW) }\end{array}$ & $\begin{array}{rr}43,732 & -3 \\
37,233 & -7 \\
36,446 & -10 \\
36,273 & -13 \\
35,144 & -A A\end{array}$ & $\begin{array}{l}29,753-24 \\
30,649-A A\end{array}$ & & & & \\
\hline $\begin{array}{l}\text { Forced Outage } \\
\text { Rate }\end{array}$ & $1.5 \%$ & $1.0 \%$ & $5 \%$ & $5 \%$ & $7 \%$ & $4 \%$ \\
\hline Maintenance Rate & $2.3 \%$ & $2.7 \%$ & $3 \%$ & $3 \%$ & $3.1 \%$ & $3.8 \%$ \\
\hline $\begin{array}{l}\text { Unit Capacity } \\
\text { (MW) }\end{array}$ & $2 \times 13 \mathrm{MW}$ & $24 \mathrm{MW}$ & $100 \mathrm{MW}$ & $100 \mathrm{MW}$ & $\begin{array}{l}30 \text { (DC) } \\
70 \text { (NC) }\end{array}$ & $\begin{array}{l}33 \text { (DC) } \\
40 \text { (NC) }\end{array}$ \\
\hline Plant Life & 30 & 30 & 29 & 30 & 25 & 25 \\
\hline
\end{tabular}

+We have converted all of the figures into 1995 dollars using the GDP Implicit Price Deflator. ++ No fuel costs because steam field has been purchased for the utilities' options.

$A A=$ Average Annual

In addition to the numbers presented above (Table C-4), DOE technology characterizations presents capital cost figures for geothermal binary, geothermal flashed steam, and geothermal hot dry rock. For a 30-MW geothermal binary plant, DOE estimates capital costs of $\$ 3,590 / \mathrm{kW}$ for 1995 falling to $\$ 1,870 / \mathrm{kW}$ in 2030 and O\&M costs of $114 \frac{\mathrm{s}}{\mathrm{kW} \cdot \mathrm{a}}$ in 1995 falling to $\$ 58 / \mathrm{kW}$ in 2030 . For $50-\mathrm{MW}$ geothermal flashed steam plant, DOE estimates capital costs 
of $\$ 2,310$ in 1995 falling to $\$ 1,560 / \mathrm{kW}$ in 2030 and O\&M costs of $124 \frac{\mathrm{s}}{\mathrm{kW \cdot a} \cdot \mathrm{in}} 1995$ falling to $60 \frac{\mathrm{s}}{k \mathrm{k} \cdot a}$ in 2030. Finally, for a 10-15 MW geothermal hot dry rock plant, DOE estimates capital costs of $\$ 5,640 / \mathrm{kW}$ for a base system, $\$ 2,530 / \mathrm{kW}$ for a second generation system, and $\$ 1,880 / \mathrm{kW}$ for a goal system, with corresponding O\&M costs of $181 \frac{\mathrm{s}}{\mathrm{kW} \cdot a}, 78 \frac{\mathrm{s}}{\mathrm{k} W \cdot a}$, and $62 \frac{\mathrm{s}}{\mathrm{kW} \cdot \mathrm{a}}$. These figures are in 1990 dollars, so 1995 values would be about 7.5 percent higher.

For our analysis, we use capital costs of $\$ 2,300$ falling to $\$ 1,600$ in 2030 for the base case, with most of the decrease occurring by 2000. This assumption is taken from DOE (1996) and is consistent with Hadley, Hill, and Perlack (1993), Hamrin and Rader (1993), and Williams and Bateman (1995). We use $\$ 1,300 / \mathrm{kW}$ for the low cost case, which is consistent with EPRI (1993). Finally, we use $\$ 2,300 / \mathrm{kW}$ for the high cost case, essentially using DOE (1996) numbers but assuming no technological innovation or cost decreases over time. We also use low, medium, and high fixed O\&M costs of $40 \frac{\mathrm{s}}{\mathrm{kH}^{\prime} \cdot a}, 50 \frac{\mathrm{s}}{\mathrm{kWWa}^{\mathrm{W}}}$, and $190 \frac{\mathrm{s}}{\mathrm{kW}^{\mathrm{W}} \mathrm{a}}$. We assume a plant size of $100 \mathrm{MW}$, a forced outage rate of five percent, maintenance rate of three percent, no variable costs, and fuel costs similar to PG\&E geothermal facilities (i.e., heat rate of 22,000 and steam price of $\$ 0.63 / \mathrm{mbtu}$ ). 


\section{C.2.7 Solar Thermal}

Table C-5. Solar Thermal Costs and Other Parameters

\begin{tabular}{|c|c|c|c|c|c|}
\hline 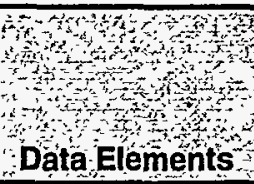 & $\begin{array}{l}\text { PpITag } \\
\text { (1993) } \\
\text { 2311Hybrid }\end{array}$ & 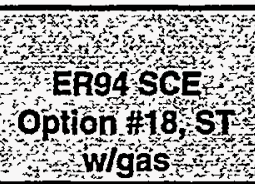 & 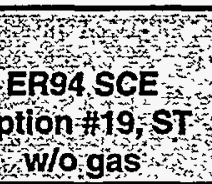 & $\begin{array}{l}\text { ER94 } \\
\text { SDG\&E } \\
\text { Optonn } \\
\text { ST pond }\end{array}$ & 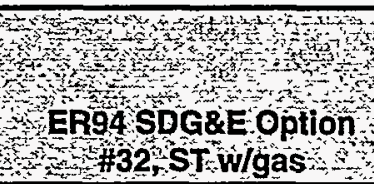 \\
\hline $\begin{array}{l}\text { Capital Costs } \\
(1995 \$ / \mathrm{kW})\end{array}$ & 3399 & 5150 & 4862 & 6085 & 3575 \\
\hline $\begin{array}{l}\text { Fixed O\&M } \\
\text { Costs } \\
\left(1995 \frac{s}{k W \cdot a}\right)\end{array}$ & 35.7 & 61.3 & 53.6 & 82.9 & 40.9 \\
\hline $\begin{array}{l}\text { Variabe O\&M } \\
\text { Costs } \\
\text { (1995\$/kWh) }\end{array}$ & $\begin{array}{r}0.0049 \\
\text { does this } \\
\text { include } \\
\text { fuel? }\end{array}$ & $\begin{array}{r}0.0102 \\
(0.87 \% \text { real esc) }\end{array}$ & $\begin{array}{r}0.0102 \\
(0.87 \% \text { real } \\
\text { esc) }\end{array}$ & 0 & $\begin{array}{r}0.0041 \\
(0.66 \% \text { real esc) }\end{array}$ \\
\hline $\begin{array}{l}\text { Heat Rate for } \\
\text { Gas (AHR } \\
\text { kJ/kWh) - Block } \\
\text { Size (MW) }\end{array}$ & $\begin{array}{r}12,977-20 \\
11,922-40 \\
10,867-60 \\
9,835-80\end{array}$ & & & & \\
\hline $\begin{array}{l}\text { Forced Outage } \\
\text { Rate }\end{array}$ & $4 \%$ & $7 \%$ & $7 \%$ & $2 \%$ & $7 \%$ \\
\hline $\begin{array}{l}\text { Maintenance } \\
\text { Rate }\end{array}$ & $3.8 \%$ & $7 \%$ & $5 \%$ & $2 \%$ & $3.8 \%$ \\
\hline $\begin{array}{l}\text { Unit Capacity } \\
\text { (MW) }\end{array}$ & 80 & 80 & 80 & $\begin{array}{l}3(D C) \\
5(N C)\end{array}$ & $\begin{array}{l}80 \text { (DC) } \\
91 \text { (NC) }\end{array}$ \\
\hline Plant Life (a) & 30 & 33 & 33 & 30 & 30 \\
\hline
\end{tabular}

+ We have converted all of the figures into 1995 dollars using the GDP Implicit Price Deflator.

++ Backup fuel is gas.

In addition to these figures (Table C-5), DOE (1994) provides capital cost figures for the following solar thermal technologies: power tower system, parabolic dish, $7.5-\mathrm{kW}$ module, parabolic dish, $25-\mathrm{kW}$ module, parabolic through power plant. The capital costs and O\&M costs for these technologies are as follows:

Table C-6. DOE Solar Thermal Plant Costs

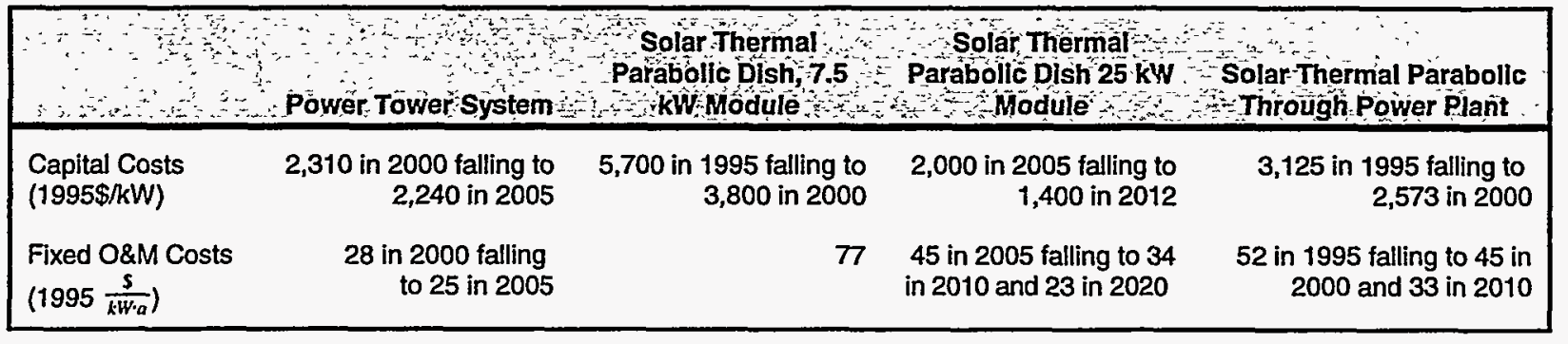

For the base case, we assume that costs fall from $\$ 3,100$ in 1995 to $\$ 2,600$ in 2000 . This assumption is consistent with DOE (1996) estimates for solar thermal parabolic through 
technology and Hadley, Hill and Perlack (1993), Hamrin and Rader (1993), and Williams and Bateman (1995). For the low cost scenario, we assume that capital costs fall and remain constant at about $\$ 2,200 / \mathrm{kW}$. This is consistent with DOE's estimate for a power tower system. Finally, for high capital costs we assume that solar thermal costs remain constant at $\$ 3,100 / \mathrm{kW}$. In addition, we generally use the operational parameters specified by EPRI, although we assume fixed costs of $\$ 55 / \mathrm{kW}$, maintenance rates of five percent, and forced outage rates of seven percent (from SCE).

\section{C.2.8 Photovoltaic}

Table C-7. PV Plant Costs and Other Parameters

\begin{tabular}{|c|c|c|c|c|c|c|}
\hline Data Elements & $\begin{array}{r}\text { EPRI Tag } \\
(1993) \\
-\quad 22: 18 \\
\end{array}$ & $\begin{array}{r}\text { EPRI Tag } \\
\text { (1993) } \\
\text { 22.1C }\end{array}$ & $\begin{array}{r}\text { EPRITag } \\
\quad \text { (1993) } \\
22.3\end{array}$ & $\begin{array}{r}\text { EPRITag } \\
(1993) \\
223\end{array}$ & $\begin{array}{l}\text { SCE PY Central } \\
\text { Station Flat } \\
\text { Plate. }\end{array}$ & $\begin{array}{l}\text { SDG\&E } \\
\text { Distributed } \\
\text { PV. }\end{array}$ \\
\hline $\begin{array}{l}\text { Capital Costs } \\
\text { (1995s/kW) }\end{array}$ & 2986 & 2659 & 3463 & 2870 & 2592 & 5067 \\
\hline $\begin{array}{l}\text { Fixed O\&M Costs } \\
\left(1995 \frac{\mathrm{s}}{k W \cdot a}\right)\end{array}$ & 9.2 & 6.6 & 23.4 & 6 & 5.9 & 11.3 \\
\hline $\begin{array}{l}\text { Variable O\&M } \\
\text { Costs }(1995 \$ / \mathrm{kWh})\end{array}$ & 0 & 0 & 0 & 0 & 0 & 0 \\
\hline \multicolumn{7}{|l|}{$\begin{array}{l}\text { Load Shapes or } \\
\text { Heat Rates for Gas? }\end{array}$} \\
\hline Forced Outage Rate & $3 \%$ & $3 \%$ & $3 . \%$ & $3 \%$ & $1 \%$ & $7 \%$ \\
\hline Maintenance Rate & $3.8 \%$ & $3.8 \%$ & $3.8 \%$ & $3.8 \%$ & $1 \%$ & $1 \%$ \\
\hline $\begin{array}{l}\text { Plant Capacity } \\
\text { (MW) }\end{array}$ & 5 & 50 & 5 & 50 & 50 & 2.5 \\
\hline Plant Life(a) & 30 & 30 & 30 & 30 & 32 & 20 \\
\hline
\end{tabular}

+We have converted all of the figures into 1995 dollars using the GDP Implicit Price Deflator.

In addition to the values given above, DOE (1994) estimates that costs for a concentrating photovoltaic plant would be about $\$ 5,000 / \mathrm{kW}$ in 1995 falling to $\$ 1,200$ in 2028 . We use this estimate as our base case. For our low-cost case, we assume that photovoltaic costs would fall from $\$ 4,000 / \mathrm{kW}$ to $\$ 1,000 / \mathrm{kW}$ in 2020 . Finally, for our high-cost case, we assume that costs would fall from $\$ 5,000 / \mathrm{kW}$ to $\$ 3,000 / \mathrm{kW}$ in 2030 . We are aware current photovoltaic costs are about $\$ 7,000 / \mathrm{kW}$ for small projects, but we are assuming that with larger scale projects, current costs could easily fall to $\$ 5,000 / \mathrm{kW}$ and to $\$ 4,000 / \mathrm{kW}$ in the most optimistic scenario. For other operational parameters, we rely primarily upon EPRI (1993). 


\section{C.2.9 Nuclear}

Table C-8. Nuclear Plant Costs and Other Parameters

\begin{tabular}{|c|c|c|c|}
\hline \multicolumn{4}{|c|}{ 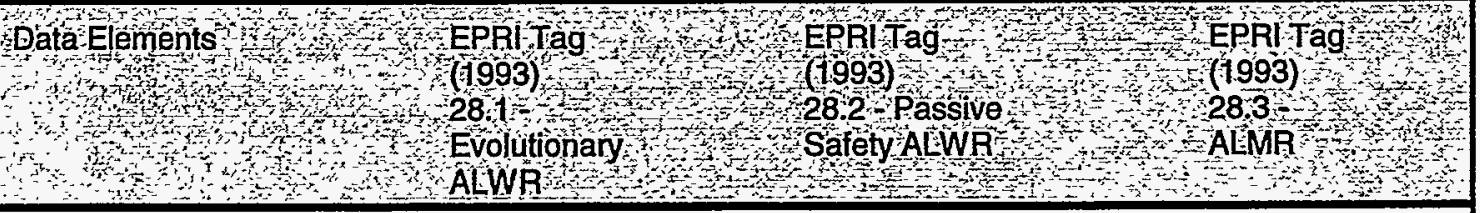 } \\
\hline Capital Costs & 1562 & 1938 & 1818 \\
\hline $\begin{array}{l}\text { Fixed O\&M Costs } \\
(1995 \$ / \mathrm{kW})\end{array}$ & 63.2 & 78.9 & 68.7 \\
\hline $\begin{array}{l}\text { Variable O\&M Costs } \\
(1995 \$ / k W h)\end{array}$ & 0.0003 & 0.0031 & 0.0003 \\
\hline $\begin{array}{l}\text { Heat Rate (AHR kJ/kWh) - } \\
\text { Block Size (MW) }\end{array}$ & $\begin{array}{r}10,762-1350 \\
11,089-\quad A A\end{array}$ & $\begin{array}{r}10,973-600 \\
11,300-A A\end{array}$ & $\begin{array}{r}10,271- \\
1,488 \\
10,582- \\
\text { AA }\end{array}$ \\
\hline Forced Outage Rate & $9.8 \%$ & $7.7 \%$ & $5.3 \%$ \\
\hline Maintenance Rate & $8.2 \%$ & $7.3 \%$ & $3.7 \%$ \\
\hline Unit Capacity (MW) & 1350 & 600 & 1488 \\
\hline Plant Life & 30 & 30 & 30 \\
\hline
\end{tabular}

+We have converted all of the figures into 1995 dollars using the GDP Implicit Price Deflator.

$\mathrm{AA}=$ Average Annual

For the base-case scenario, we assume capital costs of $\$ 2,500 / \mathrm{kW}$, which is consistent with EPRI (1993). For low capital costs, we assume $\$ 1,800 / \mathrm{kW}$ and for high costs, we assume $\$ 5,000 / \mathrm{kW}$, roughly the cost of building the Diablo Canyon plant in California. We assume variable O\&M costs of $0.3 \phi / \mathrm{kWh}$, fixed O\&M costs of $75 \frac{\mathrm{s}}{\mathrm{kW} \cdot a}$, and fuel costs of $0.5 \phi / \mathrm{kWh}$. 


\section{C.2.10 Coal Gasification-Combined Cycle}

Table C-9. Coal Gasification Combined Cycle Plant Costs and Other Parameters

\begin{tabular}{|c|c|c|c|c|}
\hline \multicolumn{5}{|c|}{ 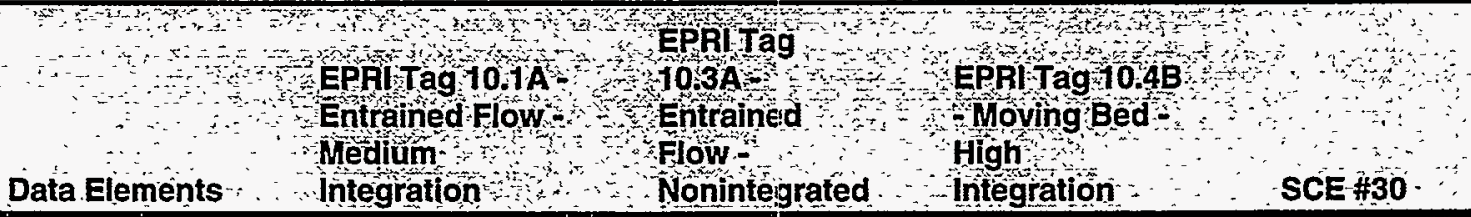 } \\
\hline Capital Costs & 1776 & 2044 & 1784 & 2829 \\
\hline $\begin{array}{l}\text { Fixed O\&M Costs } \\
\left(1995 \frac{\mathrm{s}}{\mathrm{kW-a}}\right)\end{array}$ & 53.6 & 61.9 & 52.5 & 20.4 \\
\hline $\begin{array}{l}\text { Variable O\&M } \\
\text { Costs }(1995 \$ / \mathrm{kWh})\end{array}$ & 0.0004 & 0.0006 & 0.0015 & $\begin{array}{r}0.0112 \\
(0.87 \% \text { real } \\
\text { esc })\end{array}$ \\
\hline $\begin{array}{l}\text { Heat Rate (AHR } \\
\text { kJ/kWh) - Block } \\
\text { Size (MW) }\end{array}$ & $\begin{array}{r}16,058-125 \\
11,426-250 \\
9,833-375 \\
9,211-500 \\
9,485-A A\end{array}$ & $\begin{array}{r}15,984-125 \\
11,374-250 \\
9,791-375 \\
9,168-500 \\
9,443-A A\end{array}$ & $\begin{array}{r}15,024-125 \\
10,688-250 \\
9,205-375 \\
8,620-500 \\
8,884-A A\end{array}$ & $\begin{array}{r}12,661-93 \\
11,817-186 \\
10,129-278 \\
9,707-371\end{array}$ \\
\hline $\begin{array}{l}\text { Forced Outage } \\
\text { Rate }\end{array}$ & $10.1 \%$ & $11.6 \%$ & $10.1 \%$ & $4.6 \%$ \\
\hline Maintenance Rate & $4.7 \%$ & $4.7 \%$ & $4.7 \%$ & $3 \%$ \\
\hline $\begin{array}{l}\text { Unit Capacity } \\
(\mathrm{MW})\end{array}$ & 500 & 500 & 500 & 371 \\
\hline Plant Life & 30 & 30 & 30 & 29 \\
\hline
\end{tabular}

+We have converted all of the figures into 1995 dollars using the GDP Implicit Price Deflator.

$A A=$ Average Annual

For base case capital costs, we use $\$ 2,000 / \mathrm{kW}$ falling to $\$ 1,500$ in 2030 . For low costs, we assume $\$ 1,500 / \mathrm{kW}$ and for high costs, we use $\$ 2,800 / \mathrm{kW}$, which is consistent with SCE's ER94 data set. We use EPRI's operational parameters for an entrained flow-medium integration unit. 


\section{C.2.11 Advanced Coal}

Table C-10. Advanced Coal Plant Costs and Other Parameters

\begin{tabular}{|c|c|c|c|c|c|}
\hline \multicolumn{6}{|c|}{ 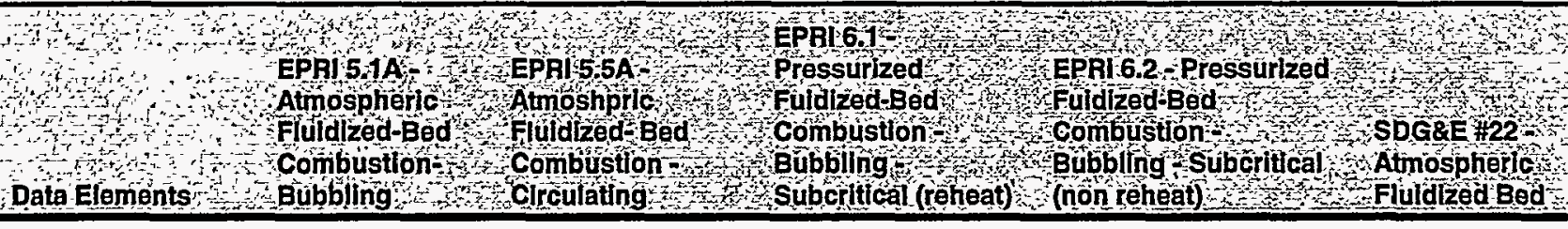 } \\
\hline $\begin{array}{l}\text { Capital Costs } \\
(1995 \$ / \mathrm{kW})\end{array}$ & 1630 & 1956 & 2109 & 1448 & 3111 \\
\hline $\begin{array}{l}\text { Fixed O\&M Costs } \\
\left(1995 \frac{s}{k W \cdot a}\right)\end{array}$ & 37.9 & 39.4 & 7435 & 44.8 & 41.7 \\
\hline $\begin{array}{l}\text { Variable O\&M } \\
\text { Costs }(1995 \$ / \mathrm{kWh})\end{array}$ & 0.0024 & 0.0013 & 0.0036 & 0.0035 & 0.0041 \\
\hline $\begin{array}{l}\text { Heat Rate (AHR } \\
\mathrm{kJ} / \mathrm{kWh} \text { - Block } \\
\text { Slze (MW) }\end{array}$ & $\begin{array}{r}13,777-50 \\
11,321-100 \\
10,717-150 \\
10,521-200 \\
10,731-\text { AA }\end{array}$ & $\begin{array}{r}14,215-50 \\
11,679-100 \\
11,058-150 \\
10,855-200 \\
11,072-A A\end{array}$ & $\begin{array}{r}-20 \\
9,976-40 \\
9,501-60 \\
9,248-80 \\
9,525-A A\end{array}$ & $\begin{array}{r}-20 \\
10,196-40 \\
9,712-60 \\
9,452-80 \\
9,736-A A\end{array}$ & $\begin{array}{l}15,332-48 \\
15,012-77 \\
12,928-106 \\
12,780-134 \\
12,338-163 \\
12,265-192\end{array}$ \\
\hline $\begin{array}{l}\text { Forced Outage } \\
\text { Rate }\end{array}$ & $4.7 \%$ & $4.1 \%$ & $11.7 \%$ & $12.2 \%$ & $1.02 \%$ \\
\hline Maintenance Rate & $5.7 \%$ & $5.7 \%$ & $8 \%$ & $8 \%$ & $9.4 \%$ \\
\hline Unit Capacity (MW) & 200 & 200 & 80 & 80 & $\begin{array}{l}192 \text { (DC) } \\
220 \text { (NC) }\end{array}$ \\
\hline Plant Life (a) & 30 & 30 & 30 & 30 & 30 \\
\hline
\end{tabular}

$+W_{\theta}$ have converted all of the figures into 1995 dollars using the GDP Implicit Price Deflator.

++ Heat Rate and Block Sizes for SDG\&E are summer values (June to October).

$\mathrm{AA}=$ Average Annual

We use $\$ 1,500 / \mathrm{kW}$ for base-case capital costs, consistent with EPRI (1993), $\$ 3,100 / \mathrm{kW}$ for high capital costs, consistent with SDG\&E's ER94 data set, and $\$ 1200 / \mathrm{kW}$ for low capital costs. 


\section{C.2.12 Biomass}

Table C-11. Biomass Plant Costs and Other Parameters

\begin{tabular}{|c|c|c|c|c|c|c|}
\hline $\begin{array}{l}\text { Data Elements } \\
\text { olements } \\
0\end{array}$ & 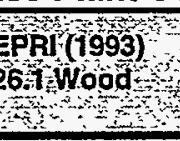 & 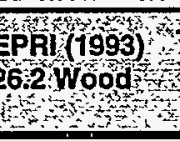 & 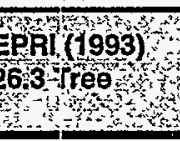 & $\begin{array}{l}\text { EPBI }(1993) \\
26,4 \mathrm{~B} \\
\mathrm{a}\end{array}$ & $\begin{array}{l}\text { iDGE } \\
\text { gricultural } \\
\text { Vaste }\end{array}$ & $\begin{array}{l}\text { DG\&E } \\
\text { Domass } \\
\text { iomass } \\
\text { orest Wasto }\end{array}$ \\
\hline Capital Costs & 1973 & 2304 & 1474 & 2279 & 2773 & 2157 \\
\hline $\begin{array}{l}\text { Fixed O\&M Costs } \\
\left(1995 \frac{\mathrm{s}}{\mathrm{kW} \cdot a}\right)\end{array}$ & 91.9 & 97.5 & 61.3 & 107.2 & 31.7 & 26.5 \\
\hline $\begin{array}{l}\text { Variable O\&M } \\
\text { Costs } \\
(1995 \$ / \mathrm{kWh})\end{array}$ & 0.0085 & 0.0093 & 0.0074 & 0.0093 & $\begin{array}{r}0.0049 \\
(0.66 \% \text { real } \\
\text { esc })\end{array}$ & $\begin{array}{r}0.0048 \\
(0.66 \% \text { real } \\
\text { esc) }\end{array}$ \\
\hline Fuel Costs & & & & & $2 / \mathrm{mmbtu}$ & 2.5/mmbtu \\
\hline $\begin{array}{l}\text { Heat Rate (AHR } \\
\mathrm{kJ} / \mathrm{kWh} \text { ) - Block } \\
\text { Size (MW) }\end{array}$ & $\begin{array}{r}14,658-50 \\
15,098-A A\end{array}$ & $\begin{array}{r}14,627-50 \\
15,066-A A\end{array}$ & $\begin{array}{r}11,241-100 \\
11,578-A A\end{array}$ & $\begin{array}{r}13,050-100 \\
12,740-A A\end{array}$ & vary & vary \\
\hline $\begin{array}{l}\text { Forced Outage } \\
\text { Rate }\end{array}$ & $10.0 \%$ & $10.0 \%$ & na & na & $9.8 \%$ & $9.8 \%$ \\
\hline Maintenance Rate & $5.6 \%$ & $5.6 \%$ & na & na & $5.7 \%$ & $5.7 \%$ \\
\hline Plant Capacity & 50 & 50 & 100 & 100 & $\begin{array}{r}17.8(\mathrm{DC}) \\
28(\mathrm{NC})\end{array}$ & $\begin{array}{l}21.2 \text { (DC) } \\
26.3 \text { (NC) }\end{array}$ \\
\hline Plant Life & 30 & 50 & 30 & 30 & 20 & 20 \\
\hline
\end{tabular}

In addition to the data provided above, DOE (1994) estimates costs for a number of biomass technologies, including biomass to electricity direct fired technology (na), biomass power gasification system ( $\$ 1,200$ falling to $\$ 1,000$ for this near commercial technology), and biomass power-biocrude combustion turbine ( $\$ 2700$ to $\$ 1,500$ in 2030 for this technology currently under development).

We use $\$ 2,000 / \mathrm{kW}$ falling to $\$ 1,500 / \mathrm{kW}$ for the base case. This falls within the parameters provided by SDG\&E's ER94 data set, EPRI (1993) and Hadley, Hill, and Perlack (1993), Hamrin and Rader (1993), and Williams and Bateman (1995). For low cost, we use $\$ 1,600 / \mathrm{kW}$ falling to $\$ 1,200 / \mathrm{kW}$ in 2030 , which is slightly higher than the DOE costs for the biomass power gasification system.

\section{C.3 Summary of Parameters Used in this Analysis}

For this analysis, we include 12 resource options. For each option, we specify low, medium, and high capital costs (see Table C-12). Although non-capital costs and other parameters vary among sources, for simplicity's sake, we only vary capital costs. For each option, we also specified the size of the plant, plant life, variable operation and maintenance (O\&M), fixed O\&M costs, fuel costs, forced outage rates, and maintenance rates (see Table C-13). Emissions rates are found in Table C-14 and offset values are shown in Figure C-1. 
Table C-12. Summary of Capital Costs Assumptions

\begin{tabular}{|c|c|c|c|}
\hline $\begin{array}{l}\text { ph } \\
\text { Resource options }\end{array}$ & 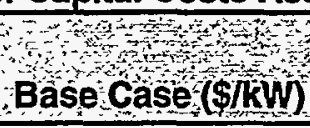 & $\begin{array}{l}\text { High CostCase } \\
\text { (SlkW) }\end{array}$ & Low Cost Case (\$lkW) \\
\hline Combined Cycle & 600 & 800 & 500 \\
\hline Combustion Turbine & 450 & 600 & 350 \\
\hline Repower & & & \\
\hline Wind Power Plant & $\begin{array}{r}900-\text { falling to } 600 \\
\text { in } 2030\end{array}$ & 900 & $\begin{array}{r}800 \text { - falling to } 500 \text { in } \\
2030\end{array}$ \\
\hline Wind Power w/CT & $\begin{array}{r}1,350 \text { - falling to } \\
1,050 \text { in } 2030\end{array}$ & 1500 & $\begin{array}{r}1,150 \text { - falling to } 850 \text { in } \\
2030\end{array}$ \\
\hline Geothermal & $\begin{array}{r}2,300 \text { - falling to } \\
1,600 \text { in } 2030\end{array}$ & 2300 & 1300 \\
\hline Solar Thermal & $\begin{array}{r}3,100 \text { - falling to } \\
2,600 \text { in } 2000\end{array}$ & 3100 & 2200 \\
\hline Photovoltaic & $\begin{array}{r}5,000 \text { - falling to } \\
1,200 \text { in } 2030\end{array}$ & $\begin{array}{r}5,000 \text { - falling to } \\
3,000 \text { in } 2030\end{array}$ & $\begin{array}{r}4,000 \text { - falling to } 1000 \text { in } \\
2020\end{array}$ \\
\hline Nuclear & 2500 & 5000 & 1800 \\
\hline Coal Gasification & $\begin{array}{r}2,000 \text { falling to } \\
1,500 \text { in } 2030\end{array}$ & 2800 & 1500 \\
\hline Advanced Coal & 1500 & 3100 & 1200 \\
\hline Biomass & $\begin{array}{r}2,000 \text { falling to } \\
1,500 \text { in } 2030\end{array}$ & 2000 & $\begin{array}{r}1,600 \text { falling to } 1,200 \text { in } \\
2030\end{array}$ \\
\hline Repower & 500 & 700 & 400 \\
\hline
\end{tabular}




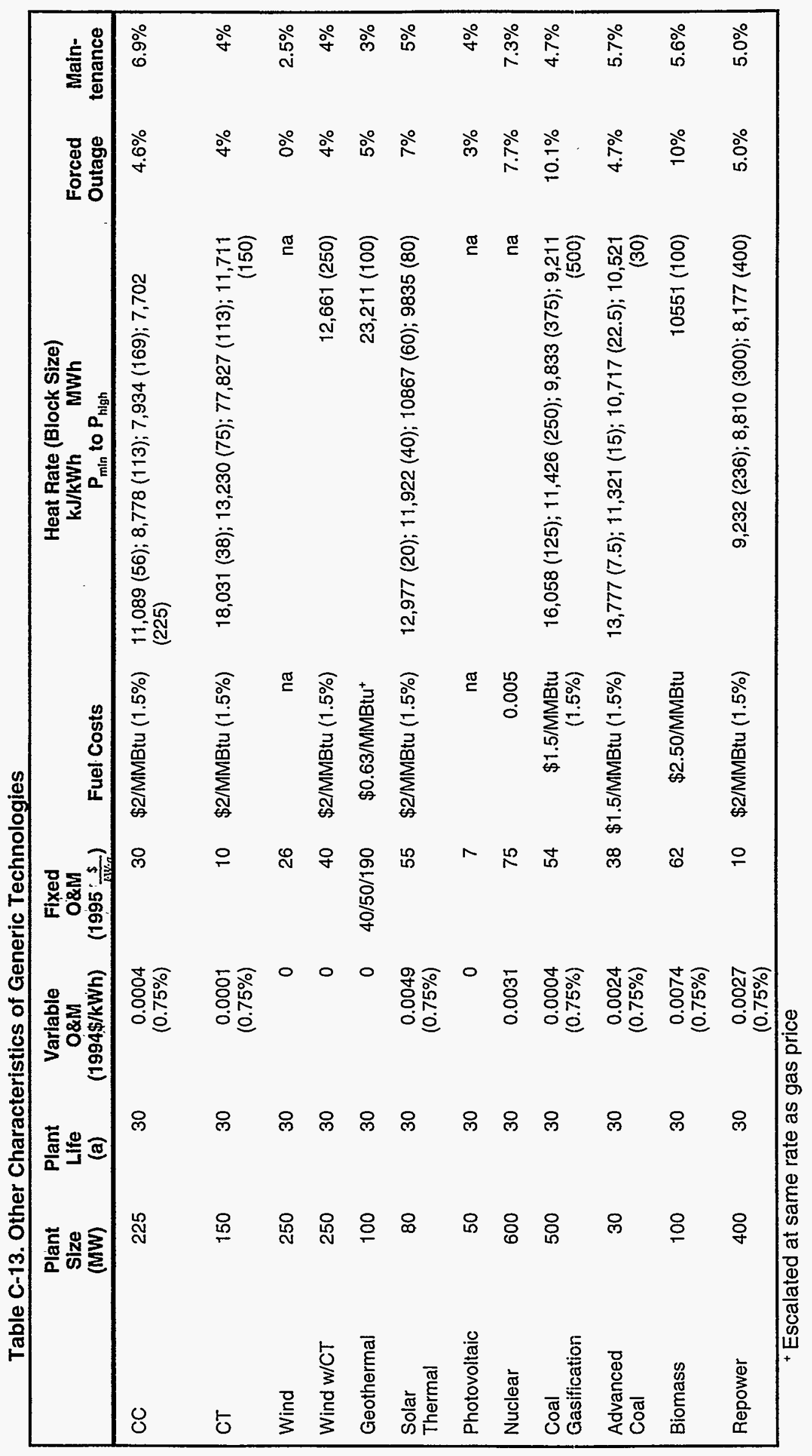


Table C-14 Emissions Characteristics of Generic Technologies (lbs/mbtu or lbs/kWh)

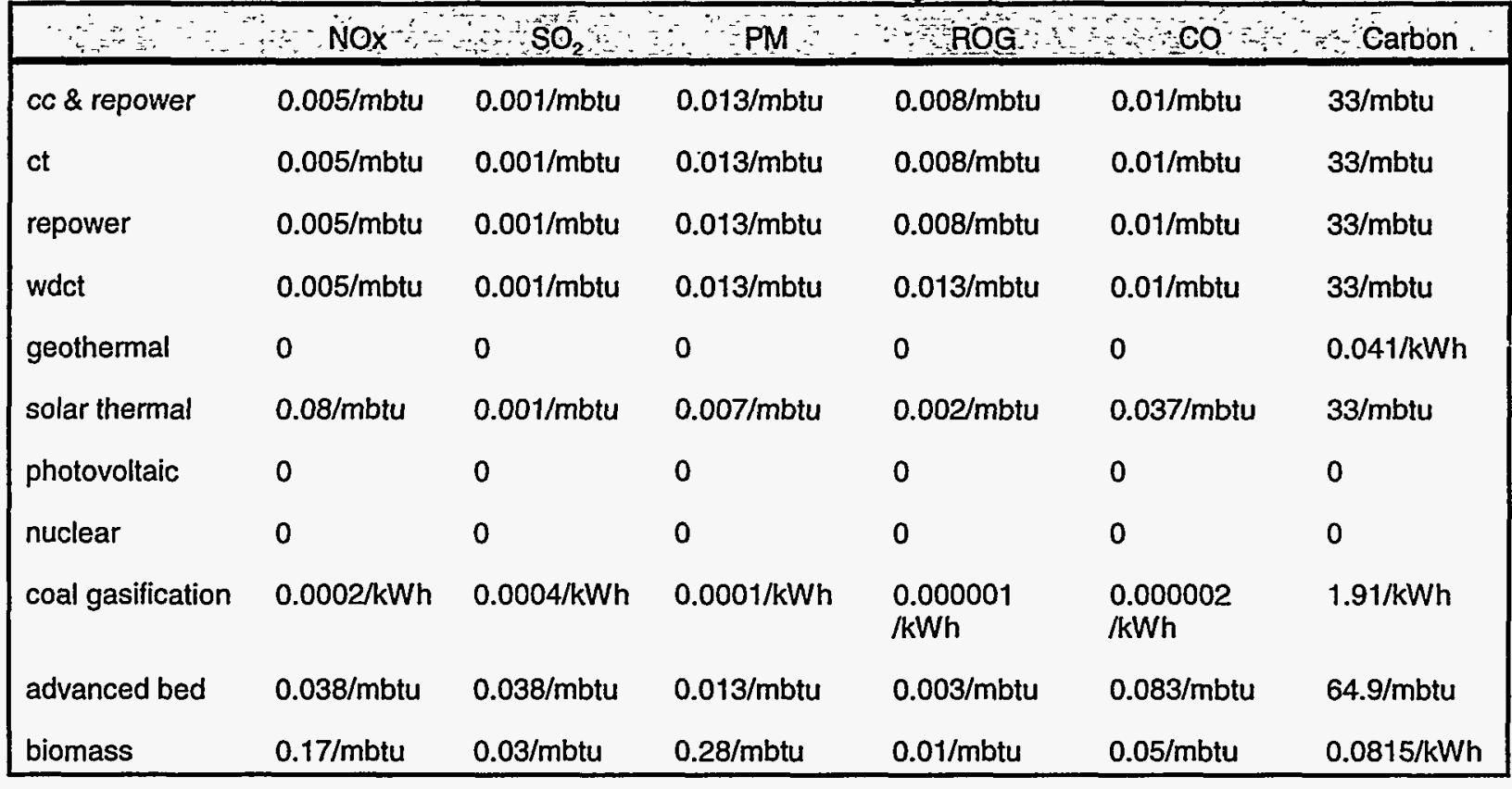

Table C-14. Emissions Characteristics of Generic Technologies $\left(g / k W / h^{+}\right)$

\begin{tabular}{|c|c|c|c|c|c|c|}
\hline 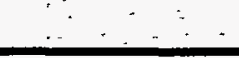 & $\therefore \mathrm{NOX}$ & $\mathrm{SO}_{2} \ldots$ & PART & $\mathrm{ROG}^{-}$ & $\mathrm{CO}$ & C \\
\hline cc \& repower & 0.017 & 0.003 & 0.043 & 0.027 & 0.033 & 109.369 \\
\hline ct & 0.025 & 0.005 & 0.066 & 0.04 & 0.054 & 166.3 \\
\hline repower & 0.018 & 0.004 & 0.046 & 0.028 & 0.035 & 116.111 \\
\hline wdet & 0.027 & 0.005 & 0.071 & 0.044 & 0.054 & 179.784 \\
\hline geothermal & 0 & 0 & 0 & 0 & 0 & 18.614 \\
\hline solar thermal & 0.339 & 0.004 & 0.03 & 0.008 & 0.157 & 139.662 \\
\hline photovoltaic & 0 & 0 & 0 & 0 & 0 & 0 \\
\hline nuclear & 0 & 0 & 0 & 0 & 0 & 0 \\
\hline coal gasification & 0.091 & 0.182 & 0.145 & 0.0005 & 0.001 & 867.14 \\
\hline advanced bed & 0.172 & 0.172 & 0.059 & 0.014 & 0.376 & 298.746 \\
\hline biomass & 0.772 & 0.136 & 1.271 & 0.045 & 0.227 & 37.001 \\
\hline
\end{tabular}

${ }^{+}$At Average Full Load Heat Rate 
Figure C-1. Forecasts of Offset Costs

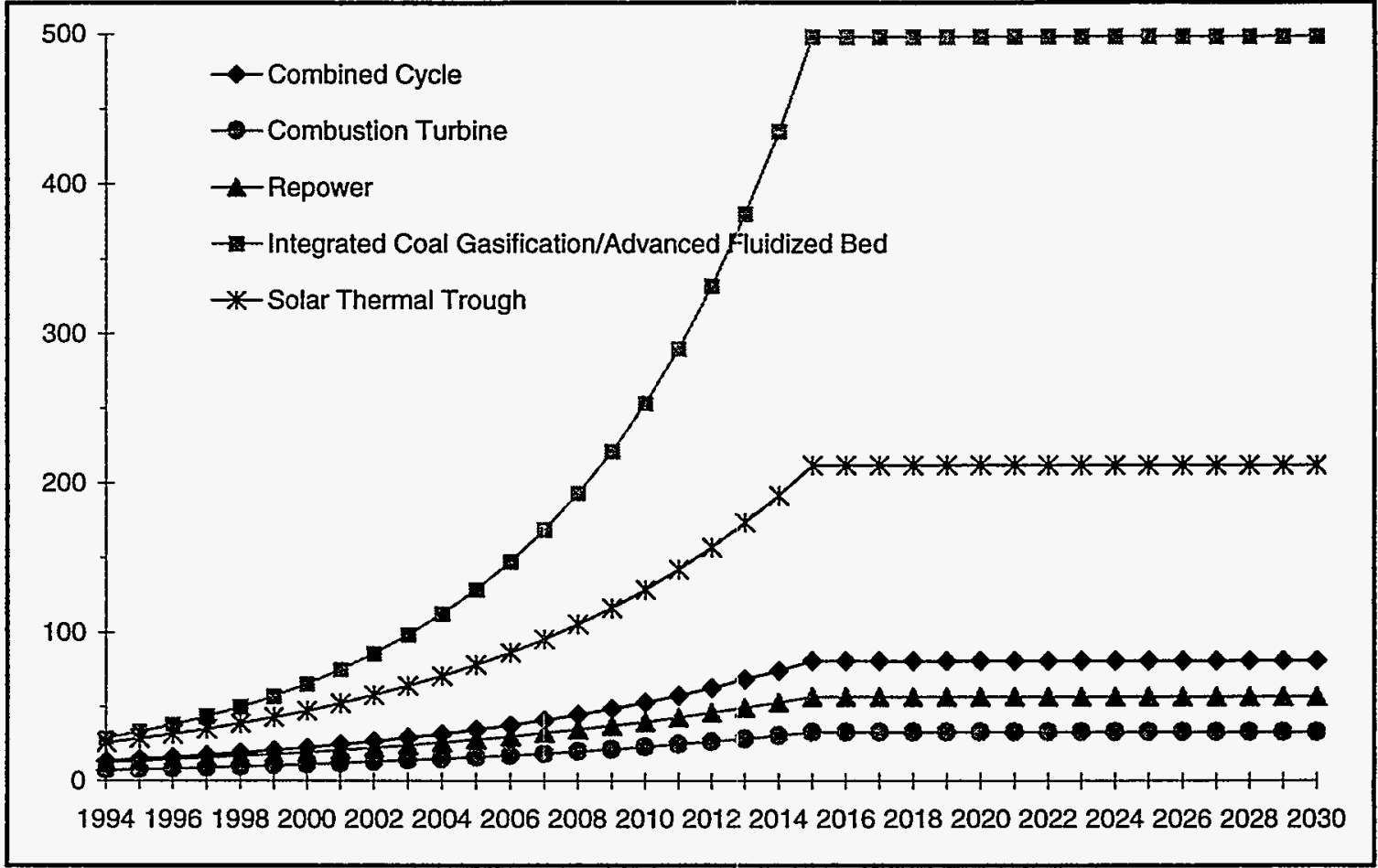

\section{C.4 Offsets}

Offset costs are required for combined cycles, combustion turbines, wind plants backed by combustion turbines, solar thermal backed by gas, coal gasification, advanced coal, and biomass. The offset costs differ considerably depending upon which air quality basin the plant will be located.

Combined cycles, combustion turbines, and repower show the most variation in offsets across basins. We use the lowest offset values for combined cycles, combustion turbines, and repowers. The solar thermal offset values remained constant across utilities as all were building these plants in Mohave Air Quality Management District (AQMD). We chose the highest value for integrated coal gasification (and assume that advanced coal is similar), and the only value for biomass. Biomass costs start at $\$ 475 / \mathrm{kW}$ in 1995 and increase well above $\$ 3,000 / \mathrm{kW}$ by 2030 . Biomass presumably has such high offset costs because it has high emissions compared to the other technologies. No offsets are required for wind, geothermal, photovoltaic, or nuclear. 


\section{Extreme Search Test For Market Equilibrium Plans}

The Elfin search for the best Market Equilibrium Plan (MEP) is not based on a global optimization procedure. Elfin starts with the minimum cost plan and searches for a profit maximizing plan which does not allow any further profitable entry. It is likely that this process is path independent. The following test was done to see if Elfin converges to the same plan when it starts at plans which are radically different.

The intention of this exercise is to look more closely at Elfin's behavior when searching for MEPs and how broad an area of possible technology combinations as MEP candidates Elfin considers. The search domain can very well be displayed in a picture of a volcanic crater. The starting point is a costly expansion plan, and could be considered a point high on the rim. The valley of the crater is a quite flat but craggy area and represents roughly the minimum cost level. Since MEPs must be close to the minimum cost solution, they can be pictured as small peaks scattered over the crater floor. The best MEP is a plan in which no further entry is possible and profits are maximized, so it can be thought of as the highest of these local peaks. In general in this work, MEPs are found by beginning with a minimum cost search, which is equivalent to finding a quick route the bottom of the crater. Then the crater is searched for MEPs. The highest peak found is declared the best MEP.

In this exercise the search area for MEPs, and thus often the result (the best MEP), is shown to be path dependent, meaning dependent on the combination of technologies that serves as starting point for the MEP search. Different starting points are used and the progress of the exploration reported. While some cases cover big areas, some are local, leading to very different results for the generation plan chosen by Elfin.

\section{D.1 Procedure}

In our extreme search MEP test runs, the search is started from different extreme plans shown in Table D-1, rather than from the minimum cost plan. Each starting point depends on a large amount of one specific technology, in addition to combustion turbines. The start plan for the minimum cost (MINC) case is the usual minimum cost plan. 
Table D-1. Start Plans for the MEP Search Test

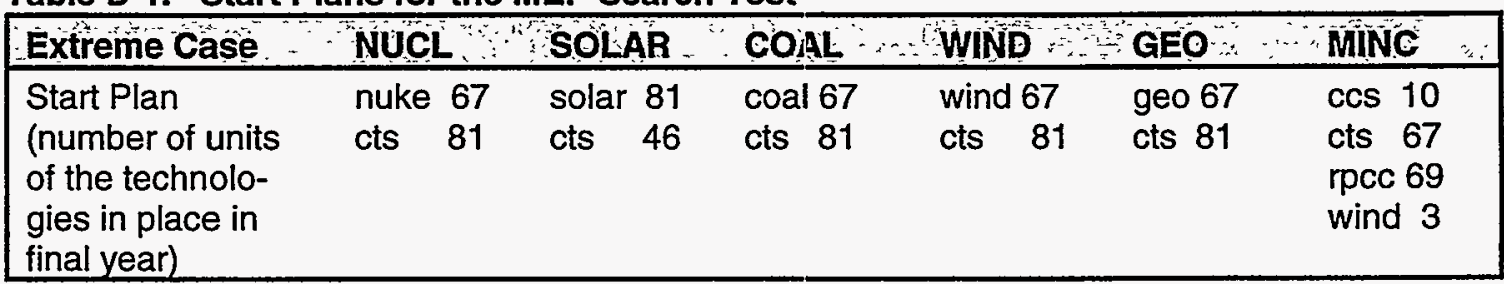

We then ran these cases searching for market equilibrium in the neutral policy environment $(\mathrm{ON})$ case. Since we did not pay attention to meeting a specific generating capacity expansion in creating our start plans, Elfin initially needed to add or delete many resources, in some cases, before starting to search for market equilibria, notably in the GEO case, where the capacity of a plant is only $100 \mathrm{MW}$.

\section{D.2 Findings}

Elfin found multiple potential market equilibrium plans for each case and chose the best market equilibrium plan among these, except for the COAL case which was stopped after 188 iterations. The results of the searches starting at different initial plans are shown in Table D-2 and Figure D-1. In all cases, the extreme technologies given in the start plans are deleted and only combustion turbines, repowers, and combined cycles remain in the MEPs. Combined cycles only exist in the GEO case. Two distinct clusters of MEPs can be seen in Figure D-1, ones with over 80 combustion turbines (cts) and about 65 repowers (rpcc) and ones with 45-58 cts and 79-83 rpcc. Note from Table D-1 that MEPs which appear close in the plot can exhibit wildly different profits, and that the same plan can apparently yield different profits because construction programs involving different years can reach the same end year construction totals.

Looking more carefully at the cases:

NUCL: The nuclear case searches in both clustered areas. The best market equilibrium plan is one with high rpcc and lower cts.

MINC: The minimum cost case only searches in one of the two areas and never reaches the second cluster. Its best MEP is also one with high rpcc and lower cts.

SOLAR: The solar case behaves like the minc case with lower profits.

COAL: The coal case is special in that it, as the nuclear case, reaches both areas but it picks its best MEP in the opposite area, the one with high cts and lower rpcc. It is the only one which identifies this market equilibrium plan with the second highest profits of all cases of $\$ 895 \mathrm{M}$. 
GEO: The geothermal case is outstanding in it is the only three-dimensional case. It searches the area with high rpcc and lower cts as well as the one with lower rpcc and higher cts but differs in that it for the second area (high cts, low rpcc) includes a third technology (ccs). Since this case is undominated and gives highest profits, it represents the best MEP.

WIND: We did not consider the wind case more closely since it gives lower profits and would not lead to more insights.

Table D-2. MEPs Found by Each Search

\begin{tabular}{|c|c|c|c|}
\hline 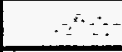 & jon- & jowers & Combined Cycle $\quad$ Profit \\
\hline N1 & 81 & 66 & 123 \\
\hline N2 & 56 & 79 & 36 \\
\hline N3 & 53 & 80 & 88 \\
\hline N4 & 50 & 81 & 97 \\
\hline N5 & 49 & 81 & 155 \\
\hline N6 & 47 & 82 & 47 \\
\hline N7 & 47 & 82 & 76 \\
\hline N8 & 47 & 82 & 113 \\
\hline N9 & 45 & 83 & 203 \\
\hline N10* & 45 & 83 & 265 \\
\hline MCP1 & 54 & 80 & 265 \\
\hline MCP2 & 51 & 81 & 245 \\
\hline MCP3 & 50 & 81 & 265 \\
\hline MCP4 & 48 & 82 & 72 \\
\hline MCP5 & 47 & 82 & 240 \\
\hline MCP6 & 45 & 83 & 237 \\
\hline MCP7* & 50 & 81 & 484 \\
\hline MCP8 & 51 & 81 & 82 \\
\hline S1 & 53 & 80 & 159 \\
\hline$S 2^{*}$ & 53 & 80 & 188 \\
\hline $\mathrm{Cl}^{*}$ & 81 & 65 & 895 \\
\hline C2 & 55 & 79 & 296 \\
\hline C3 & 56 & 79 & 206 \\
\hline C4 & 55 & 79 & 299 \\
\hline $\mathrm{G} 1 *$ & 81 & 65 & 1250 \\
\hline G2 & 56 & 79 & 618 \\
\hline G3 & 58 & 78 & 405 \\
\hline G4 & 52 & 80 & 552 \\
\hline G5 & 52 & 80 & 532 \\
\hline G6 & 53 & 80 & 211 \\
\hline G7 & 50 & 81 & 230 \\
\hline G8 & 50 & 81 & 264 \\
\hline G9 & 49 & 81 & 518 \\
\hline G10 & 50 & 81 & 200 \\
\hline G11 & 49 & 81 & 566 \\
\hline G12 & 50 & 82 & 200 \\
\hline
\end{tabular}

* best MEP found in case 
Figure D-1. MEPs Found by Each Search

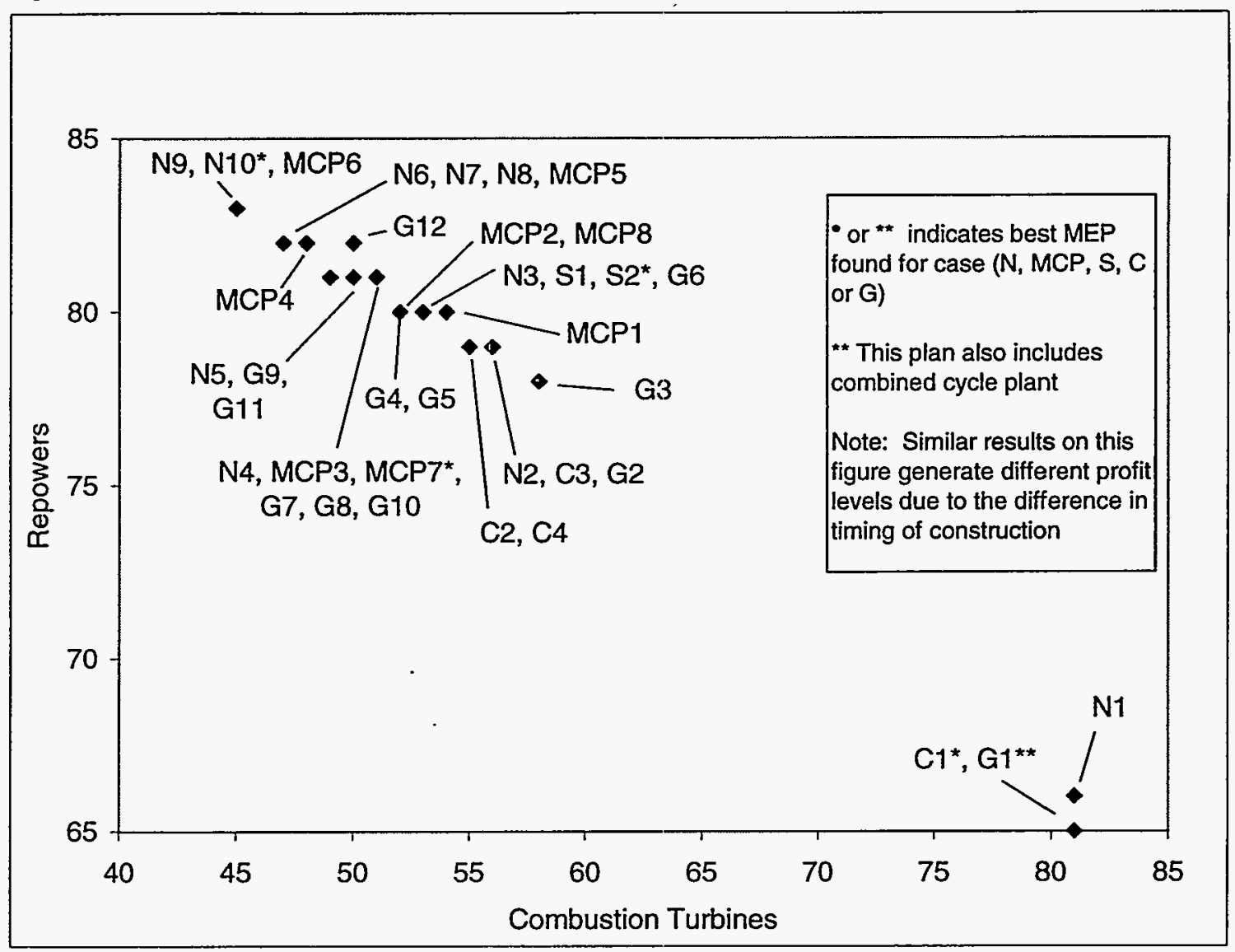

\section{D.3 Conclusion}

Elfin does not necessarily reach all relevant areas in its search algorithm and does not lead to one consistent 'best MEP' for all different cases. This shows that the MEP search algorithm is path dependent. While for some starting plans the area may well be explored, in others it is not. This is particularly well displayed investigating the coal and solar cases. The coal case searches both clusters in Figure D-1 and finds its best MEP in the area with very high profits. The solar case, on the other hand, restricts the search to only one area and never reaches the cluster where the coal case MEP is located. This indicates that Elfin occasionally misses potentially better combinations of technologies.

These results underscore the difficulty of finding the solution sought in this work. Plans that differ in small details can result in significantly divergent profits, and the path by which the results can be found is not at all clearly marked. On the other hand, qualitatively MEPs do appear to cluster and if all clusters could be found and searched, reasonable results are feasible. In future work, the search algorithm will be further refined. 


\section{Simulation Difficulties in the B Policy Simulation}

We encountered a fundamental problem with the B case, unfortunately, one not amenable to ready solution. The problem is simply that meeting a target level of total subsidy payments by searching across various levels of subsidy results in a highly unstable search. Consider the per kWh and total subsidy results of the run that we report here, as shown in Figures E-1 and E-2. Figure E-1 shows the average per-kWh subsidy applied in the B policy, while Figure

Figure E-1. Per kWh Subsidy to Wind - BN

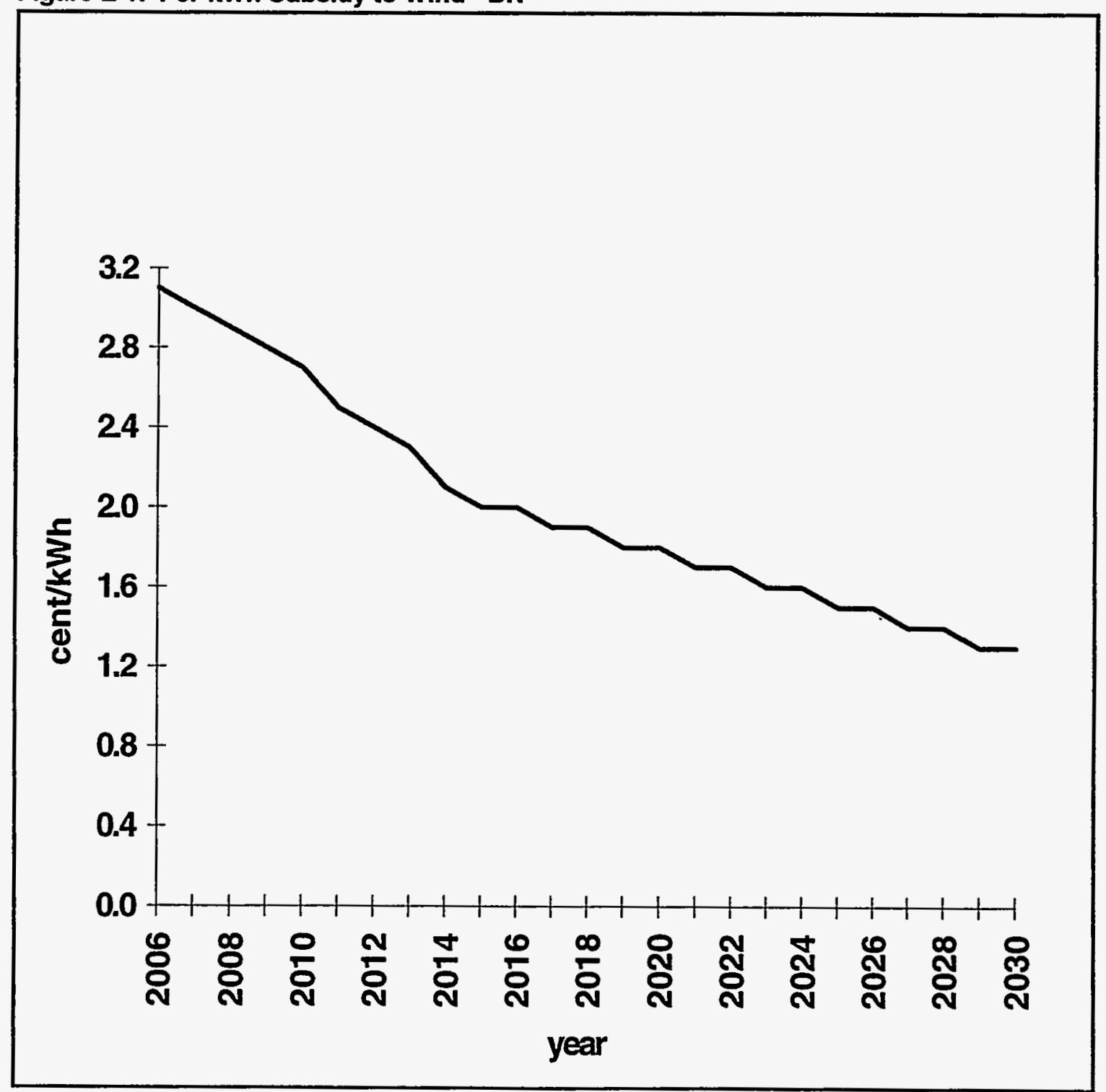


E-2 shows the total annual cost of the subsidy. The first obvious characteristic of these two graphs is that, although the level of subsidy declines in an apparently predictable manner, the overall cost of the subsidy is erratic, rising dramatically, then falling from 2013 to 2018. The second interesting feature of the subsidy level is that required subsidies are high, starting at over $3 \phi / \mathrm{kWh}$ and never reaching $1 \phi / \mathrm{kWh}$.

Figure E-2. Net Total Subsidy to Wind - BN

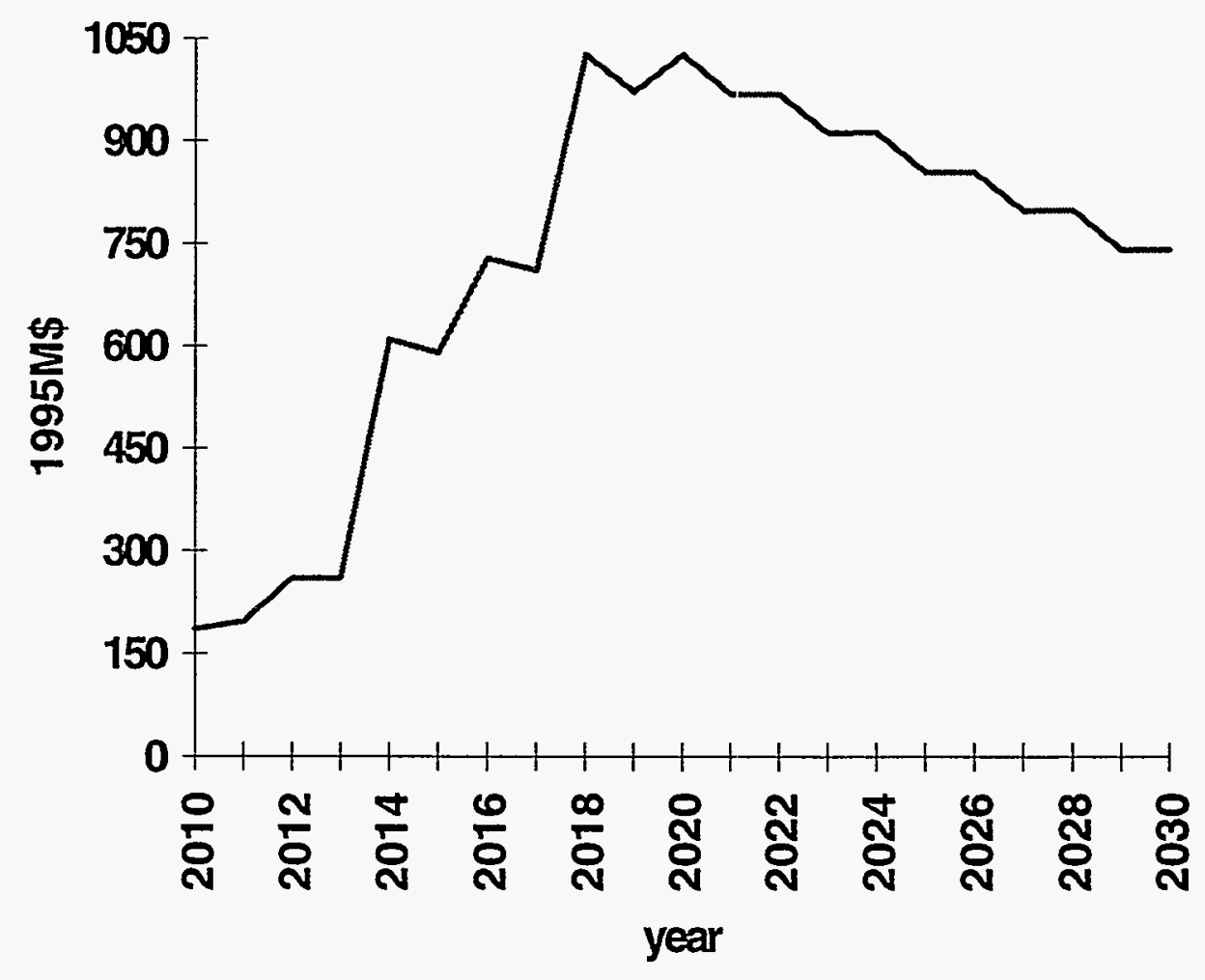

The cause of these results is simply that the search for the correct level of subsidy required to meet a predetermined target total subsidy cost is highly unstable. This effect apparently 
arises from three sources. First, changes made in any year affect the construction choices made in all other years. Therefore, a minor change in the level of subsidy in any year will change not only the amount of subsidy collected by new resources built in that same year, but also the amount of subsidy required to meet the obligation to new generation built in all other years. Second, the level of the subsidy must not only compensate the investor in a renewable technology for the high cost of today's technology but also for the lost opportunity to invest in future years' improved technology. For example, if a wind generator is built this year, not only is it not viable compared to thermal generation options, but it is also not viable compared to wind technology in future years. Therefore, the subsidy must compensate for both of these effects, effectively raising the required subsidy level in early years beyond expectations. And third, increasing generation by zero marginal cost generators tends to dampen market prices, thereby diminishing the value of the subsidy to developers.

These problems underscore one feature and one limitation of Elfin. First, a key feature of the ITRE logic is perfect foresight. New construction is chosen not only by technology but also by year. A new plant will never be built today if it is more profitable in present value terms to wait for a future year's technology. An alternative search algorithm, such as ICEM, that lacks this foresight would result in more early construction of falling-cost technologies, but neither perfect nor absent foresight are credible assumptions. ${ }^{5}$ Second, Elfin lacks the capability of imposing a fixed level of subsidy directly. While developing a suitable algorithm for this feature was beyond the scope of this project, it must be undertaken if useful analysis of fixed subsidies is to be possible. considers investments year-by-year without foresight. 


\section{Carbon Tax Policy: Policy H}

In Policy $\mathrm{H}$, the introduction of a modest carbon tax of $\$ 3.00 / t_{\mathrm{C}}$ is assumed. Our results are shown in Table F-1.

Table F-1. Summary of Elfin Pool Results with a Low Carbon Tax and a Neutral Environment

\begin{tabular}{|lcc|}
\hline & Neútral (ON) & Carbon Tax (HN) \\
\hline 2030 Cumulative New Renewable (MW) & 0 & 5000 \\
2030 NOx Emissions (t) & 224277 & $184,892(82 \%)$ \\
2030 Carbon Emissions ( $t)$ & 39683706 & $21,679,018(55 \%)$ \\
$2030 \%$ Thermal & $81 \%$ & $68 \%$ \\
2030 Gas Consumption (EJ) & 1.563 & $0.519(33 \%)$ \\
NPV System Costs (\$M) & $\$ 132,002$ & $\$ 237,190(180 \%)$ \\
\hline
\end{tabular}

Curiously enough, Policy $\mathrm{H}$ results in only $5 \mathrm{GW}$ of new renewable construction (all geothermal). However, this case results in a staggering $14.4 \mathrm{GW}$ of new nuclear construction, producing the most dramatic reductions in emissions, thermal dependence and gas consumption of any policy modeled relative to the neutral, or base, case. Under the policy's carbon tax, NOx emissions are cut by 18 percent, carbon emissions by 45 percent, thermal dependence by 13 percent, and gas consumption by a stunning 67 percent. Naturally, these savings are not achieved on the back of just $5 \mathrm{GW}$ of new renewable energy source capacity alone, and major source of these benefits is the nuclear construction. Total costs for Policy $\mathrm{H}$ are 180 percent of costs in the neutral case. Costs increase in all components of overall system costs. Production costs rise by over 50 percent, and because of the high cost of nuclear construction and $O \& M$, these costs also rise significantly.

As discussed below, Policy $\mathrm{H}$ represents the high end for both potential emissions reduction and total cost of any of the policies modeled here. However, the results of this carbon case should be viewed with some suspicion. The equivalent HB and HG cases result in quite different outcomes, neither of which involve nuclear. Interestingly, the HG case includes biomass, the only case in which that renewable proves competitive under our assumptions. The HB results in an outcome quite similar to the $\mathrm{OB}$ case, although output is lower. The results of the $\mathrm{HN}$ case, then, are quite disturbing. It seems that our search has not found a credible MEP in this instance. We report the $\mathrm{HN}$ case here primarily to demonstrate that the MEP search algorithm, described in Appendix B, exhibits quirky behavior and work is ongoing to improve its performance. However, it should be noted that the nuclear results can 
be highly sensitive to carbon tax scenarios. In other work conducted at Berkeley Lab, this effect has been investigated more rigorously. ${ }^{6}$

$6 \quad$ See Marnay and Pickle (1998). 


\section{Cost Duration Curves for the California Pool}

This appendix contains some cost duration curves for busbar cost. Remembering that in this work, marginal cost bidding is assumed, these curves show the basic pattern of competitive prices. Curves are shown for each fifth year from 2010 to 2030 in Figures G-1 to G-5. The qualitative pattern of prices is the same in each graph, and similar to the pattern shown in the body of this report. The numbers presented are for the best guess scenario (ON case). For most hours, the variation in prices is minimal. The peaks occur during summer afternoons. Gas is clearly the marginal fuel most of the time, and variation in prices is driven by heat rate variation. For a few hours, however, prices peak dramatically, and these peaks become more spectacular in later years.

The marginal costs increase during the years 2010 to 2030. The peaking hours aside, marginal costs for the flat region in Figure G-1 range from 27 \$/MWh to 19 \$/MWh. This range moves up to $34 \$ / M W h$ to $26 \$ / M W h$ by the year 2030 and this escalation happens evenly during the period studied. The marginal cost during the peak hour escalates from $50 \$ / \mathrm{MWh}$ in 2010 to about $275 \$ \mathrm{MWh}$ in 2025 , and from there on declines to about $150 \$ / \mathrm{MWh}$ by the year 2030.

One possible interpretation of these results is that since our expansion planning options contain a limited number of alternatives, once it is no longer profitable to built the technology most suited for peaking duty, no more capacity is built, resulting in a shortfall and the inevitable peak in prices. Together these graphs show more clearly the basic pattern of pool price results described in the body of this report. 


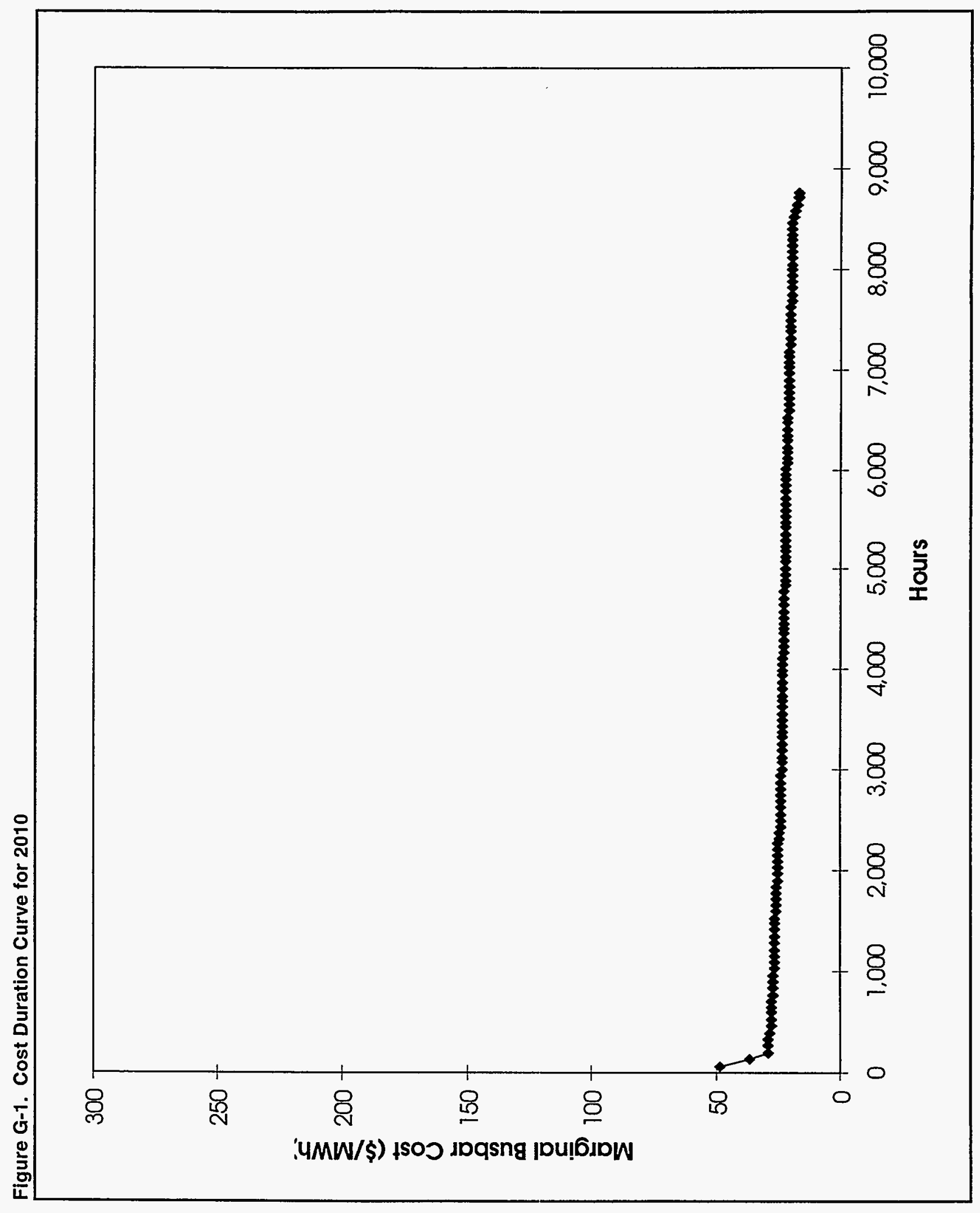




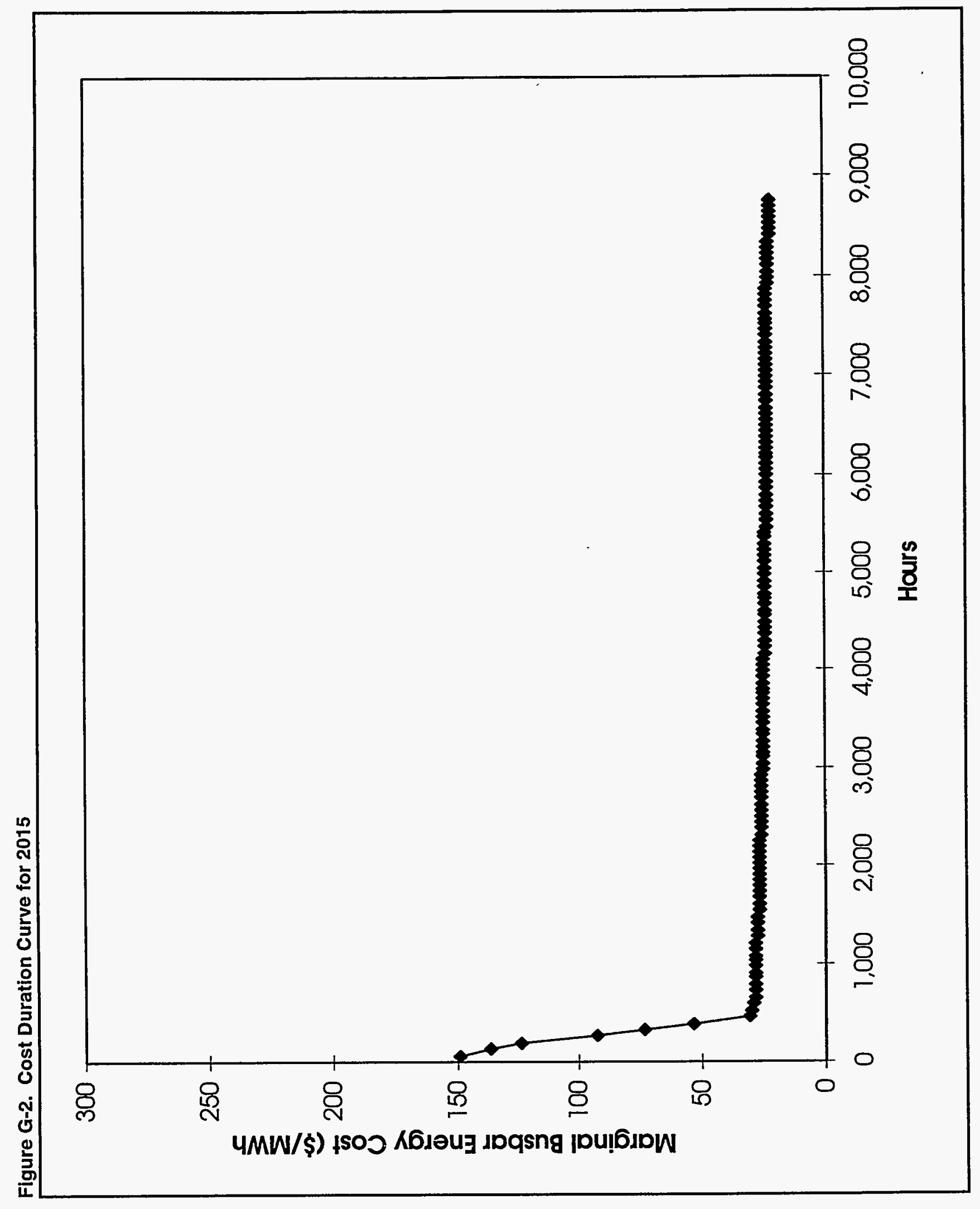




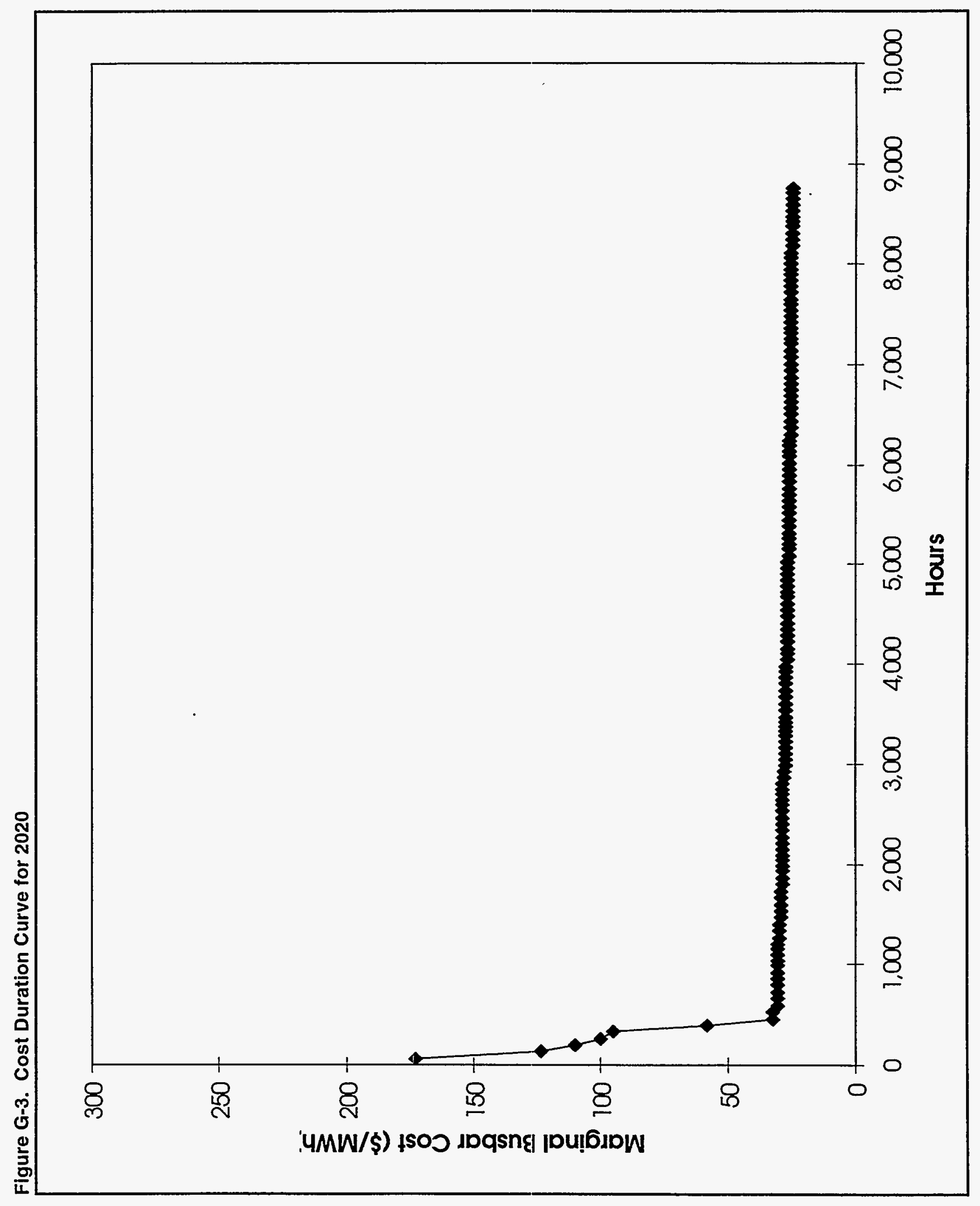




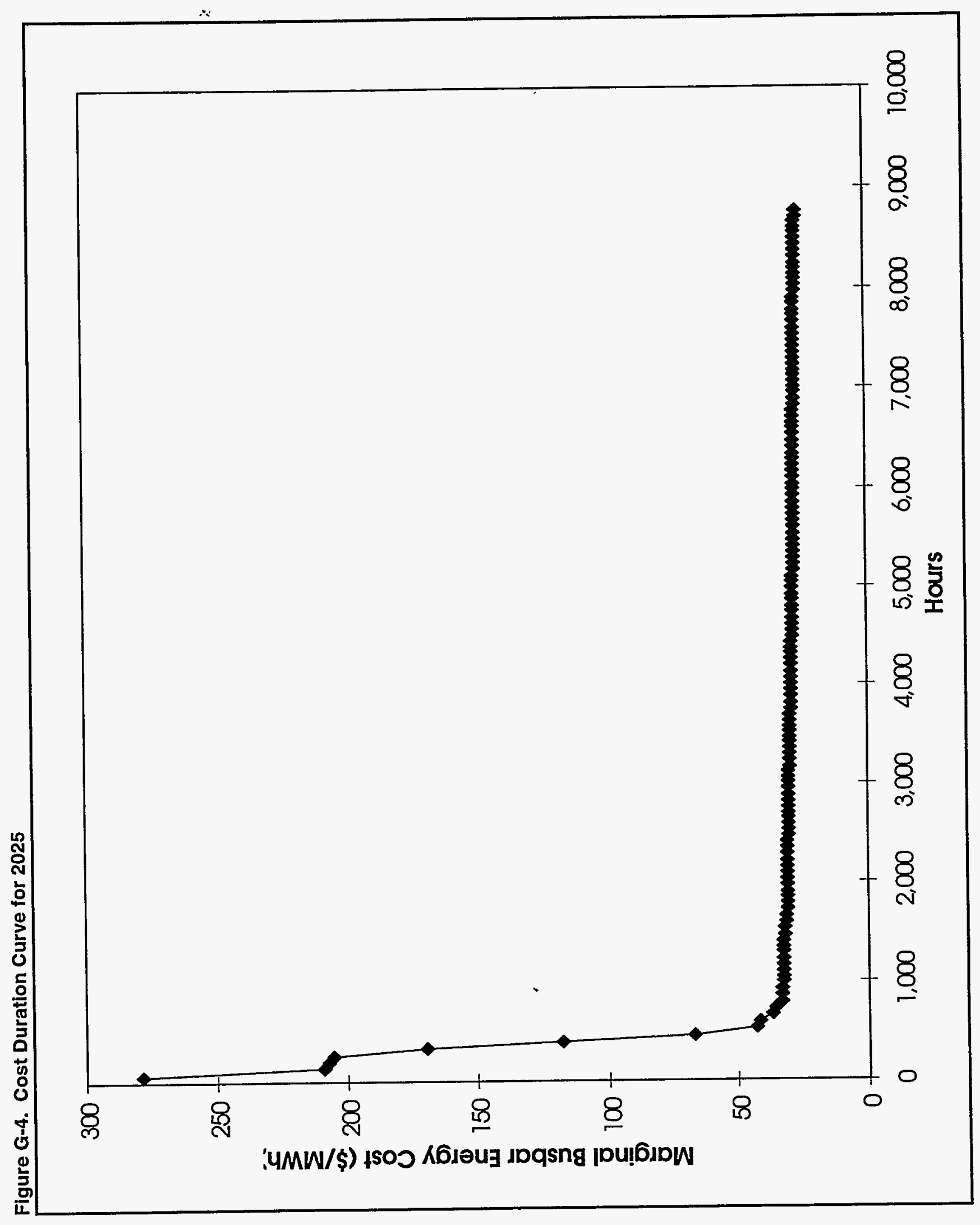




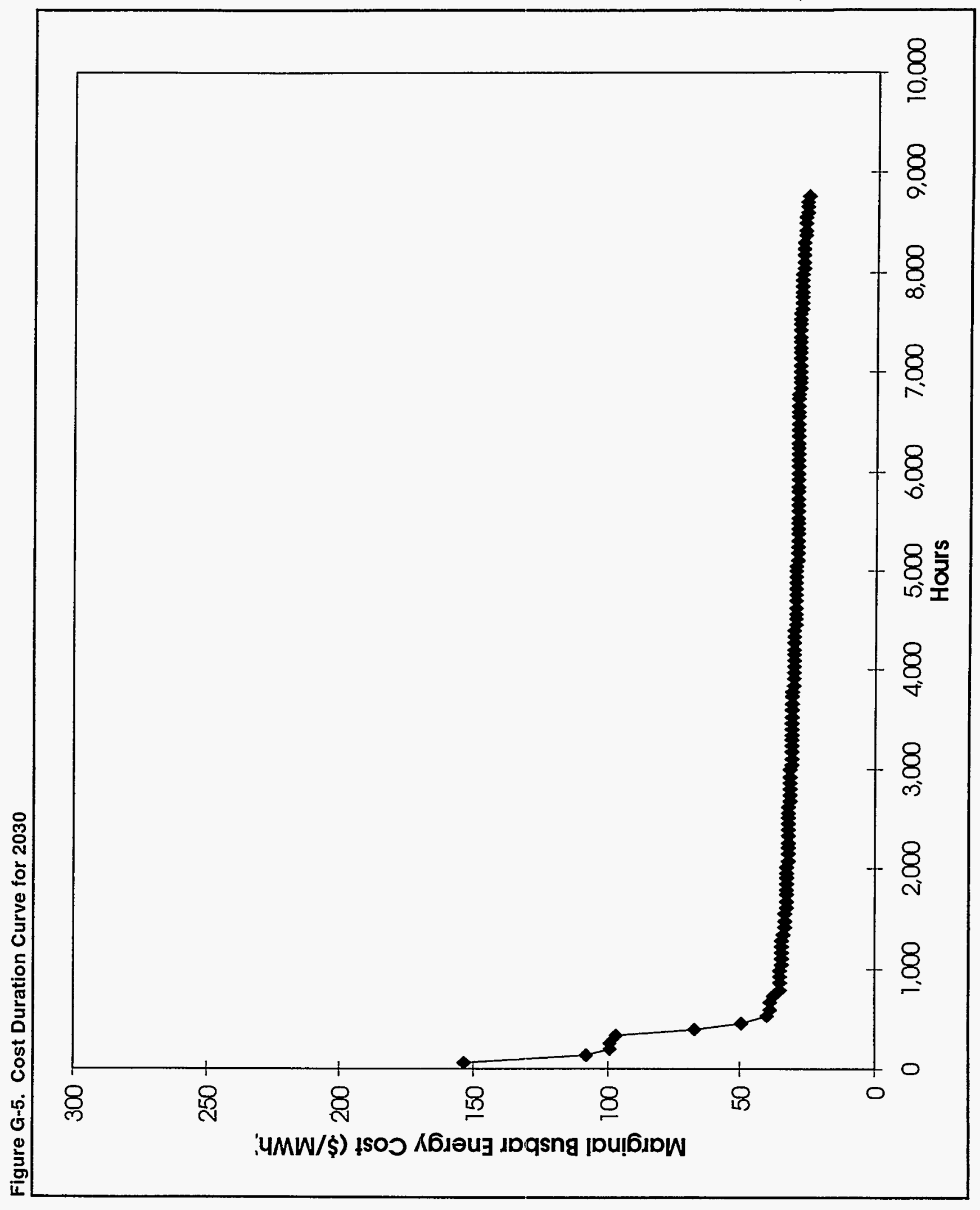

